\title{
Problemas Resueltos \\ de Teoría de la Decisión
}

Federico Garriga Garzón

OmniaScience

Scholar 
Problemas resueltos de teoría de la decisión

1a Edición: (2013 OmniaScience (Omnia Publisher SL)

Federico Garriga Garzón, 2013

(c) (i) (9)

Problemas resueltos de teoría de la decisión por Federico Garriga Garzón se encuentra bajo una Licencia Creative Commons Atribución-NoComercial 3.0 Unported.

DOI: http://dx.doi.org/10.3926/oss.9

ISBN: 978-84-940624-2-1

DL: B-33104-2012

Diseño cubierta: OmniaScience

Fotografía cubierta: @ Jakub Jirsák - Fotolia.com 


\section{Presentación}

El presente libro de problemas resueltos de teoría de la decisión no pretende ser una aportación científica al campo de la teoría de la decisión pues todos los conceptos que en él se incorporan están recogidos en excelentes publicaciones sobre el tema. La finalidad de esta publicación es exclusivamente didáctica, y únicamente se justifica por razones pedagógicas.

Ha sido concebido para su utilización por personas con conocimientos de teoría de la decisión y estadística, con la finalidad de facilitar el aprendizaje de los procedimientos de formulación y resolución de problemas de análisis de decisiones, a los estudiantes de dicha materia en las diversas Facultades, Escuelas Técnicas, y Escuelas de Negocios en las que se imparte.

El libro no presenta ninguna estructura predeterminada, los ejercicios no están agrupados siguiendo un criterio predefinido, sino que se concilian ejercicios sencillos con ejercicios complejos con el ánimo de hacer más ameno el estudio, incrementando así el interés por el análisis de los problemas de decisión.

Los ejercicios que integran el libro se fundamentan en de la resolución de los problemas de toma de decisiones primordialmente mediante el uso de árboles de decisión, siendo el enfoque expuesto marcadamente práctico.

La publicación no es exclusivamente un libro de ejercicios resueltos de teoría de la decisión para estudiantes, sino una metodología que facilite la toma de decisiones a los directivos así como a toda aquella persona que en algún momento de su vida deba tomar una decisión. Por ello, resulta de enorme interés tanto para estudiantes como para directivos, así como para cualquier persona que a lo largo de su vida requerirá tomar decisiones que afectarán el transcurso de la misma. 


\section{Capítulo 1}

\section{Enunciado de los problemas}

\section{Ejercicio 1}

Una empresa compra la materia prima a dos proveedores A y B, cuya calidad se muestra en la tabla siguiente:

\begin{tabular}{|c|c|c|}
\hline $\begin{array}{c}\text { Piezas } \\
\text { defectuosas }\end{array}$ & $\begin{array}{c}\text { Probabilidad para } \\
\text { el proveedor A }\end{array}$ & $\begin{array}{c}\text { Probabilidad para } \\
\text { el proveedor B }\end{array}$ \\
\hline $1 \%$ & 0.80 & 0.40 \\
\hline $2 \%$ & 0.10 & 0.30 \\
\hline $3 \%$ & 0.10 & 0.30 \\
\hline
\end{tabular}

La probabilidad de recibir un lote del proveedor $A$ en el que haya un $1 \%$ de piezas defectuosas es del $70 \%$. Los pedidos que realiza la empresa ascienden a 1.000 piezas. Una pieza defectuosa puede ser reparada por 1 euro. Si bien tal y como indica la tabla la calidad del proveedor B es menor, éste está dispuesto a vender las 1.000 piezas por 10 euros menos que el proveedor $A$. Indique el proveedor que debe utilizar.

\section{Solución en página 14}




\section{Ejercicio 2}

Se está planteando construir una nueva sección en su negocio de comida rápida, si bien no sabe si hacer la nueva sección grande o pequeña. Al mismo tiempo se plantea si reúne información sobre las ventas previstas o si por el contrario no hace nada. La información sobre las ventas previstas puede aconsejarle un mercado creciente o un mercado decreciente, siendo de 500 euros el coste de dicha información, y la probabilidad de que la información sea favorable del $60 \%$. Si el mercado es creciente las ganancias previstas son de 9.000 euros si la sección es grande y 3.000 si es pequeña. Si el mercado es decreciente puede perder 10.000 euros si la sección es grande y 5.000 si es pequeña. Si no reúne información adicional, la estimación de probabilidades de que el mercado sea creciente es del $60 \%$, contrariamente un informe favorable incrementaría la probabilidad de un mercado creciente al $80 \%$ y un informe desfavorable disminuiría la probabilidad de un mercado creciente al $40 \%$. Indique la decisión que debe tomar.

\section{Solución en página 19}

\section{Ejercicio 3}

Un empresario adquiere pescado fresco en el mercado central para su posterior venta. Cada caja de pescado la identifica como excelente o no excelente en función del porcentaje de pescado que se considere de calidad excelente. Una caja de pescado excelente contiene un $90 \%$ de pescado de alta calidad, mientras que una caja de pescado no excelente contiene solo un $20 \%$ de pescado de alta calidad. Una caja de de pescado excelente genera un beneficio de 100 euros, mientras que una caja de pescado no excelente causa unas pérdidas de 100 euros por la mala imagen de la empresa que se llevan los clientes. Antes de comprar una caja el empresario puede comprobar la calidad de la misma extrayendo un ejemplar de pescado con el objetivo de verificar si se trata o no de pescado de alta calidad. Establezca la estrategia que debe seguir el empresario, así como el coste de la información.

\section{Solución en página 25}

\section{Ejercicio 4}

El gerente de una empresa tiene dos diseños posibles para su nueva línea de cerebros electrónicos, la primera opción tiene un $80 \%$ de probabilidades de producir el $70 \%$ de cerebros electrónicos buenos y un $20 \%$ de probabilidades de producir el $50 \%$ de cerebros electrónicos buenos, siendo el coste de este diseño de 450.000 de euros. La segunda opción tiene una probabilidad del $70 \%$ de producir el $70 \%$ de cerebros electrónicos buenos y una probabilidad del 30\% de producir el 50\% de cerebros electrónicos buenos, el coste de este diseño asciende a 600.000 euros. El coste de cada cerebro electrónico es de 100 euros, si es bueno se vende por 250 euros, mientras que si es malo no tiene ningún valor. Conociendo que la previsión es de fabricar 50.000 cerebros electrónicos, decida el diseño que debe elegir el gerente de la empresa.

\section{Solución en página 32}




\section{Ejercicio 5}

Un establecimiento comercial está analizando la posibilidad de realizar los pedidos de un determinado producto con un mes de antelación, con la finalidad de evitar roturas de inventario. Si realiza pedido con un mes de anticipación el coste por unidad de producto es de 50 euros, por el contrario, si la demanda de dicho producto durante el mes excede el número de unidades en almacén, debe ordenar las unidades necesarias a un coste de 100 euros por unidad. La tabla muestra la demanda mensual de dicho producto durante los tres últimos años:

\begin{tabular}{|c|c|}
\hline $\begin{array}{c}\text { Demanda } \\
\text { (unidades) }\end{array}$ & $\begin{array}{c}\text { Frecuencia } \\
\text { (meses) }\end{array}$ \\
\hline 10 & 20 \\
\hline 20 & 12 \\
\hline 30 & 8 \\
\hline
\end{tabular}

Sugiera la política de pedidos para la empresa así como el coste de la misma.

Solución en página 36

\section{Ejercicio 6}

Una empresa fabricante de componentes electrónicos está estudiando cuatro posibilidades de expansión de su capacidad productiva: construir una nueva planta en Brasil, una joint-venture en China, ampliar su planta de España o construir una nueva planta en Alemania. Los beneficios estimados durante los próximos años para cada alternativa se muestran en la tabla siguiente en función de la demanda.

\begin{tabular}{|c|c|c|c|c|}
\hline & \multicolumn{2}{|c|}{$\begin{array}{c}\text { Incremento de la } \\
\text { demanda del }\end{array}$} & $\begin{array}{c}\text { Demanda } \\
\text { constante }\end{array}$ & $\begin{array}{c}\text { Disminución de } \\
\text { la demanda en }\end{array}$ \\
\hline & $30 \%$ & $20 \%$ & & $5 \%$ \\
\hline Brasil & 1.000 & 900 & 600 & 400 \\
\hline China & 1.300 & 1.100 & 700 & 300 \\
\hline España & 1.200 & 1.400 & 600 & -100 \\
\hline Alemania & 1.000 & 900 & 700 & 700 \\
\hline
\end{tabular}

1. Formule la decisión óptima siguiendo el criterio optimista, el pesimista, y el de Laplace.

2. Establezca la decisión óptima, si se considera que la probabilidad de que la demanda se incremente un $30 \%$ es del $20 \%$, de que aumente un $20 \%$ es del $30 \%$, de que se mantenga es del $40 \%$ y de que se reduzca de un $10 \%$.

\section{Solución en página 41}




\section{Ejercicio 7}

Para hacer frente a las ventas una empresa puede tomar las siguientes acciones: hacer horas extras, contratar mano de obra, alquilar maquinaria, e incluso puede no tomar ninguna acción. Las ventas por su parte pueden ser crecientes o decrecientes, siendo $\mathrm{p}$ la probabilidad de que las ventas sean crecientes. A tenor de un estudio realizado por la propia empresa, los beneficios esperados en cada caso se muestran en la tabla siguiente en miles de euros:

\begin{tabular}{|c|c|c|}
\hline & Ventas crecientes & Ventas decrecientes \\
\hline Horas extras & 500 & 100 \\
\hline Contratar mano de obra & 700 & 0 \\
\hline Alquilar maquinaria & 900 & -100 \\
\hline No tomar ninguna acción & 400 & 200 \\
\hline
\end{tabular}

Halle los valores de la probabilidad p por los que decidirá hacer horas extras, contratar mano de obra, alquilar maquinaria, o no tomar ninguna acción, respectivamente.

\section{Solución en página 44}

\section{Ejercicio 8}

Una empresa de aviónica está investigando la posibilidad de fabricar y comercializar un nuevo microprocesador dotado de inteligencia casi natural para los aviones del futuro. El proyecto requiere la compra de un sofisticado centro de supercomputación, o bien la contratación de más ingenieros, obviamente la empresa se reserva la opción de no desarrollar el producto. El nuevo producto puede tener una acogida favorable o desfavorable en el mercado, con una acogida favorable en el mercado las ventas estimadas alcanzarían los 50.000 microprocesadores, por el contrario, si la acogida del mercado no fuese favorable las ventas estimadas serían de 20.000 microprocesadores. El precio de venta de los microprocesadores es de 200 euros cada unidad. El coste del centro de supercomputación es de 2.000.000 de euros, mientras que el de contratar y formar a los nuevos ingenieros asciende a 1.000.000 de euros. El coste de fabricación previsto es de 40 euros cada unidad si se fabrica sin la ayuda del centro de supercomputación, y de 10 euros si se fabrica con dicha ayuda. La probabilidad de que el nuevo microprocesador reciba una acogida favorable por parte del mercado es del $50 \%$.

1. Sugiera la decisión que debe tomar la dirección de la empresa en base a la aplicación del criterio del valor esperado.

2. Determine para qué rango de probabilidades de mercado favorable debe comprar el centro de supercomputación.

3. Se han definido las ventas favorables como las que alcancen las 50.000 unidades. Es probable que dicha cifra sea demasiado optimista, halle el valor por el que cambiaría su decisión y contrataría más ingenieros.

\section{Solución en página 49}




\section{Ejercicio 9}

El departamento de I + D de una pequeña empresa está desarrollando un nuevo producto. El gerente de la empresa puede: vender dicho producto a una gran compañía multinacional por 100 millones de euros, poner en marcha una prueba de mercado antes de tomar una decisión, o bien, adelantar la campaña de marketing del nuevo producto con la finalidad de adelantarse a la competencia, confiando en que el desarrollo del mismo culminará con éxito.

Las pruebas de mercado del producto ascienden a 8 millones de euros, existiendo un $60 \%$ de probabilidades de que los resultados de las mismas sean favorables, en cuyo caso se estima que valor del nuevo producto asciende a 40 millones de euros. En caso de un resultado desfavorable pueden encontrase aplicaciones alternativas para el producto en uno de cada cinco casos, si bien el valor del mismo se reduce a 20 millones de euros.

En caso de que el resultado de las pruebas de mercado sea favorable, la probabilidad de que el producto tenga una buena acogida por parte de los clientes es tan solo del $60 \%$. Si se opta por comercializar el producto, los gastos de comercialización ascienden a 5 millones de euros.

La posibilidad de que el gerente adopte la tercera alternativa, adelantar la campaña de marketing del nuevo producto, se estiman en una entre cuatro. Sin embargo, los resultados esperados si hiciera esto con éxito son de ciento sesenta millones de euros. En caso de resultado desfavorable de las pruebas de mercado como siempre, existe la posibilidad de encontrar aplicaciones alternativas para el producto en uno de cada cinco casos, en cuyo caso el valor del mismo es de 80 millones de euros.

Esta tercera alternativa requiere llevar a cabo las pruebas de mercado así como la comercialización del producto, tanto sí el producto tiene éxito como sino. Indique la decisión que deberá tomar el gerente de la empresa.

\section{Solución en página 57}




\section{Ejercicio 10}

Una empresa cuyo objeto es la venta de coches de segunda mano cobra un $10 \%$ de comisión sobre las ventas. Dicha empresa ha recibido el pedido de un cliente de vender tres automóviles de su propiedad, el primero de ellos un flamante utilitario valorado en 10.000 euros, el segundo un deportivo valorado en 60.000 euros y el tercero un vehículo todoterreno $4 \times 4$ Turbo casi nuevo cuya valoración asciende a 100.000 euros. Las cláusulas pactadas en el pedido entre el cliente y la empresa establecen que obligatoriamente el utilitario debe ser vendido primero en el plazo de un mes, en caso contrario queda anulado el pedido. Vendido el utilitario, la empresa puede optar por vender el deportivo, el todoterreno, o cancelar el pedido. Por último, una vez vendido el segundo vehículo, la empresa podrá cancelar el pedido o vender el tercer coche. Los gastos de publicidad que estima la empresa serán necesarios para vender dichos automóviles así como la probabilidad de vender cada uno de ellos, vienen dados en la tabla siguiente:

\begin{tabular}{|c|c|c|}
\hline & Gastos publicidad & Probabilidad \\
\hline Utilitario & 3.000 euros & $40 \%$ \\
\hline Deportivo & 1.000 euros & $80 \%$ \\
\hline Todo terreno 4x4 Turbo & 2.000 euros & $60 \%$ \\
\hline
\end{tabular}

Determine si el gerente de la empresa debe o no aceptar el pedido que le formaliza el cliente.

\section{Solución en página 63}

\section{Ejercicio 11}

El gerente de la empresa dedicada a la venta de coches de segunda mano del ejercicio anterior, conoce a un importante piloto de carreras que puede proporcionarle información cien por cien fiable de los automóviles que conseguirá vender, así como el orden en que logrará dichas ventas. Calcule lo que el gerente estaría dispuesto a pagar al piloto por proporcionarle dicha información.

\section{Solución en página 70}

\section{Ejercicio 12}

El gerente de la empresa dedicada a la venta de coches de segunda mano del ejercicio número 10, está interesado en estudiar si vale la pena proponer a su cliente, que una vez vendido el utilitario le permita vender el deportivo y el todoterreno $4 \times 4$ turbo simultáneamente, en lugar de primero vender uno y después el otro, tal como especifica el pedido.

\section{Solución en página 75}




\section{Ejercicio 13}

El director de un restaurante de comida lenta está estudiando la posibilidad de ampliar su negocio, para ello está dispuesto a llevar a cabo las reformas que sean necesarias. En concreto está analizando tres mejoras posibles, la primera consistiría en ofrecer además del servicio de restauración, un nuevo servicio como hostal con un total de 8 habitaciones con baño. La segunda mejora se limita a incrementar el número de mesas del restaurante, para ello tiene la posibilidad de usar el segundo piso del local que está ocupando en la actualidad. La tercera mejora se resumiría en dejarlo todo intacto tal como está ahora el restaurante. La tabla siguiente muestra los beneficios que estima el director para cada una de las tres posibles mejoras, así como las probabilidades a priori de que la demanda sea alta o media, según la mejora que ponga en marcha:

\begin{tabular}{|c|c|c|c|c|}
\hline Mejora & Demanda Alta & $p$ & Demanda media & $p$ \\
\hline 1 & 200.000 euros & 0.6 & 70.000 euros & 0.4 \\
\hline 2 & 180.000 euros & 0.4 & 160.000 euros & 0.6 \\
\hline 3 & 150.000 euros & 0.2 & 140.000 euros & 0.8 \\
\hline
\end{tabular}

\section{Solución en página 81}

\section{Ejercicio 14}

Una empresa está estudiando la construcción de una nueva fábrica que le permita incrementar su capacidad productiva para hacer frente al incremento de la demanda previsto para los próximos años. Las alternativas de localización de la misma son las ciudades de Sevilla, Soria, Valencia, y Orense. Los beneficios estimados para cada alternativa a lo largo de los próximos años se recogen en la tabla.

\begin{tabular}{|c|c|c|c|}
\cline { 2 - 4 } \multicolumn{1}{c|}{} & \multicolumn{3}{c|}{ Incremento de la demanda } \\
\cline { 2 - 4 } \multicolumn{1}{c|}{} & Moderado & Elevado & Muy elevado \\
\hline Sevilla & 100.000 & 400.000 & 650.000 \\
\hline Soria & 140.000 & 350.000 & 450.000 \\
\hline Valencia & 150.000 & 570.000 & 1.000 .000 \\
\hline Orense & 200.000 & 500.000 & 950.000 \\
\hline
\end{tabular}

Determine la ubicación óptima de la nueva planta:

1. Siguiendo los criterios optimista, pesimista y Laplace.

2. Si la probabilidad de un incremento moderado de la demanda es del $60 \%$, de un incremento elevado es del $30 \%$, y de un incremento muy elevado es del $10 \%$.

Solución en página 85 


\section{Ejercicio 15}

Una empresa, con el fin de fabricar una nueva línea de productos, está analizando la reforma de su planta actual. La demanda de la nueva línea de productos puede ser favorable o desfavorable. Si la empresa efectúa una reforma profunda de la planta actual, el beneficio estimado en el caso de que la demanda de la nueva línea de productos sea favorable es de 500.000 euros, mientras que si la demanda es desfavorable el beneficio estimado asciende tan solo a 100.000 euros. En el caso de que la reforma que se efectúe en la planta sea moderada, si la demanda es favorable se estiman unos beneficios de 400.000 euros, mientras que si es desfavorable los beneficios estimados son de 250.000 euros. La probabilidad a priori de que la demanda sea favorable o desfavorable es la misma. Obviamente, ni que decir tiene, que la empresa tiene la opción de no poner en marcha la nueva línea de productos.

1. Determine la decisión que debe tomar el empresario.

2. Antes de tomar su decisión, el empresario puede obtener información adicional contratando una firma de investigación de mercado para llevar a cabo un estudio de la demanda. ¿Cuánto estaría dispuesto a pagar por la información exacta?

\section{Solución en página 88}

\section{Ejercicio 16}

El departamento de investigación y desarrollo de una empresa pretende diseñar un nuevo sistema de comunicación, para ello puede adoptar tres estrategias posibles de diseño. Cuanto mejor sea la estrategia de diseño menor será el coste variable, según el responsable del departamento de investigación y desarrollo, la estimación de costes para cada una de las estrategias es la siguiente:

Estrategia basada en baja tecnología y costes reducidos, consistente en contratar a ingenieros becarios en prácticas. Esta opción tiene un coste fijo de 10.000 euros y unos costes variables unitarios de 1,7, 1,6 y 1,5 euros, con unas probabilidades del $40 \%, 35 \%$, y $25 \%$, respectivamente.

La segunda estrategia se fundamenta en la subcontratación, recurriendo a personal externo cualificado de alta calidad, lo que conduce a unos costes fijos de 100.000 euros y unos costes variables unitarios de $1,4,1,3$ y 1,2 euros, con unas probabilidades del $60 \%, 25 \%$, y $15 \%$, respectivamente.

Por último, la tercera estrategia se apoya en alta tecnología, para ello se utilizará el mejor personal de la empresa así como la última tecnología en diseño asistido por computador electrónico. Este enfoque tiene un coste fijo de 250.000 euros y unos costes variables unitarios de 1,1 y 1 euro, con unas probabilidades del $75 \%$ y $25 \%$, respectivamente.

Conociendo que la demanda prevista es de 500.000 unidades, determine la decisión que deberá adoptar el responsable del departamento de investigación y desarrollo.

\section{Solución en página 97}




\section{Ejercicio 17}

Una empresa está estudiando la compra de unos terrenos en los que es probable que haya gas. $\mathrm{Si}$ encuentra gas, la empresa podrá enajenar los terrenos obteniendo un beneficio de 125.000 .000 de euros, o bien explotarlos ella misma en cuyo caso los beneficios dependerán de la demanda, si ésta es alta los beneficios serán de 200.000 .000 de euros, en caso contrario, si la demanda es baja los beneficios solo alcanzarán los 75.000 .000 de euros. La probabilidad a priori de que la demanda sea alta o baja, es exactamente la misma. En el caso de no encontrar gas en dichos terrenos, la empresa soportará unas pérdidas de 50.000 .000 de euros, si bien la probabilidad de encontrar gas según los expertos es del 70\%. Determine si la empresa debe o no adquirir los terrenos.

\section{Solución en página 101}

\section{Ejercicio 18}

La siguiente matriz muestra los beneficios para cada alternativa de decisión, así como las probabilidades a priori de cada estado de la naturaleza.

\begin{tabular}{|c|c|c|c|c|}
\cline { 2 - 5 } \multicolumn{1}{c|}{} & \multicolumn{4}{c|}{ Estados de la naturaleza } \\
\cline { 2 - 5 } \multicolumn{1}{c|}{} & Estado 1 & Estado 2 & Estado 3 & Estado 4 \\
\hline Alternativa 1 & 100 & 90 & -20 & -45 \\
\hline Alternativa 2 & 85 & 80 & 10 & -20 \\
\hline Alternativa 3 & 0 & 70 & 90 & 60 \\
\hline Alternativa 4 & -30 & 0 & 40 & 65 \\
\hline Alternativa 5 & -35 & -10 & 85 & 120 \\
\hline & $15 \%$ & $30 \%$ & $10 \%$ & $45 \%$ \\
\hline
\end{tabular}

Determine la mejor decisión aplicando los criterios:

1. Pesimista.

2. Optimista.

3. Laplace.

4. Pesimista y Laplace a la matriz de costes de oportunidad.

5. Beneficio máximo esperado.

6. Calcule el valor esperado de la información perfecta.

\section{Solución en página 104}




\section{Ejercicio 19}

Una empresa está considerando la posibilidad de contratar un experto en ingeniería industrial para la planificación de su estrategia de operaciones. Una adecuada planificación supondría a la empresa unos beneficios de 1.000 .000 de euros, mientras que si la planificación no fuera correctamente elaborada, la empresa estima unas pérdidas de 400.000 euros. El director industrial estima que la probabilidad de que el experto realice una adecuada planificación es del 75\%. Antes de contratar al experto, la empresa tiene la opción de realizar unas pruebas para determinar la idoneidad del candidato, dichas pruebas tienen una fiabilidad del $80 \%$ a la hora de determinar el éxito potencial del candidato en la realización de la planificación de las operaciones de la empresa. Determine la decisión óptima para la empresa, así como el coste que puede asumir la empresa por realizar la prueba de idoneidad.

\section{Solución en página 111}

\section{Ejercicio 20}

Una empresa está considerando ampliar sus instalaciones para hacer frente a la demanda de sus productos. Las alternativas de que dispone la empresa son: construir una nueva fábrica, ampliar la fábrica actual, o no hacer nada. Existe un $30 \%$ de probabilidades de que la demanda prevista para los próximos años aumente, un $60 \%$ de probabilidades de que se mantenga igual, y un $10 \%$ de probabilidades de que entre en recesión. Determine la opción más rentable para la empresa, siendo los beneficios estimados los que muestra la tabla.

\begin{tabular}{|c|c|c|c|}
\cline { 2 - 4 } \multicolumn{1}{c|}{} & \multicolumn{3}{c|}{ Demanda } \\
\cline { 2 - 4 } \multicolumn{1}{c|}{} & Aumenta & Estable & Disminuye \\
\hline Construir fábrica nueva & 8.000 .000 & 5.000 .000 & -5.000 .000 \\
\hline Ampliar fábrica actual & 6.500 .000 & 2.000 .000 & -3.000 .000 \\
\hline No hacer nada & 2.000 .000 & 1.000 .000 & -2.000 .000 \\
\hline
\end{tabular}

Solución en página 118 


\section{Ejercicio 21}

Una empresa está estudiando el contrato de 600 euros semanales que tiene con su proveedor de servicios de mantenimiento. Desde la firma del contrato la media es de 2,5 averías semanales, entrañando cada fallo un coste de reparación de 1.000 euros. Las averías semanales de la empresa, antes de la firma del contrato, se muestran en la tabla.

\begin{tabular}{|c|c|c|c|c|c|c|c|}
\hline Averías & 0 & 1 & 2 & 3 & 4 & 5 & 6 \\
\hline Semanas que hubo estas averías & 9 & 10 & 12 & 16 & 24 & 18 & 11 \\
\hline
\end{tabular}

Ayude a la empresa a decidir si le conviene o no la renovación del contrato de mantenimiento con su actual proveedor.

\section{Solución en página 122}

\section{Ejercicio 22}

Una empresa tiene dos opciones:

1. Producir la nueva línea de productos de la que acaba de dar a conocer los prototipos.

2. Antes de iniciar la producción, pedir a los ingenieros de producto que lleven a cabo un análisis del valor de la nueva línea de productos.

Con la primera opción la empresa esperar alcanzar unas ventas de 300.000 unidades con una probabilidad del 30\%, y de 150.000 unidades con una probabilidad del 70\%, siendo el precio unitario de venta de 600 euros. Por el contrario, si recurre a realizar el análisis del valor de la nueva línea de productos, las ventas esperadas son de 225.000 unidades con una probabilidad del $40 \%$, y de 140.000 unidades con una probabilidad del $60 \%$, siendo en este caso el precio unitario de venta de 900 euros. La empresa estima que el análisis del valor le ocasionará unos costes de 100.000 euros. Indique la decisión óptima que debe tomar la empresa.

\section{Solución en página 124}

\section{Ejercicio 23}

La dirección de una empresa dedicada a la fabricación y venta de cremosos helados, se está planteando la compra de una nueva máquina para la fabricación de su nuevo helado de chocolate con el perfil de uno de los participantes en un famoso concurso. Tres son los modelos de la máquina que hay en el mercado en función de la calidad (tipo 1, tipo 2 y tipo 3). Si dicho concursante gana el concurso los beneficios que presume la dirección de la empresa que se alcanzarán son de 70.000, 75.000 y 80.000 euros para cada modelo de máquina, si por el contrario el concursante resulta finalista, pero no ganador del concurso, los beneficios estimados son $65.000,70.000$ y 75.000 euros, pero si dicho concursante es expulsado antes de llegar a la final, los beneficios esperados son tan solo de 55.000, 
60.000 y 65.000 euros, respectivamente. La dirección de la empresa, tras una ronda de consultas con familiares, amigos, clientes, etc., estima que la probabilidad de que dicho concursante acabe ganando el concurso es del 10\%, que llegue a finalista y no gane el concurso es también del $30 \%$, y que lo expulsen del concurso antes de llegar a la final del $60 \%$. Sugiera a la dirección de la empresa la máquina que debe adquirir.

\section{Solución en página 127}

\section{Ejercicio 24}

Una empresa está considerando cambiar uno de sus equipos tecnológicamente avanzados, para ello dispone de dos opciones, la primera es comprar dos nuevos equipos idénticos al actual a 200.000 euros cada uno, y la segunda consiste en comprar un nuevo sistema integrado por 800.000 euros. Las ventas estimadas por la empresa a lo largo de la vida útil de cualquiera de sus equipos son de 5.000 .000 de euros en el caso de que el mercado sea alcista, a lo que la empresa le asigna una probabilidad de que suceda del $30 \%$, en caso contrario, si el mercado es bajista las ventas esperadas son de 3.500 .000 euros. Indique al director de dicha empresa la opción que debe tomar.

\section{Solución en página 131}




\section{Capítulo 2}

\section{Resolución de los problemas}

\section{Ejercicio 1}

Una empresa compra la materia prima a dos proveedores $A$ y $B$, cuya calidad se muestra en la tabla siguiente:

\begin{tabular}{|c|c|c|}
\hline $\begin{array}{c}\text { Piezas } \\
\text { defectuosas }\end{array}$ & $\begin{array}{c}\text { Probabilidad para } \\
\text { el proveedor A }\end{array}$ & $\begin{array}{c}\text { Probabilidad para } \\
\text { el proveedor B }\end{array}$ \\
\hline $1 \%$ & 0.80 & 0.40 \\
\hline $2 \%$ & 0.10 & 0.30 \\
\hline $3 \%$ & 0.10 & 0.30 \\
\hline
\end{tabular}

La probabilidad de recibir un lote del proveedor $A$ en el que haya un 1\% de piezas defectuosas es del 70\%. Los pedidos que realiza la empresa ascienden a 1.000 piezas. Una pieza defectuosa puede ser reparada por 1 euro. Si bien tal y como indica la tabla la calidad del proveedor $B$ es menor, éste está dispuesto a vender las 1.000 piezas por 10 euros menos que el proveedor $A$.

Indique el proveedor que debe utilizar. 


\section{Solución:}

Paso 1 - Enumere las diferentes alternativas de decisión.

\section{Proveedor A.}

Proveedor B.

Paso 2 - Enumere para cada una de las alternativas de decisión, los estados de la naturaleza asociados a la misma.

\begin{tabular}{|c|c|}
\hline Alternativas & Estados de la naturaleza \\
\hline & 1\% de piezas defectuosas \\
Proveedor A & $2 \%$ de piezas defectuosas \\
& $3 \%$ de piezas defectuosas \\
\hline \multirow{2}{*}{ Proveedor B } & 1\% de piezas defectuosas \\
& 2\% de piezas defectuosas \\
& $3 \%$ de piezas defectuosas \\
\hline
\end{tabular}

Paso 3 - Explicite el árbol de decisión.

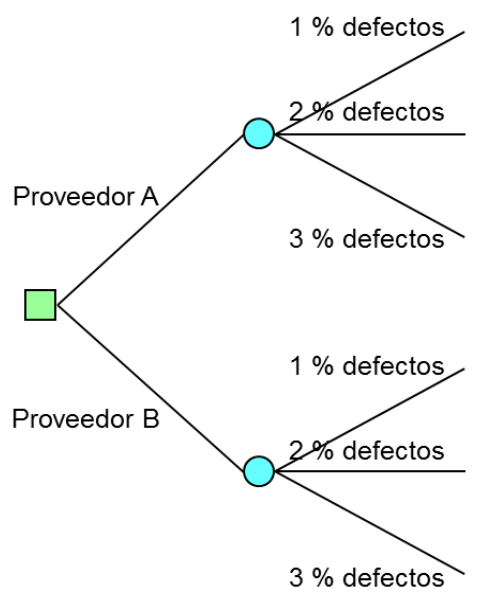


Paso 4 - Asigne las probabilidades a priori de cada uno de los estados de la naturaleza.

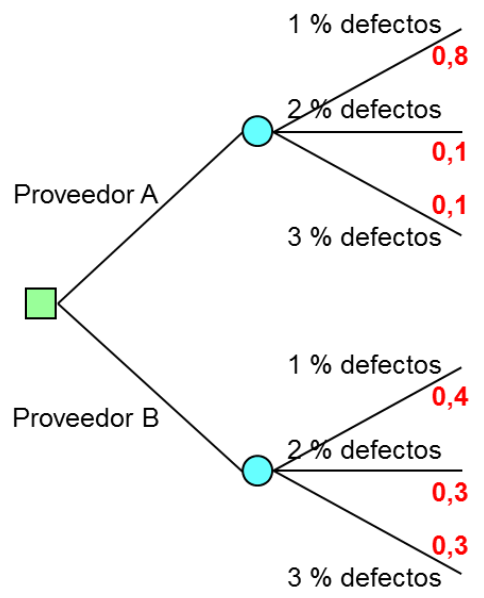

Paso 5 - Calcule el coste de cada una de las ramas del árbol.

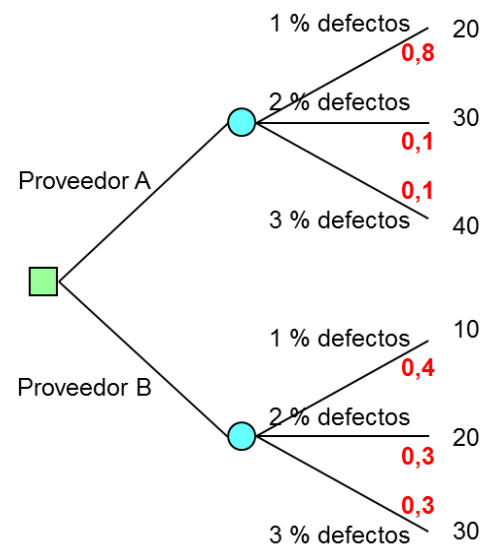

El coste de cada rama lo obtiene a partir del número de unidades defectuosas. Siendo los pedidos de 1.000 piezas, las unidades defectuosas serán:

En el caso de $1 \%$ defectuosas:

$$
1.000 \text { piezas } \times 1 \% / \text { defectuosas }=10 \text { piezas } / \text { defectuosas }
$$

En el caso de $2 \%$ defectuosas:

$$
1.000 \text { piezas } \times 2 \% / \text { defectuosas }=20 \text { piezas } / \text { defectuosas }
$$


En el caso de 3\% defectuosas:

\subsection{0 piezas $\times 3 \% /$ defectuosas $=30$ piezas $/$ defectuosas}

Si cada pieza defectuosa puede ser reparada por 1 euro, el coste de la reparación asciende a:

En el caso de $1 \%$ defectuosas:

$$
10 \text { piezas/defectuosas } \times 1 \text { euro / pieza defectuosa }=10 \text { euros }
$$

En el caso de $2 \%$ defectuosas:

$$
20 \text { piezas / defectuosas } \times 1 \text { euro / pieza defectuosa }=20 \text { euros }
$$

En el caso de 3\% defectuosas:

$$
30 \text { piezas/defectuosas } \times 1 \text { euro / pieza defectuosa }=30 \text { euros }
$$

En el caso del proveedor A el coste es 10 euros superior al del proveedor B, tal y como indica el enunciado del ejercicio.

Paso 6 - Resuelva el árbol de decisión de derecha a izquierda. Dado que la etapa final es probabilista debe aplicar el criterio de la esperanza matemática con el objetivo de determinar el coste esperado de cada alternativa de decisión.

$$
\begin{aligned}
& (20 \times 0,8)+(30 \times 0,1)+(40 \times 0,1)=23 \text { euros } \\
& (10 \times 0,4)+(20 \times 0,3)+(30 \times 0,3)=19 \text { euros }
\end{aligned}
$$

Coloque el resultado encima del nudo correspondiente.

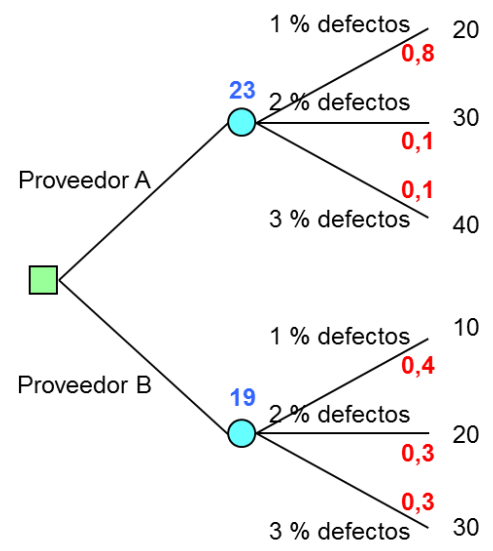


Paso 7 - Resuelva la etapa anterior. Dado que esta primera etapa es determinista y que los valores que ha calculado son costes, debe elegir la alternativa cuyo coste sea menor y colocar el resultado encima del nudo correspondiente.

El coste esperado de comprar la pieza al proveedor A es de 23 euros según ha calculado en el paso anterior, mientras que el de comprar la pieza al proveedor B es de 19 euros, por lo que deberá comprar la pieza el proveedor B dado que el coste es menor.

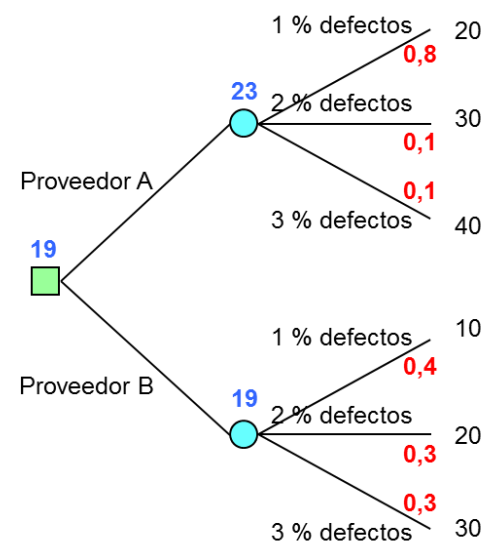

Siguiendo el criterio de la esperanza matemática debe comprar la pieza al proveedor B. 


\section{Ejercicio 2}

Se está planteando construir una nueva sección en su negocio de comida rápida, si bien no sabe si hacer la nueva sección grande o pequeña. Al mismo tiempo se plantea si reúne información sobre las ventas previstas o si por el contrario no hace nada. La información sobre las ventas previstas puede aconsejarle un mercado creciente o un mercado decreciente, siendo de 500 euros el coste de dicha información, y la probabilidad de que la información sea favorable del 60\%. Si el mercado es creciente las ganancias previstas son de 9.000 euros si la sección es grande y 3.000 si es pequeña. Si el mercado es decreciente puede perder 10.000 euros si la sección es grande y 5.000 si es pequeña. Si no reúne información adicional, la estimación de probabilidades de que el mercado sea creciente es del $60 \%$, contrariamente un informe favorable incrementaría la probabilidad de un mercado creciente al $80 \%$ y un informe desfavorable disminuiría la probabilidad de un mercado creciente al $40 \%$.

Indique la decisión que debe tomar.

\section{Solución:}

Paso 1 - Enumere las diferentes alternativas de decisión.

Reunir información adicional sobre las ventas previstas.

NO reunir información adicional sobre las ventas previstas.

En el caso de que opte por no reunir información adicional, debe decidir si construye la nueva sección grande o pequeña.

Paso 2 - Enumere para cada una de las alternativas de decisión, los estados de la naturaleza asociados a la misma.

\begin{tabular}{|c|c|c|}
\hline \multicolumn{2}{|c|}{ Alternativas } & Estados de la naturaleza \\
\hline \multicolumn{2}{|c|}{ Con información } & $\begin{array}{c}\text { Información favorable } \\
\text { Información desfavorable }\end{array}$ \\
\hline \multirow{3}{*}{ Sin información } & Grande & $\begin{array}{c}\text { Creciente } \\
\text { Decreciente }\end{array}$ \\
\cline { 2 - 3 } & Pequeña & $\begin{array}{c}\text { Creciente } \\
\text { Decreciente }\end{array}$ \\
\hline
\end{tabular}

Obtenida la información, sea ésta favorable o desfavorable, debe decidir si construye la nueva sección grande o pequeña, tras lo cual el mercado podrá ser creciente o decreciente. 
Paso 3 - Explicite el árbol de decisión.

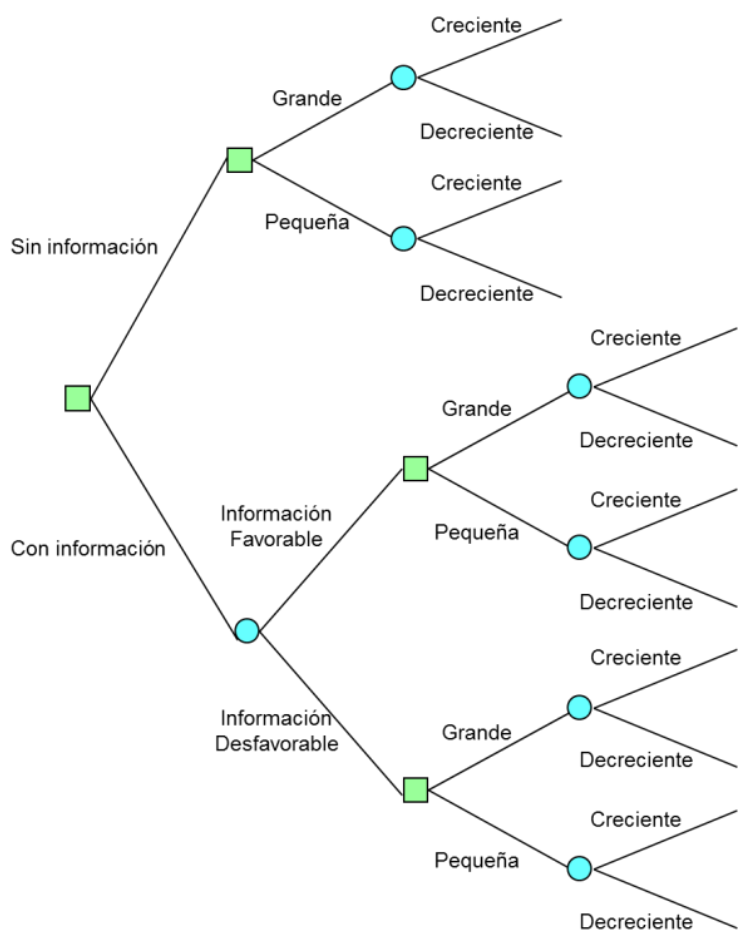

Paso 4 - Asigne las probabilidades a priori de cada uno de los estados de la naturaleza. 


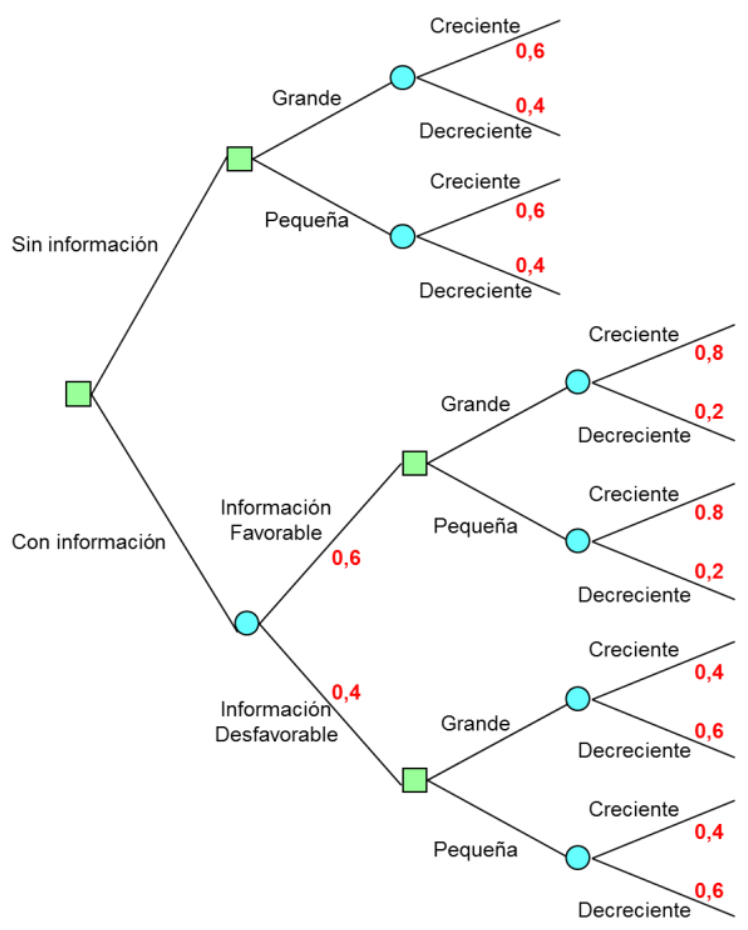

Paso 5 - Calcule el beneficio de cada una de las ramas del árbol.

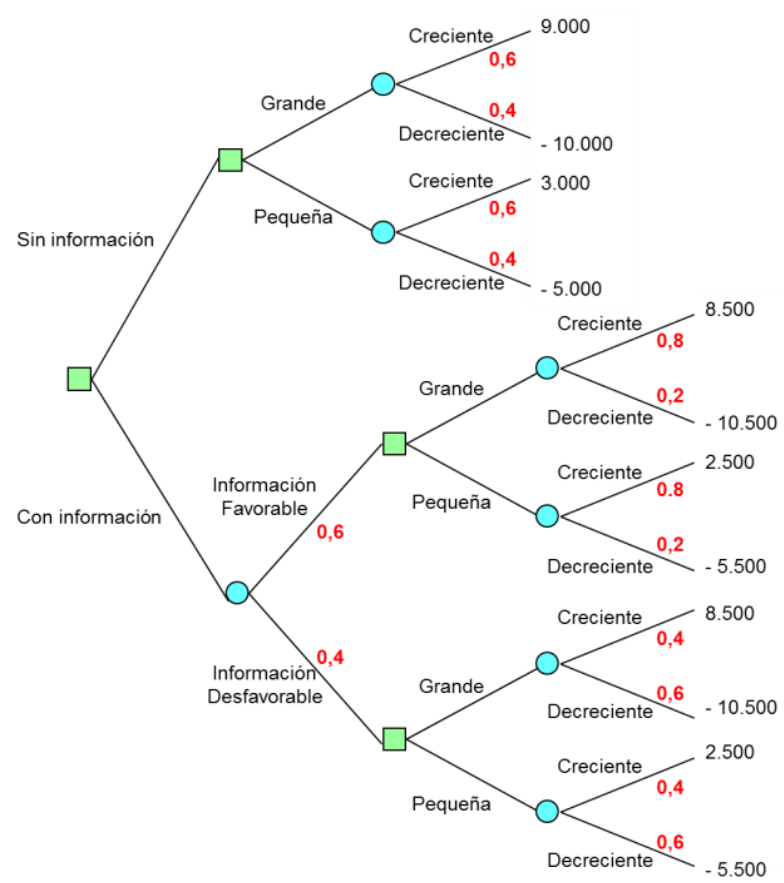


El beneficio en el caso de no reunir información sobre las ventas viene dado directamente en el enunciado del ejercicio:

\begin{tabular}{|c|c|c|}
\cline { 2 - 3 } \multicolumn{1}{c|}{} & Mercado creciente & Mercado decreciente \\
\hline Construye sección grande & 9.000 euros & -10.000 euros \\
\hline Construye sección pequeña & 3.000 euros & -5.000 euros \\
\hline
\end{tabular}

En caso de reunir información sobre las ventas, a estos valores debe restar los 500 euros correspondientes al coste de la información.

Paso 6 - Resuelva el árbol de decisión de derecha a izquierda. Dado que la etapa final es probabilista debe aplicar el criterio de la esperanza matemática con el objetivo de determinar el beneficio esperado de cada alternativa de decisión.

$$
\begin{gathered}
(9.000 \times 0,6)+(-10.000 \times 0,4)=1.400 \text { euros } \\
(3.000 \times 0,6)+(-5.000 \times 0,4)=-200 \text { euros } \\
(8.500 \times 0,8)+(-10.500 \times 0,2)=4.700 \text { euros } \\
(2.500 \times 0,8)+(-5.500 \times 0,2)=900 \text { euros } \\
(8.500 \times 0,4)+(-10.500 \times 0,6)=-2.900 \text { euros } \\
(2.500 \times 0,4)+(-5.500 \times 0,6)=-2.300 \text { euros }
\end{gathered}
$$

Coloque el resultado encima del nudo correspondiente.

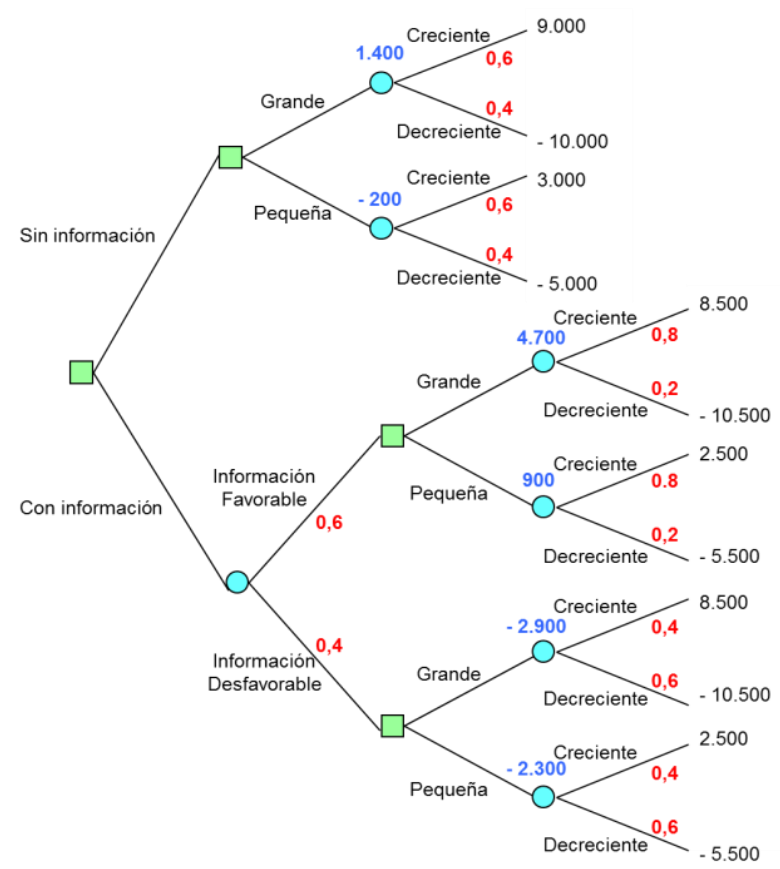


Paso 7 - Resuelva la etapa anterior. Dado que dicha etapa es determinista y que los valores que ha calculado son beneficios, debe elegir la alternativa cuyo beneficio sea mayor y colocar el resultado encima del nudo correspondiente.

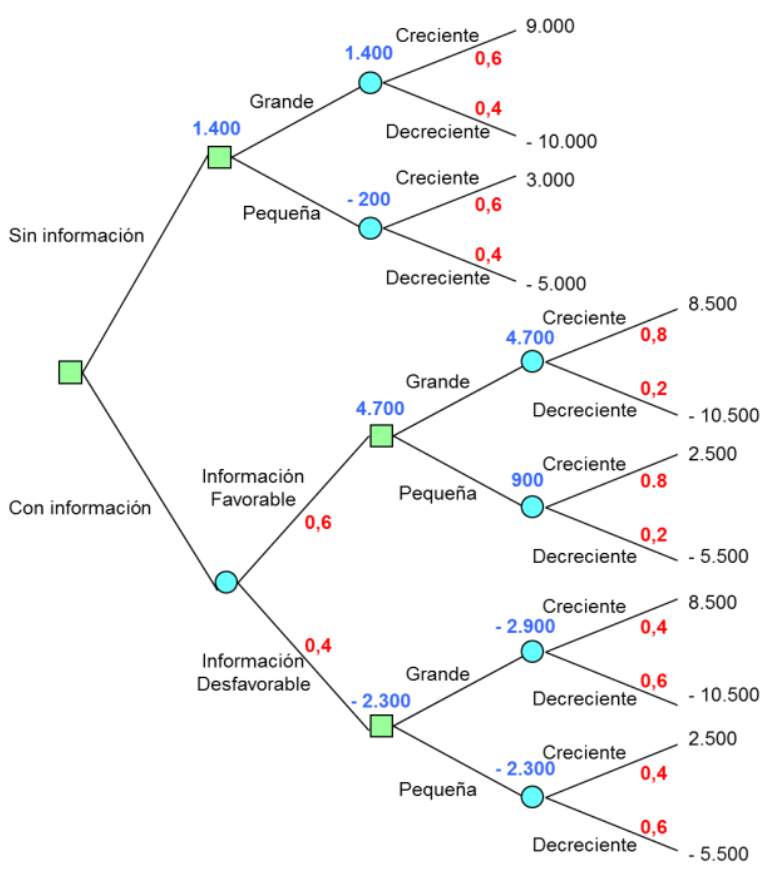

Paso 8 - Resuelva las dos últimas etapas. La etapa penúltima es probabilista por lo que debe aplicar el criterio de la esperanza matemática con el objetivo de determinar el beneficio esperado.

$$
(4.700 \times 0,6)+((-2.300) \times 0,4)=1.900 \text { euros }
$$

La última etapa es determinista, debe pues elegir la alternativa cuyo beneficio sea mayor y colocar el resultado encima del nudo correspondiente. 


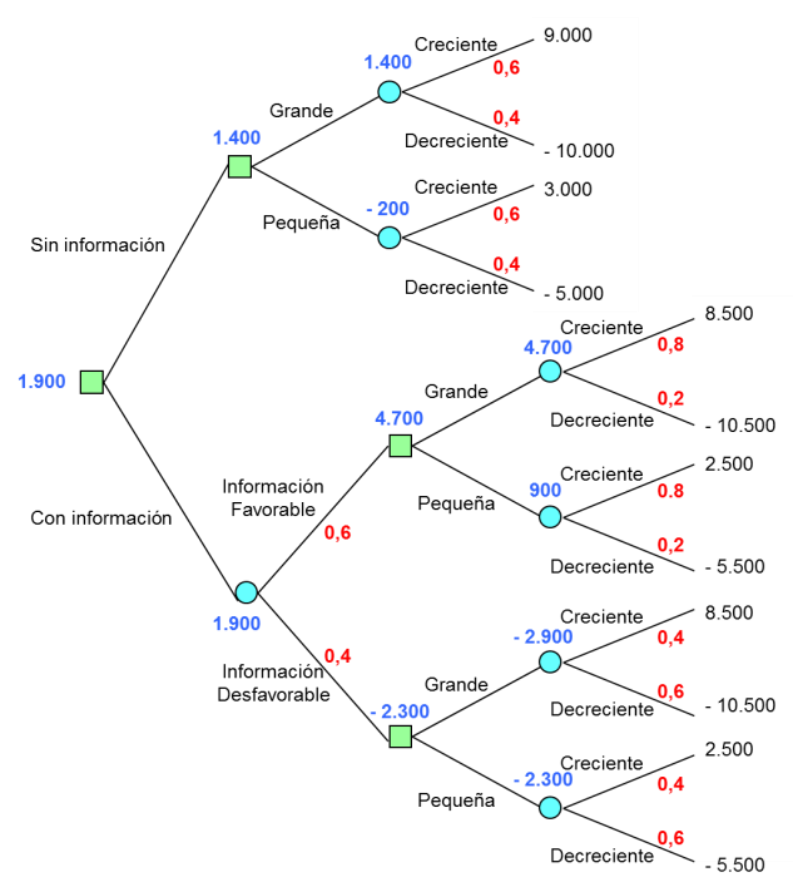

El beneficio esperado de reunir información adicional es de 1.900 euros y el de no reunir información adicional es de 1.400 euros, por lo que debe reunir información adicional dado que el beneficio es mayor, y si dicha información resulta favorable debe construir una sección grande, en caso contrario construya una sección pequeña. 


\section{Ejercicio 3}

Un empresario adquiere pescado fresco en el mercado central para su posterior venta. Cada caja de pescado la identifica como excelente o no excelente en función del porcentaje de pescado que se considere de calidad excelente. Una caja de pescado excelente contiene un $90 \%$ de pescado de alta calidad, mientras que una caja de pescado no excelente contiene solo un $20 \%$ de pescado de alta calidad. Una caja de de pescado excelente genera un beneficio de 100 euros, mientras que una caja de pescado no excelente causa unas pérdidas de 100 euros por la mala imagen de la empresa que se llevan los clientes. Antes de comprar una caja el empresario puede comprobar la calidad de la misma extrayendo un ejemplar de pescado con el objetivo de verificar si se trata o no de pescado de alta calidad. Establezca la estrategia que debe seguir el empresario, así como el coste de la información.

\section{Solución:}

Paso 1 - Enumere las diferentes alternativas de decisión.

Comprar la caja de pescado.

NO comprar la caja de pescado.

Probar la caja de pescado $\rightarrow$ Comprobar la calidad de la caja extrayendo un ejemplar de pescado con el objetivo de verificar si se trata o no de pescado de alta calidad.

Paso 2 - Enumere para cada una de las alternativas de decisión, los estados de la naturaleza asociados a la misma.

\begin{tabular}{|c|c|}
\hline Alternativas & Estados de la naturaleza \\
\hline Comprar & $\begin{array}{c}\text { Caja de pescado excelente } \\
\text { Caja de pescado no excelente }\end{array}$ \\
\hline No comprar & \\
\hline Probar & $\begin{array}{c}\text { Ejemplar de pescado de alta calidad } \\
\text { Ejemplar de pescado de baja calidad }\end{array}$ \\
\hline
\end{tabular}

Obtenida la información, sea ésta que el ejemplar de pescado verificado es de alta o baja calidad, debe decidir si compra o no compra la caja de pescado, tras lo cual la caja de pescado podrá ser excelente o no excelente. 
Paso 3 - Explicite el árbol de decisión.

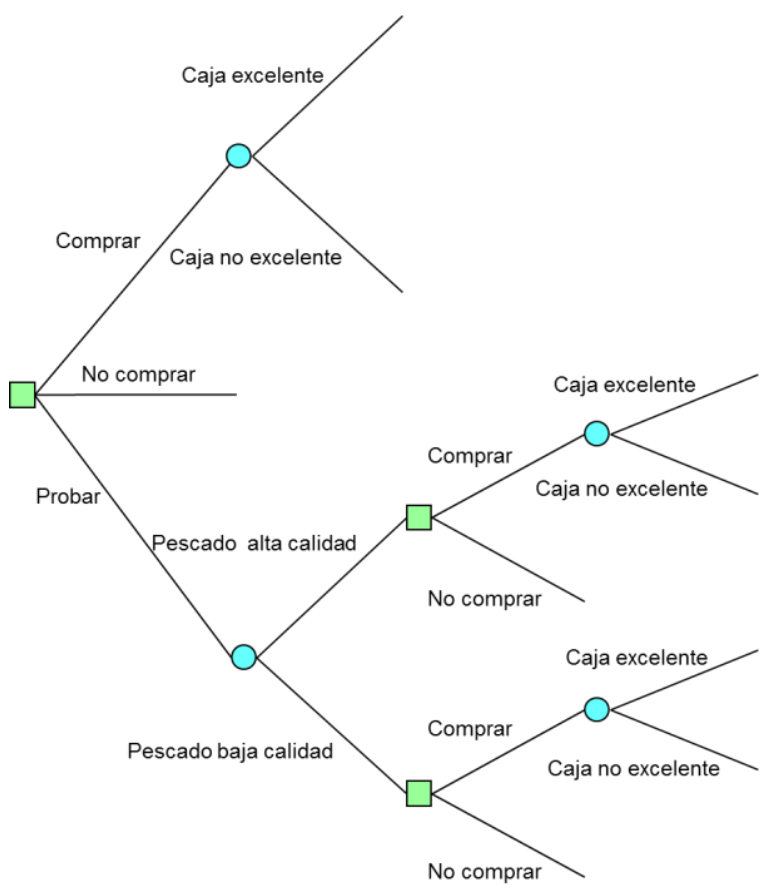

Paso 4 - Asigne las probabilidades de cada uno de los estados de la naturaleza. En este caso se trata de probabilidades a posteriori, por lo que debe utilizar el teorema de Bayes para calcular dichas probabilidades.

Para la aplicación del teorema de Bayes puede utilizar el árbol que se muestra a continuación. Los estados de la naturaleza son que la caja comprada sea o no de excelente calidad, y los acontecimientos, que el ejemplar de pescado verificado es de alta o baja calidad.

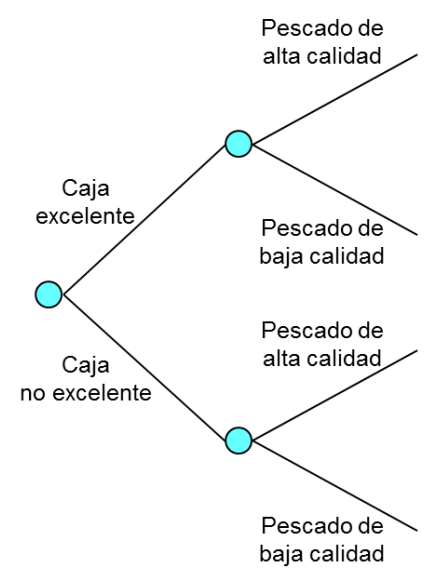


La probabilidad a priori de que una caja de pescado sea o no de excelente calidad es obviamente del $50 \%$. Por su parte, las probabilidades condicionales vienen dadas, según se indica en el enunciado del ejercicio, por los siguientes valores:

$$
\begin{gathered}
P(\text { Pescado sea de alta calidad / Caja es excelente })=0,9 \\
P(\text { Pescado sea de baja calidad / Caja es excelente })=0,1 \\
P(\text { Pescado sea de alta calidad / Caja no es excelente })=0,2 \\
P(\text { Pescado sea de baja calidad / Caja no es excelente })=0,8
\end{gathered}
$$

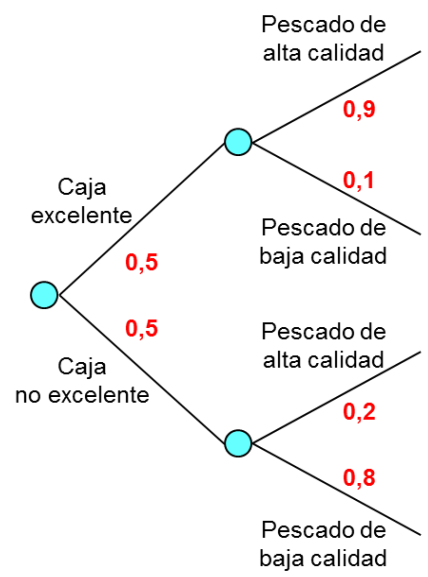

De donde, la probabilidad a priori de cada uno de los acontecimientos:

$\mathrm{P}($ Pescado de alta calidad $)=[\mathrm{P}($ Caja excelente $) \times \mathrm{P}($ Pescado de alta calidad / Caja excelente $)]+[\mathrm{P}($ Caja no excelente) $\times \mathrm{P}($ Pescado de alta calidad / Caja no excelente $)]=[0,5 \times 0,9]+[0,5 \times 0,2]=0,55$

$\mathrm{P}($ Pescado de baja calidad $)=[\mathrm{P}($ Caja excelente $) \times \mathrm{P}($ Pescado de baja calidad / Caja excelente $)]+[\mathrm{P}(\mathrm{Caja}$ no excelente) $\times \mathrm{P}($ Pescado de baja calidad / Caja no excelente $)]=[0,5 \times 0,1]+[0,5 \times 0,8]=0,45$

Seguidamente, mediante la aplicación del teorema de Bayes determine las probabilidades a posteriori de cada uno de los estados de la naturaleza.

$\mathrm{P}($ Caja excelente $/$ Pescado alta calidad $)=\frac{\mathrm{P}(\text { Caja excelente }) \times \mathrm{P}(\text { Pescado alta calidad } / \text { Caja excelente })}{\mathrm{P}(\text { Pescado alta calidad })}$

$\mathrm{P}($ Caja excelente / Pescado alta calidad $)=\frac{0,5 \times 0,9}{0,55}=0,82$ 
$\mathrm{P}($ Caja no excelente $/$ Pescado alta calidad $)=\frac{\mathrm{P}(\text { Caja no excelente }) \times \mathrm{P}(\text { Pescado alta calidad } / \text { Caja no excelente })}{\mathrm{P}(\text { Pescado alta calidad })}$ $\mathrm{P}($ Caja no excelente / Pescado alta calidad $)=\frac{0,5 \times 0,2}{0,55}=0,18$

$\mathrm{P}($ Caja excelente $/$ Pescado baja calidad $)=\frac{\mathrm{P}(\text { Caja excelente }) \times \mathrm{P}(\text { Pescado baja calidad } / \text { Caja excelente })}{\mathrm{P}(\text { Pescado baja calidad })}$

$$
\mathrm{P}(\text { Caja excelente / Pescado baja calidad })=\frac{0,5 \times 0,1}{0,45}=0,10
$$

$\mathrm{P}($ Caja no excelente $/$ Pescado baja calidad $)=\frac{\mathrm{P}(\text { Caja no excelente }) \times \mathrm{P}(\text { Pescado baja calidad } / \text { Caja no excelente })}{\mathrm{P}(\text { Pescado baja calidad })}$

$$
\mathrm{P}(\text { Caja no excelente / Pescado baja calidad })=\frac{0,5 \times 0,8}{0,45}=0,90
$$

\section{De donde, el árbol de decisión incluyendo las probabilidades:}

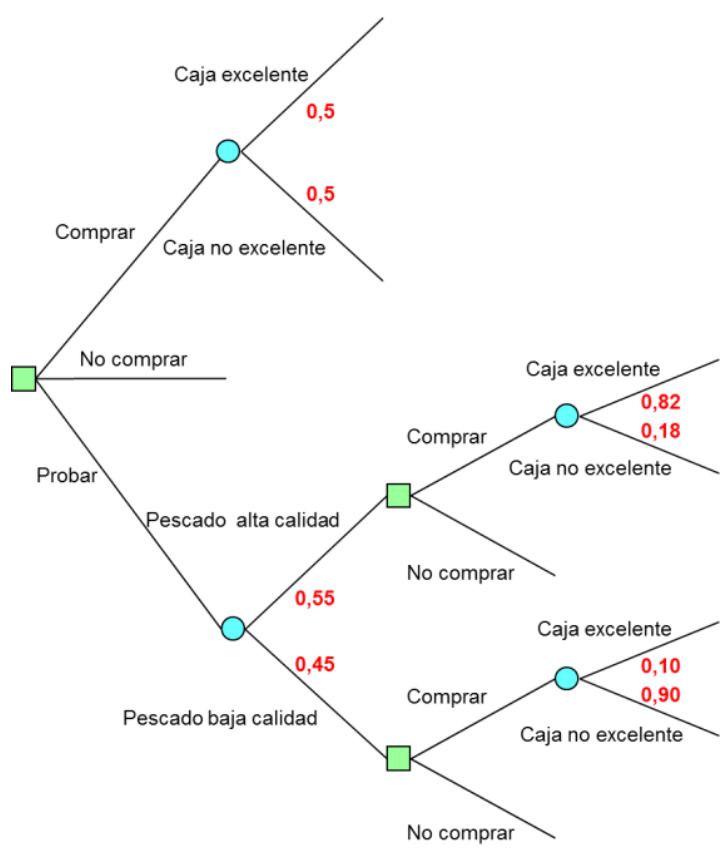


Paso 5 - Calcule el beneficio de cada una de las ramas del árbol.

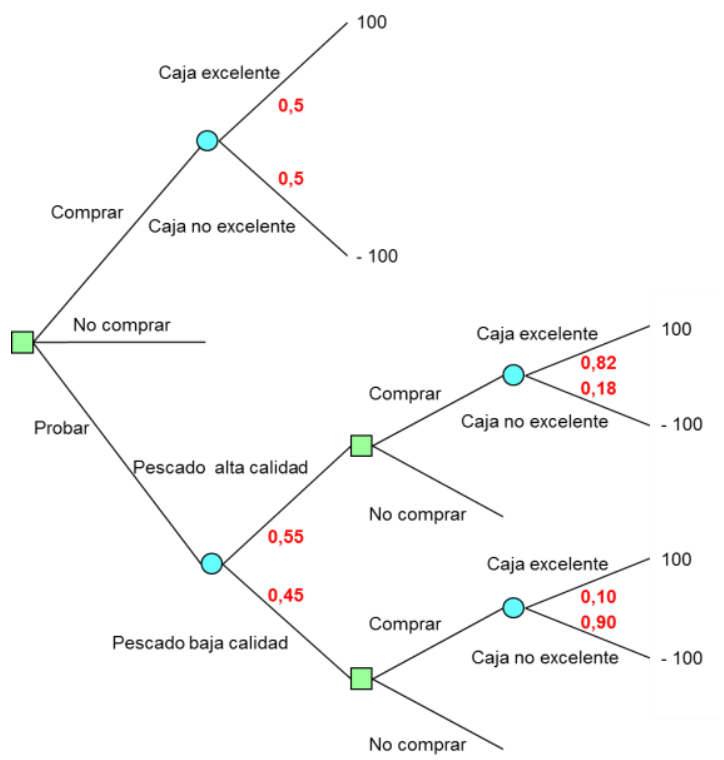

El beneficio de una caja de pescado excelente (100 euros) y el de una caja de pescado no excelente (100 euros) viene dado en el enunciado del ejercicio.

Paso 6 - Resuelva el árbol de decisión de derecha a izquierda. Dado que la etapa final es probabilista debe aplicar el criterio de la esperanza matemática con el objetivo de determinar el beneficio esperado de cada alternativa de decisión.

$$
\begin{aligned}
& (100 \times 0,82)+((-100) \times 0,18)=64 \text { euros } \\
& (100 \times 0,10)+((-100) \times 0,90)=-80 \text { euros } \\
& (100 \times 0,50)+((-100) \times 0,50)=0 \text { euros }
\end{aligned}
$$

Coloque estos resultados en el árbol de decisión encima del nudo correspondiente. 


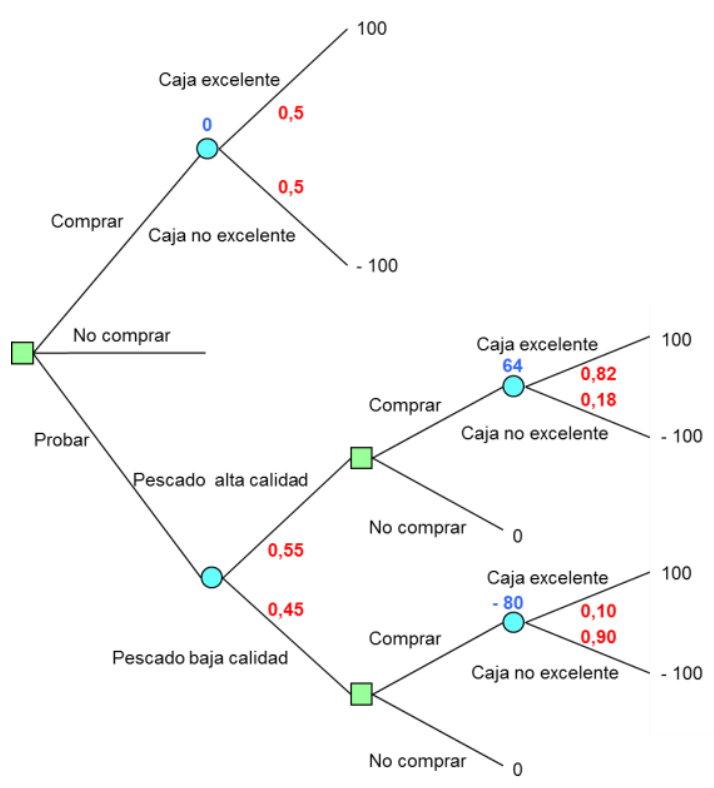

Paso 7 - Resuelva la etapa anterior. Dado que dicha etapa es determinista y que los valores que ha calculado son beneficios, debe elegir la alternativa cuyo beneficio sea mayor y colocar el resultado encima del nudo correspondiente.

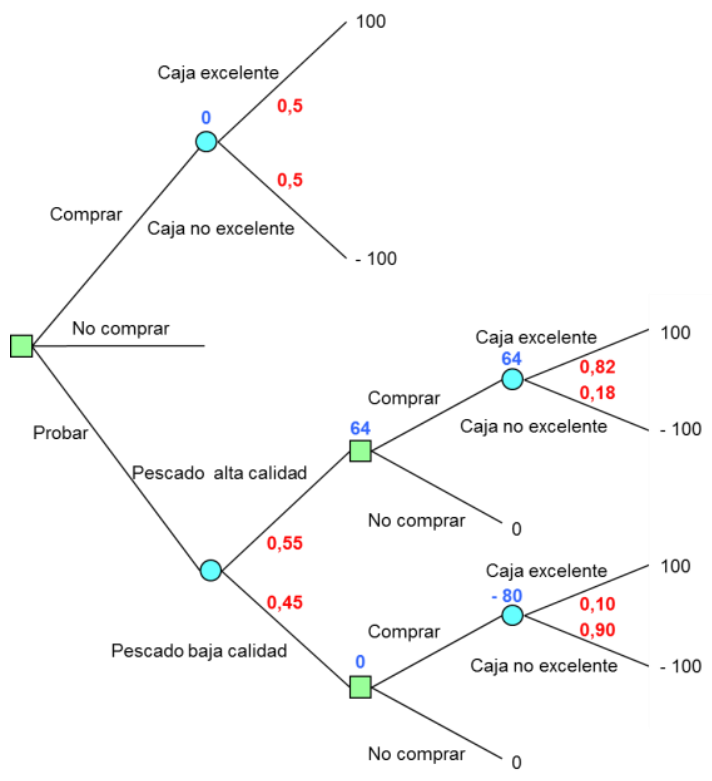


Paso 8 - Resuelva las dos últimas etapas. La penúltima etapa es probabilista por lo que debe aplicar el criterio de la esperanza matemática con el objetivo de determinar el beneficio esperado.

$$
(64 \times 0,55)+(0 \times 0,45)=35,2 \text { euros }
$$

La última etapa es determinista, debe pues elegir la alternativa cuyo beneficio sea mayor y colocar el resultado encima del nudo correspondiente.

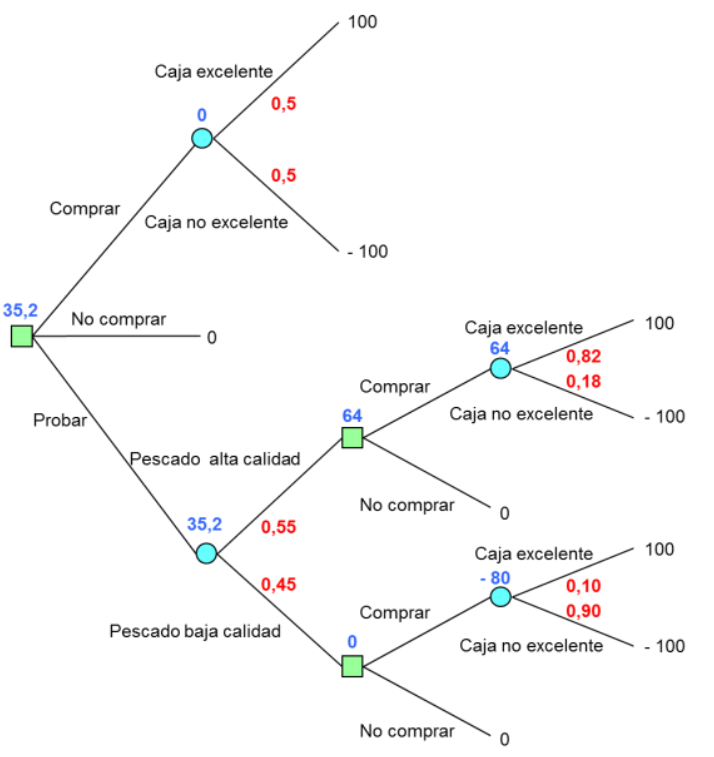

La estrategia que debe seguir el empresario es la de extraer un ejemplar de pescado con el objetivo de verificar si se trata o no de pescado de alta calidad, en el caso de que el pescado extraído sea de alta calidad, debe comprar la caja de pescado, por el contrario, si el pescado extraído es de baja calidad, no debe comprar la caja de pescado. Con esta estrategia el beneficio esperado es de 35,2 euros.

El valor de la información $=35,2-0=35,2$ euros es el valor de la información que aporta la extracción de un ejemplar de pescado con el objetivo de verificar si se trata o no de pescado de alta calidad. Si por llevar a cabo este control de calidad le cobraran más de 35,2 euros, no interesa llevarlo a cabo. 


\section{Ejercicio 4}

El gerente de una empresa tiene dos diseños posibles para su nueva línea de cerebros electrónicos, la primera opción tiene un $80 \%$ de probabilidades de producir el $70 \%$ de cerebros electrónicos buenos y un $20 \%$ de probabilidades de producir el $50 \%$ de cerebros electrónicos buenos, siendo el coste de este diseño de 450.000 de euros. La segunda opción tiene una probabilidad del $70 \%$ de producir el $70 \%$ de cerebros electrónicos buenos y una probabilidad del 30\% de producir el 50\% de cerebros electrónicos buenos, el coste de este diseño asciende a 600.000 euros. El coste de cada cerebro electrónico es de 100 euros, si es bueno se vende por 250 euros, mientras que si es malo no tiene ningún valor. Conociendo que la previsión es de fabricar 50.000 cerebros electrónicos, decida el diseño que debe elegir el gerente de la empresa.

\section{Solución:}

Paso 1 - Enumere las diferentes alternativas de decisión.

\section{Diseño 1.}

\section{Diseño 2.}

Paso 2 - Enumere para cada una de las alternativas de decisión, los estados de la naturaleza asociados a la misma.

\begin{tabular}{|c|c|}
\hline Alternativas & Estados de la naturaleza \\
\hline \multirow{2}{*}{ Diseño 1 } & $\begin{array}{l}70 \% \text { de cerebros electrónicos buenos } \\
50 \% \text { de cerebros electrónicos buenos }\end{array}$ \\
\hline \multirow{2}{*}{ Diseño 2} & $\begin{array}{l}70 \% \text { de cerebros electrónicos buenos } \\
50 \% \text { de cerebros electrónicos buenos }\end{array}$ \\
\hline
\end{tabular}

Paso 3 - Explicite el árbol de decisión.

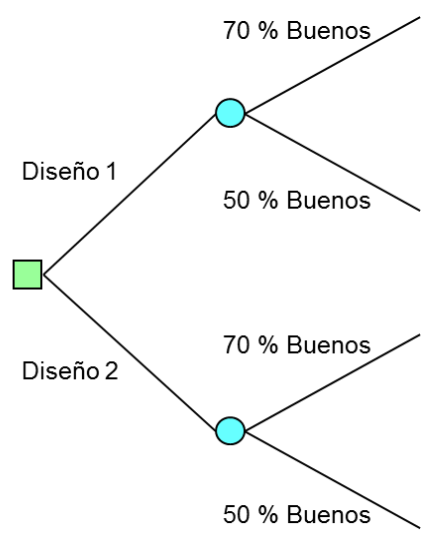


Paso 4 - Asigne las probabilidades a priori de cada uno de los estados de la naturaleza.

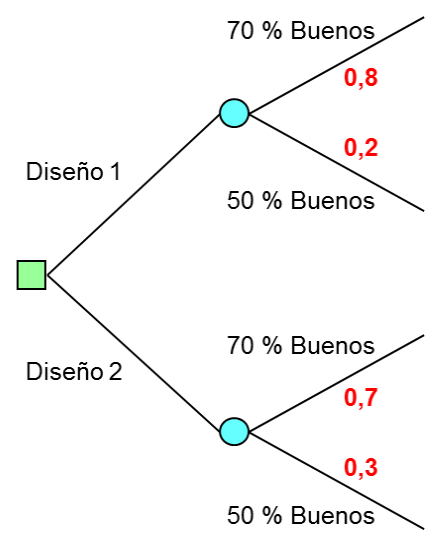

Paso 5 - Calcule el beneficio de cada una de las ramas del árbol.

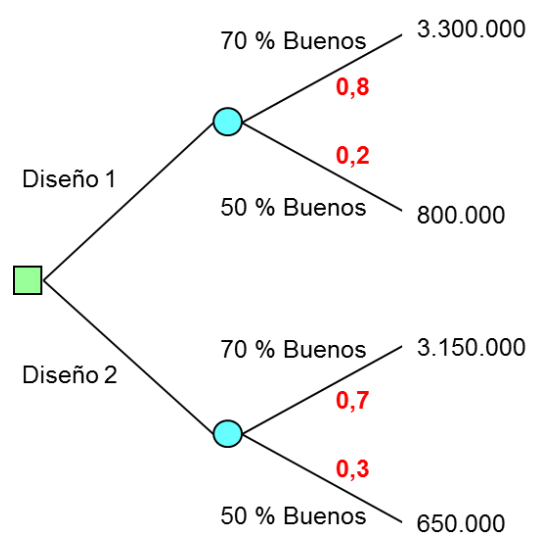

El beneficio de cada rama lo obtiene restando los gastos de los ingresos. Para el cálculo de los ingresos, debe tener en cuenta el número de unidades buenas, dado que las malas no tienen ningún valor. Siendo la previsión de fabricar 50.000 cerebros, las unidades buenas serán:

En el caso de $70 \%$ buenas:

$$
50.000 \times 0,70=35.000 \text { cerebros }
$$

En el caso de $50 \%$ buenas:

$$
50.000 \times 0,50=25.000 \text { cerebros }
$$


De donde, los ingresos:

En el caso de $70 \%$ buenas:

35.000 cerebros $\times 250$ euros/cerebro $=8.750 .000$ euros

En el caso de $50 \%$ buenas:

25.000 cerebros $x 250$ euros/cerebro $=6.250 .000$ euros

Tomando en consideración los gastos de compra/fabricación de los cerebros electrónicos que ascienden a:

50.000 cerebros $x 100$ euros $/$ cerebro $=5.000 .000$ de euros

Y los gastos del diseño, que en el caso del diseño 1 se elevan a 450.000 euros, mientras que en el diseño 2 son de 600.000 euros, resultan unos beneficios de:

Diseño 1 y $70 \%$ buenas:

$$
8.750 .000-5.000 .000-450.000=3.300 .000 \text { euros }
$$

Diseño 1 y 50\% buenas:

$$
6.250 .000-5.000 .000-450.000=800.000 \text { euros }
$$

Diseño 2 y $70 \%$ buenas:

$$
8.750 .000-5.000 .000-600.000=3.150 .000 \text { euros }
$$

Diseño 2 y $50 \%$ buenas:

$$
6.250 .000-5.000 .000-600.000=650.000 \text { euros }
$$

Paso 6 - Resuelva el árbol de decisión de derecha a izquierda. Dado que la etapa final es probabilista debe aplicar el criterio de la esperanza matemática con el objetivo de determinar el coste esperado de cada alternativa de decisión.

$$
\begin{aligned}
& (3.300 .000 \times 0,8)+(800.000 \times 0,2)=2.800 .000 \text { euros } \\
& (3.150 .000 \times 0,7)+(650.000 \times 0,3)=2.400 .000 \text { euros }
\end{aligned}
$$


Coloque los resultados en el árbol de decisión encima del nudo correspondiente.

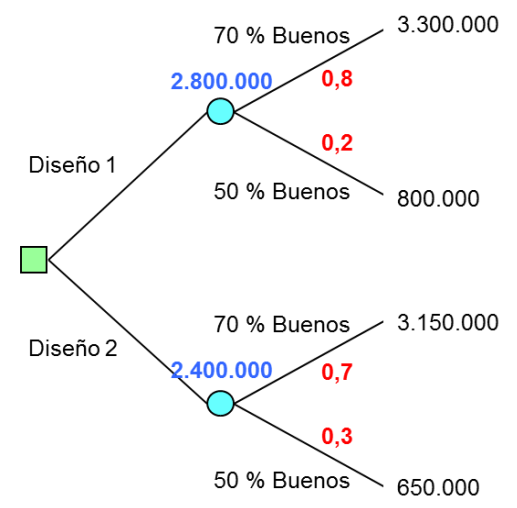

Paso 7 - Resuelva la etapa anterior. Dado que esta primera etapa es determinista y que los valores que ha calculado son beneficios, debe elegir la alternativa cuyo beneficio sea mayor y colocar el resultado encima del nudo correspondiente.

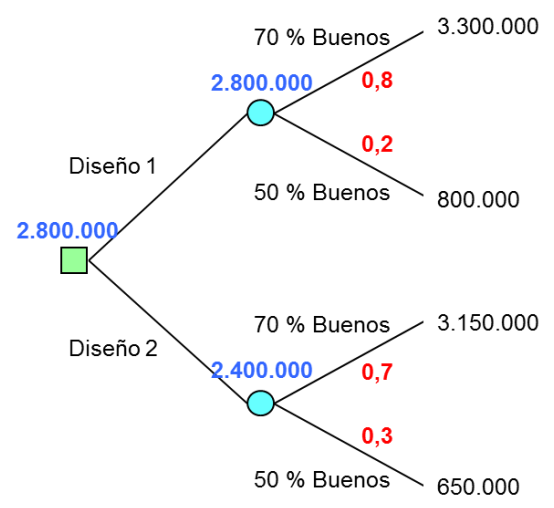

El gerente debe elegir el diseño 1, en espera de alcanzar un beneficio de 2.800 .000 euros. 


\section{Ejercicio 5}

Un establecimiento comercial está analizando la posibilidad de realizar los pedidos de un determinado producto con un mes de antelación, con la finalidad de evitar roturas de inventario. Si realiza pedido con un mes de anticipación el coste por unidad de producto es de 50 euros, por el contrario, si la demanda de dicho producto durante el mes excede el número de unidades en almacén, debe ordenar las unidades necesarias a un coste de 100 euros por unidad. La tabla muestra la demanda mensual de dicho producto durante los tres últimos años:

\begin{tabular}{|c|c|}
\hline $\begin{array}{c}\text { Demanda } \\
\text { (unidades) }\end{array}$ & $\begin{array}{c}\text { Frecuencia } \\
\text { (meses) }\end{array}$ \\
\hline 10 & 20 \\
\hline 20 & 12 \\
\hline 30 & 8 \\
\hline
\end{tabular}

Sugiera la política de pedidos para la empresa así como el coste de la misma.

\section{Solución:}

Paso 1 - Enumere las diferentes alternativas de decisión.

Comprar 10 unidades.

Comprar 20 unidades.

Comprar 30 unidades.

Paso 2 - Enumere para cada una de las alternativas de decisión, los estados de la naturaleza asociados a la misma.

\begin{tabular}{|c|c|}
\hline Alternativas & Estados de la naturaleza \\
\hline \multirow{3}{*}{ Comprar 10 } & $\begin{array}{c}\text { Vender } 10 \text { unidades } \\
\text { Vender } 20 \text { unidades } \\
\text { Vender } 30 \text { unidades }\end{array}$ \\
\hline \multirow{3}{*}{ Comprar 20 } & $\begin{array}{l}\text { Vender } 10 \text { unidades } \\
\text { Vender } 20 \text { unidades } \\
\text { Vender } 30 \text { unidades }\end{array}$ \\
\hline \multirow{2}{*}{ Comprar 30 } & $\begin{array}{l}\text { Vender } 10 \text { unidades } \\
\text { Vender } 20 \text { unidades } \\
\end{array}$ \\
& Vender 30 unidades \\
\hline
\end{tabular}


Paso 3 - Explicite el árbol de decisión

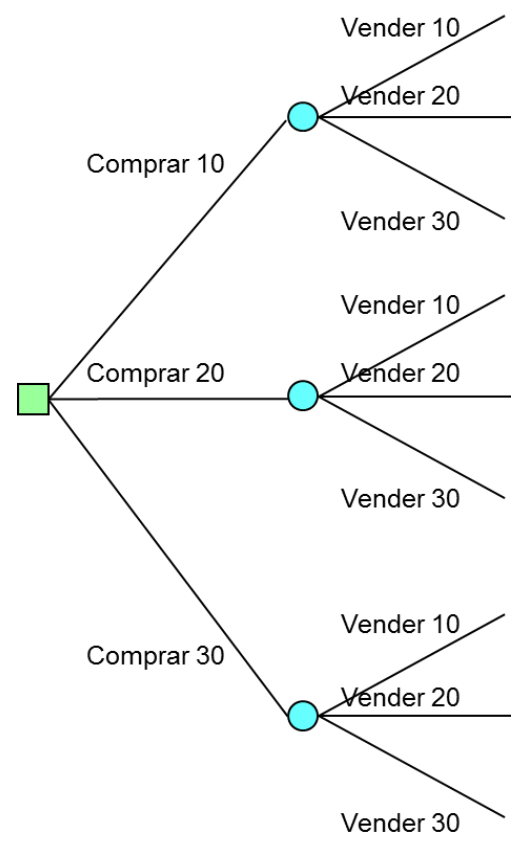

Paso 4 - Asigne las probabilidades a priori de cada uno de los estados de la naturaleza.

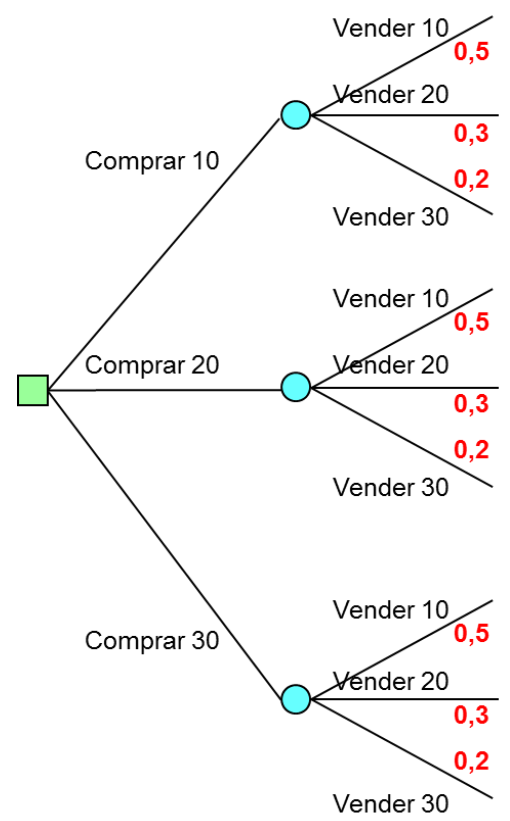


Se ha analizado un total de 40 meses, de los cuales en la mitad (20 meses) la demanda mensual fue de 10 unidades, en 12 de los 40 meses la demanda mensual ascendió a 20 unidades, y solo en 8 meses, la demanda fue de 30 unidades, según la tabla que aparece en el enunciado del ejercicio. De donde, las probabilidades a priori de cada uno de los estados de la naturaleza viene dada por:

$$
\begin{aligned}
& P(\text { Vender } 10 \text { unidades al mes })=20 \text { meses } / 40 \text { meses }=0,5 \\
& P(\text { Vender } 20 \text { unidades al mes })=12 \text { meses } / 40 \text { meses }=0,3 \\
& P(\text { Vender } 30 \text { unidades al mes })=8 \text { meses } / 40 \text { meses }=0,2
\end{aligned}
$$

Paso 5 - Calcule el coste de cada una de las ramas del árbol.

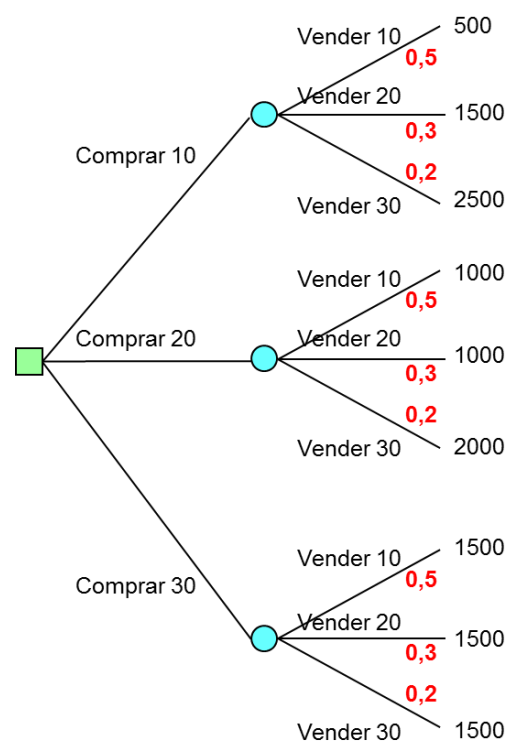

Coste de comprar 10 unidades y vender 10:

10 unidades $\times 50$ euros/unidad $=500$ euros

Coste de comprar 10 unidades y vender 20:

$(10$ unidades $\times 50$ euros/unidad $)+(10$ unidades $\times 100$ euros/unidad $)=1.500$ euros

Coste de comprar 10 unidades y vender 30:

(10 unidades $\times 50$ euros/unidad $)+(20$ unidades $\times 100$ euros/unidad $)=2.500$ euros 
Coste de comprar 20 unidades y vender 10:

$$
20 \text { unidades } \times 50 \text { euros/unidad }=1.000 \text { euros }
$$

Coste de comprar 20 unidades y vender 20:

$$
20 \text { unidades } \times 50 \text { euros/unidad }=1.000 \text { euros }
$$

Coste de comprar 20 unidades y vender 30:

$$
\text { (20 unidades } \times 50 \text { euros/unidad })+(10 \text { unidades } \times 100 \text { euros/unidad })=2.000 \text { euros }
$$

Coste de comprar 30 unidades y vender 10:

$$
30 \text { unidades } \times 50 \text { euros/unidad }=1.500 \text { euros }
$$

Coste de comprar 30 unidades y vender 20:

$$
30 \text { unidades } \times 50 \text { euros/unidad }=1.500 \text { euros }
$$

Coste de comprar 30 unidades y vender 30:

$$
30 \text { unidades } \times 50 \text { euros/unidad }=1.500 \text { euros }
$$

Paso 6 - Resuelva el árbol de decisión de derecha a izquierda. Dado que la etapa final es probabilista debe aplicar el criterio de la esperanza matemática con el objetivo de determinar el coste esperado de cada alternativa de decisión.

$$
\begin{aligned}
& (500 \times 0,5)+(1.500 \times 0,3)+(2.500 \times 0,2)=1.200 \text { euros } \\
& (1.000 \times 0,5)+(1.000 \times 0,3)+(2.000 \times 0,2)=1.200 \text { euros } \\
& (1.500 \times 0,5)+(1.500 \times 0,3)+(1.500 \times 0,2)=1.500 \text { euros }
\end{aligned}
$$


Coloque los resultados en el árbol de decisión encima del nudo correspondiente.

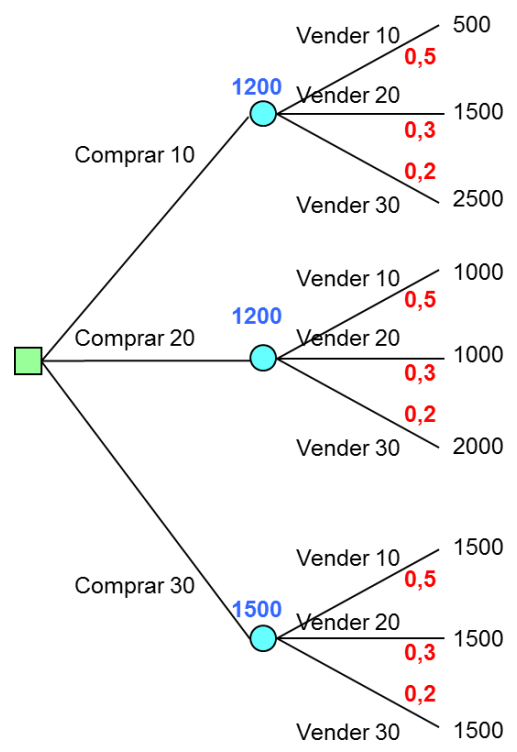

Paso 7 - Resuelva la etapa anterior. Dado que esta primera etapa es determinista y que los valores que ha calculado son costes, debe elegir la alternativa cuyo coste sea menor y colocar el resultado encima del nudo correspondiente.

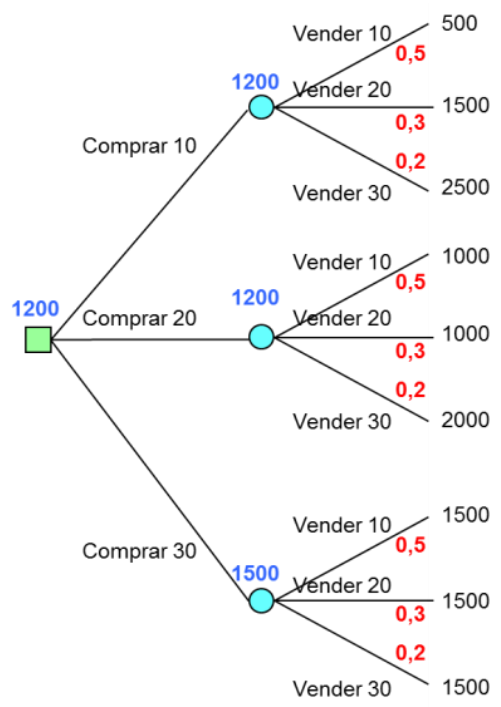

La política óptima de pedidos para la empresa es hacer pedidos de 10 o de 20 unidades del producto, siendo el coste esperado de dicha política de 1.200 euros. 


\section{Ejercicio 6}

Una empresa fabricante de componentes electrónicos está estudiando cuatro posibilidades de expansión de su capacidad productiva: construir una nueva planta en Brasil, una joint-venture en China, ampliar su planta de España o construir una nueva planta en Alemania. Los beneficios estimados durante los próximos años para cada alternativa se muestran en la tabla siguiente en función de la demanda.

\begin{tabular}{|c|c|c|c|c|}
\hline & \multicolumn{2}{|c|}{$\begin{array}{c}\text { Incremento de la } \\
\text { demanda del }\end{array}$} & $\begin{array}{c}\text { Demanda } \\
\text { constante }\end{array}$ & $\begin{array}{c}\text { Disminución de } \\
\text { la demanda en }\end{array}$ \\
\hline & $30 \%$ & $20 \%$ & & $5 \%$ \\
\hline Brasil & 1000 & 900 & 600 & 400 \\
\hline China & 1300 & 1100 & 700 & 300 \\
\hline España & 1200 & 1400 & 600 & -100 \\
\hline Alemania & 1000 & 900 & 700 & 700 \\
\hline
\end{tabular}

1. Formule la decisión óptima siguiendo el criterio optimista, el pesimista, y el de Laplace.

2. Establezca la decisión óptima, si se considera que la probabilidad de que la demanda se incremente un $30 \%$ es del $20 \%$, de que aumente un $20 \%$ es del $30 \%$, de que se mantenga es del $40 \%$ y de que se reduzca de un $10 \%$.

\section{Solución:}

\subsection{Criterio optimista}

Maximizar \{Máximo \{Beneficio\}\}

\begin{tabular}{|c|c|c|c|c|c|}
\hline & $\Delta 30 \%$ & $\Delta 20 \%$ & $=$ & $\nabla 5 \%$ & Máximo $\{$ Beneficio $\}$ \\
\hline Brasil & 1.000 & 900 & 600 & 400 & 1.000 \\
\hline China & 1.300 & 1.100 & 700 & 300 & 1.300 \\
\hline España & 1.200 & 1.400 & 600 & -100 & 1.400 \\
\hline Alemania & 1.000 & 900 & 700 & 700 & 1.000 \\
\hline
\end{tabular}

Máx. $\{$ Máx. $\{$ Beneficio $\}=$ Máx. $\{1.000,1.300,1.400,1.000\}=1.400$

La decisión óptima siguiendo el criterio optimista es la de ampliar la planta de España. 


\subsection{Criterio pesimista}

Maximizar $\{$ Mínimo \{Beneficio\}\}

\begin{tabular}{|c|c|c|c|c|c|}
\hline & $\Delta 30 \%$ & $\Delta 20 \%$ & $=$ & $\nabla 5 \%$ & Mínimo $\{$ Beneficio $\}$ \\
\hline Brasil & 1000 & 900 & 600 & 400 & 400 \\
\hline China & 1300 & 1100 & 700 & 300 & 300 \\
\hline España & 1200 & 1400 & 600 & -100 & -100 \\
\hline Alemania & 1000 & 900 & 700 & 700 & 700 \\
\hline
\end{tabular}

Máx. $\{$ Mín. $\{$ Beneficio\} $\}=$ Máx. $\{400,300,-100,700\}=700$

La decisión óptima siguiendo el criterio pesimista es la de construir una nueva planta en Alemania.

\subsection{Criterio Laplace}

Criterio de Laplace $\rightarrow$ Criterio equiprobable $\rightarrow$ Todos los estados de la naturaleza tienen la misma probabilidad. En este caso los estados de la naturaleza posibles son cuatro:

1. Incremento de un $30 \%$ de la demanda.

2. Incremento de un $20 \%$ de la demanda.

3. La demanda permanece constante.

4. La demanda disminuye un $5 \%$.

Dado que los estados de la naturaleza son cuatro y que todos deben tener la misma probabilidad (criterio de Laplace), la probabilidad a priori de cada uno de ellos es del $100 / 4=25 \%$.

\begin{tabular}{|c|c|c|c|c|c|}
\hline & $\Delta 30 \%$ & $\Delta 20 \%$ & $=$ & $\nabla 5 \%$ & Valor esperado $\mathrm{E}[\mathrm{x}]$ \\
\hline Brasil & 1.000 & 900 & 600 & 400 & 725 \\
\hline China & 1.300 & 1.100 & 700 & 300 & 850 \\
\hline España & 1.200 & 1.400 & 600 & -100 & 775 \\
\hline Alemania & 1.000 & 900 & 700 & 700 & 825 \\
\hline & $25 \%$ & $25 \%$ & $25 \%$ & $25 \%$ & \multicolumn{1}{|c}{} \\
\cline { 2 - 5 } & \multicolumn{3}{|l}{}
\end{tabular}

Máx. $\{$ Beneficio esperado $\}=$ Máx. $\{725,850,775,825\}=850$

La decisión óptima siguiendo el criterio de Laplace es la de hacer una joint-venture en China. 
2. Establezca la decisión óptima, si se considera que la probabilidad de que la demanda se incremente un $30 \%$ es del $20 \%$, de que aumente un $20 \%$ es del $3 \%$, de que se mantenga es del $40 \%$ y de que se reduzca de un $10 \%$.

En este caso debe aplicarse el criterio de la esperanza matemática.

\begin{tabular}{|c|c|c|c|c|c|}
\hline & $\Delta 30 \%$ & $\Delta 20 \%$ & $=$ & $\nabla 5 \%$ & Valor esperado $\mathrm{E}[\mathrm{x}]$ \\
\hline Brasil & 1.000 & 900 & 600 & 400 & 750 \\
\hline China & 1.300 & 1.100 & 700 & 300 & 900 \\
\hline España & 1.200 & 1.400 & 600 & -100 & 890 \\
\hline Alemania & 1.000 & 900 & 700 & 700 & 820 \\
\hline & $20 \%$ & $30 \%$ & $40 \%$ & $10 \%$ & \multicolumn{1}{|c}{} \\
\cline { 2 - 6 } & \multicolumn{3}{|l}{}
\end{tabular}

Máx. $\{$ Beneficio esperado $\}=$ Máx. $\{750,900,890,820\}=900$

La decisión óptima siguiendo el criterio de la esperanza matemática, con las probabilidades a priori dadas en el enunciado del ejercicio, es la de hacer una joint-venture en China. 


\section{Ejercicio 7}

Para hacer frente a las ventas una empresa puede tomar las siguientes acciones: hacer horas extras, contratar mano de obra, alquilar maquinaria, e incluso puede no tomar ninguna acción. Las ventas por su parte pueden ser crecientes o decrecientes, siendo $p$ la probabilidad de que las ventas sean crecientes. A tenor de un estudio realizado por la propia empresa, los beneficios esperados en cada caso se muestran en la tabla siguiente en miles de euros:

\begin{tabular}{|c|c|c|}
\hline & Ventas crecientes & Ventas decrecientes \\
\hline Horas extras & 500 & 100 \\
\hline Contratar mano de obra & 700 & 0 \\
\hline Alquilar maquinaria & 900 & -100 \\
\hline No tomar ninguna acción & 400 & 200 \\
\hline
\end{tabular}

Halle los valores de la probabilidad p por los que decidirá hacer horas extras, contratar mano de obra, alquilar maquinaria, o no tomar ninguna acción, respectivamente.

\section{Solución:}

Paso 1 - Enumere las diferentes alternativas de decisión.

Horas extraordinarias.

Contratar Mano de Obra (MO).

Alquilar maquinaria.

No tomar ninguna acción.

Paso 2 - Enumere para cada una de las alternativas de decisión, los estados de la naturaleza asociados a la misma.

\begin{tabular}{|c|c|}
\hline Alternativas & Estados de la naturaleza \\
\hline Horas extras & $\begin{array}{c}\text { Ventas crecientes } \\
\text { Ventas decrecientes }\end{array}$ \\
\hline Contratar MO & $\begin{array}{c}\text { Ventas crecientes } \\
\text { Ventas decrecientes }\end{array}$ \\
\hline Alquilar maquinaria & $\begin{array}{c}\text { Ventas crecientes } \\
\text { Ventas decrecientes }\end{array}$ \\
\hline No tomar ninguna decisión & $\begin{array}{c}\text { Ventas crecientes } \\
\text { Ventas decrecientes }\end{array}$ \\
\hline
\end{tabular}


Paso 3 - Explicite el árbol de decisión.

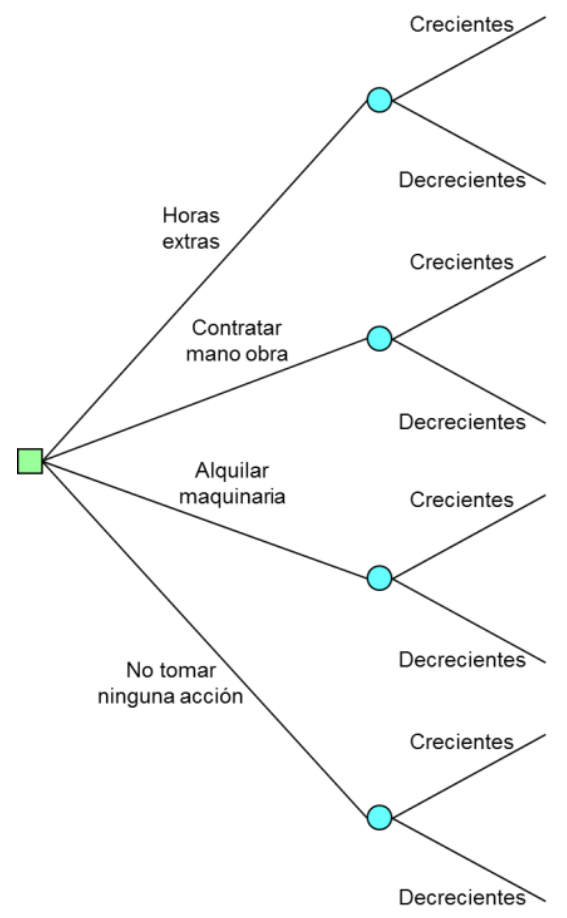

Paso 4 - Asigne las probabilidades a priori de cada uno de los estados de la naturaleza. 


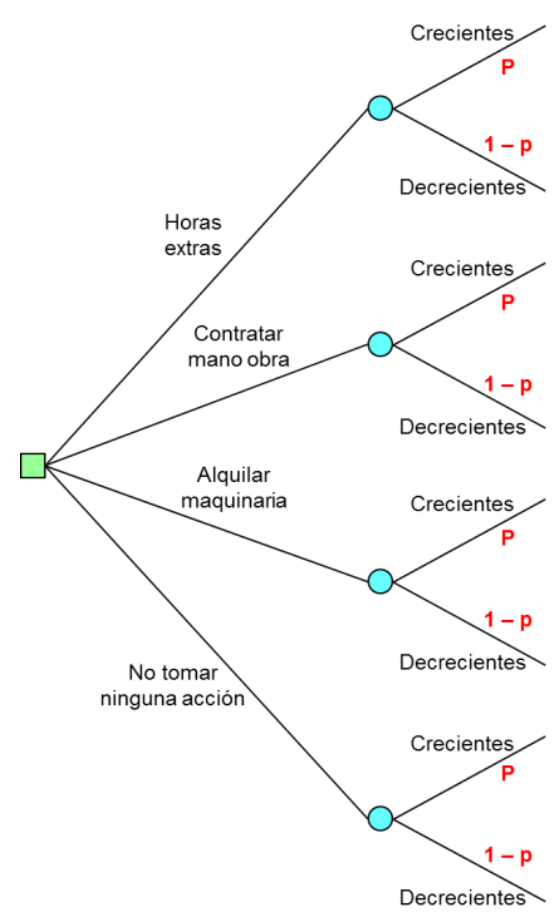

Siendo $\mathrm{p}$ la probabilidad a priori de que las ventas sean crecientes y $(1-\mathrm{p})$ la probabilidad a priori de que las ventas sean decrecientes.

Paso 5 - Calcule el beneficio de cada una de las ramas del árbol.

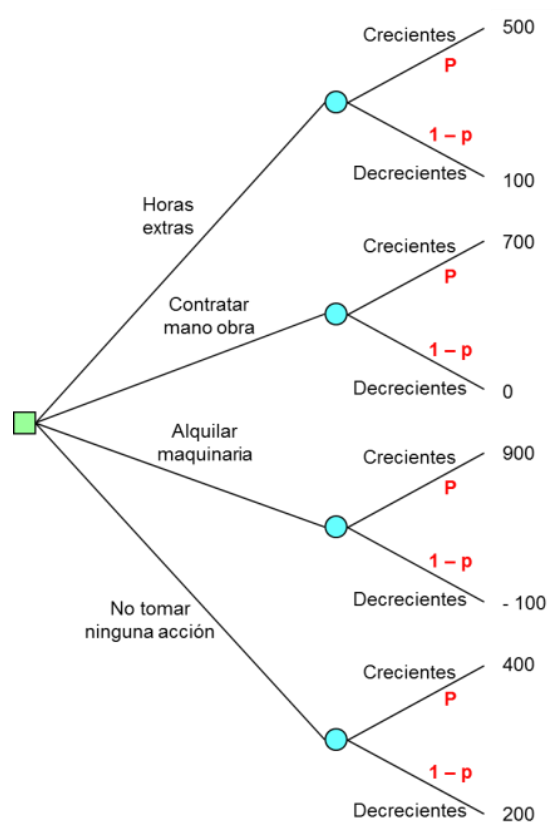


El beneficio de cada una de las ramas viene dado directamente en la tabla que forma parte del enunciado del ejercicio.

Paso 6 - Resuelva el árbol de decisión de derecha a izquierda. Dado que la etapa final es probabilista debe aplicar el criterio de la esperanza matemática con el objetivo de determinar el beneficio esperado de cada alternativa de decisión.

$$
\begin{gathered}
(500 \times p)+(100 \times(1-p))=100+400 p \\
(700 \times p)+(0 \times(1-p))=700 p \\
(900 \times p)+((-100) \times(1-p))=-100+1000 p \\
(400 \times p)+(200 \times(1-p))=200+200 p
\end{gathered}
$$

Coloque los resultados en el árbol de decisión encima del nudo correspondiente.

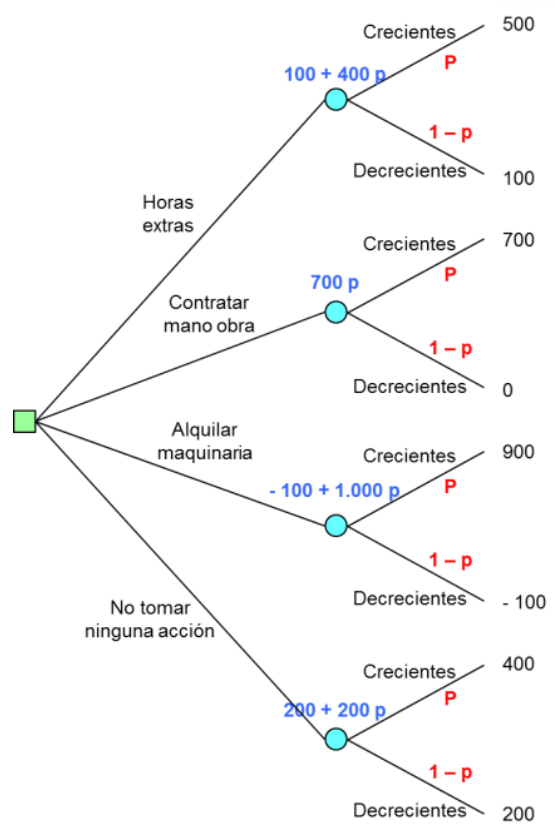

Representando gráficamente las cuatro ecuaciones correspondientes al beneficio de cada una de las alternativas de decisión, para cada uno de los valores de p, resulta el gráfico siguiente. 
Problemas resueltos de teoría de la decisión

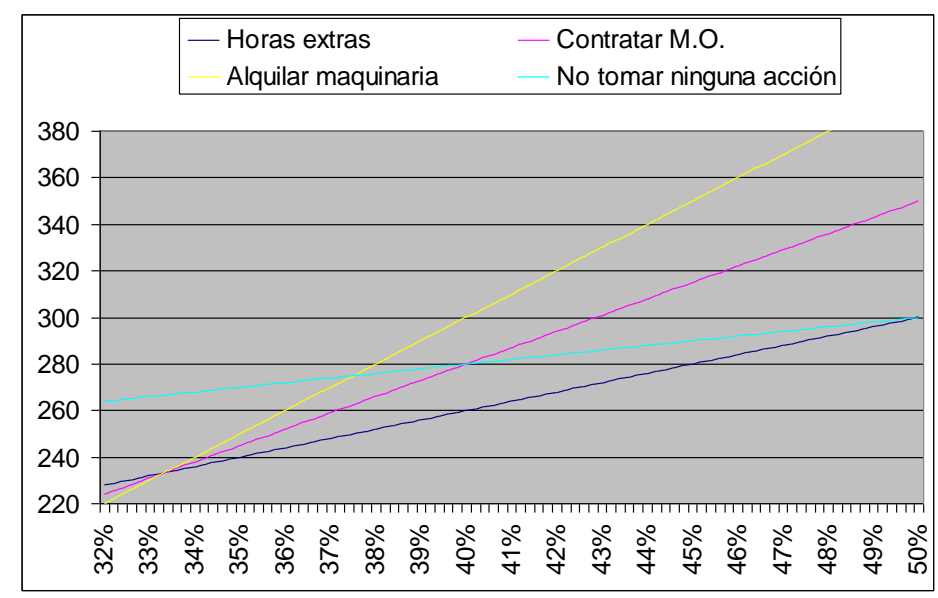

En el gráfico puede ver que le interesa no tomar ninguna acción cuando $p<0,375$, dado que el beneficio es máximo. Mientras que para valores de $p>0,375$ le interesa alquilar maquinaria con el fin de maximizar el beneficio.

$$
-100+1.000 p>200+200 p \rightarrow p>0,375
$$




\section{Ejercicio 8}

Una empresa de aviónica está investigando la posibilidad de fabricar y comercializar un nuevo microprocesador dotado de inteligencia casi natural para los aviones del futuro. El proyecto requiere la compra de un sofisticado centro de supercomputación, o bien la contratación de más ingenieros, obviamente la empresa se reserva la opción de no desarrollar el producto. El nuevo producto puede tener una acogida favorable o desfavorable en el mercado, con una acogida favorable en el mercado las ventas estimadas alcanzarían los 50.000 microprocesadores, por el contrario, si la acogida del mercado no fuese favorable las ventas estimadas serían de 20.000 microprocesadores. El precio de venta de los microprocesadores es de 200 euros cada unidad. El coste del centro de supercomputación es de 2.000.000 de euros, mientras que el de contratar y formar a los nuevos ingenieros asciende a 1.000.000 de euros. El coste de fabricación previsto es de 40 euros cada unidad si se fabrica sin la ayuda del centro de supercomputación, y de 10 euros si se fabrica con dicha ayuda. La probabilidad de que el nuevo microprocesador reciba una acogida favorable por parte del mercado es del $50 \%$.

1. Sugiera la decisión que debe tomar la dirección de la empresa en base a la aplicación del criterio del valor esperado.

2. Determine para qué rango de probabilidades de mercado favorable debe comprar el centro de supercomputación.

3. Se han definido las ventas favorables como las que alcancen las 50.000 unidades. Es probable que dicha cifra sea demasiado optimista, halle el valor por el que cambiaría su decisión y contrataría más ingenieros.

\section{Solución:}

1. Sugiera la decisión que debe tomar la dirección de la empresa en base a la aplicación del criterio del valor esperado

Paso 1 - Enumere las diferentes alternativas de decisión.

Comprar centro de supercomputación.

Contratar más ingenieros.

No desarrollar el nuevo producto.

Paso 2 - Enumere para cada una de las alternativas de decisión, los estados de la naturaleza asociados a la misma.

\begin{tabular}{|c|c|}
\hline Alternativas & Estados de la naturaleza \\
\hline $\begin{array}{c}\text { Comprar centro de } \\
\text { supercomputación }\end{array}$ & $\begin{array}{c}\text { Mercado favorable } \\
\text { Mercado desfavorable }\end{array}$ \\
\hline $\begin{array}{c}\text { No desarrollar el nuevo } \\
\text { producto }\end{array}$ & $\begin{array}{c}\text { Mercado favorable } \\
\text { Mercado desfavorable }\end{array}$ \\
\hline
\end{tabular}


Paso 3 - Explicite el árbol de decisión.

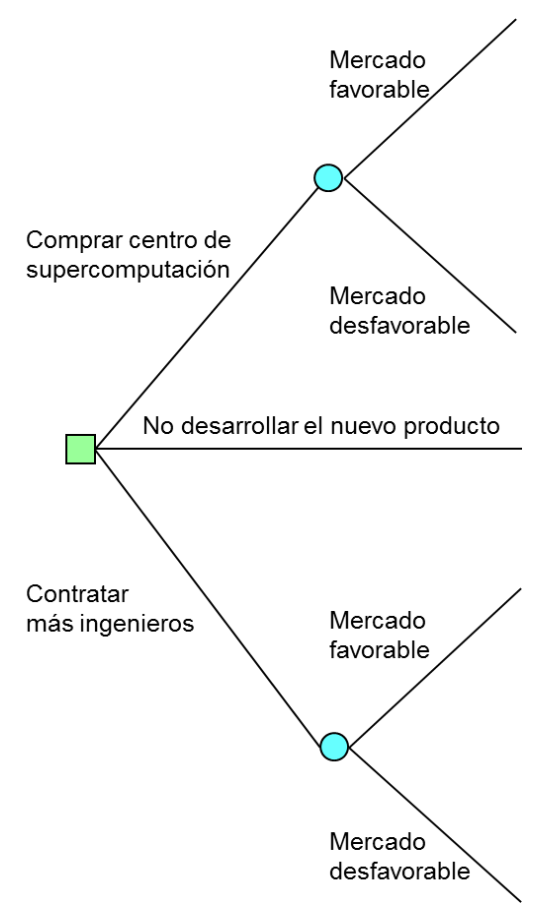

Paso 4 - Asigne las probabilidades a priori de cada uno de los estados de la naturaleza.

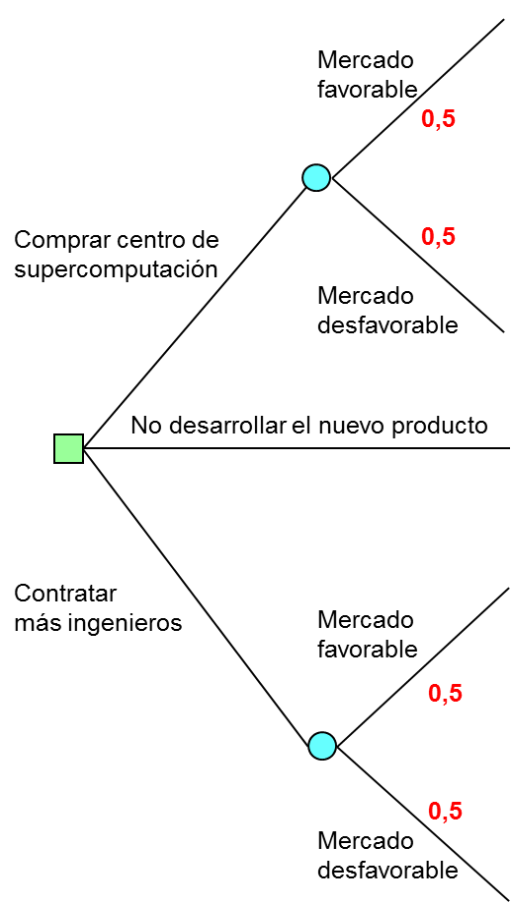


Paso 5 - Calcule el beneficio de cada una de las ramas del árbol.

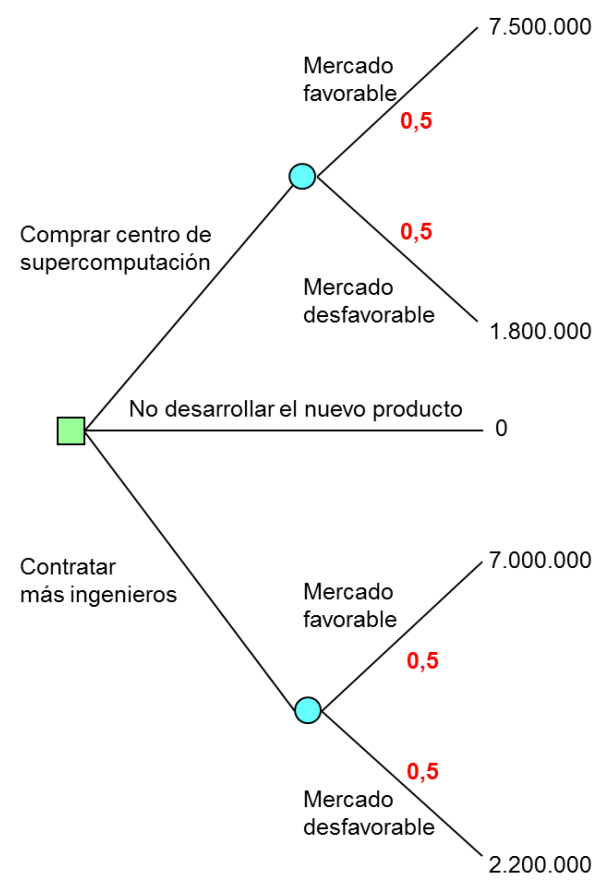

\section{Ingresos:}

En el caso de mercado favorable:

50.000 microprocesadores $\times 200$ euros/microprocesador $=10.000 .000$ euros.

En caso de mercado desfavorable:

20.000 microprocesadores $\times 200$ euros $/$ microprocesador $=4.000 .000$ euros.

\section{Costes de fabricación:}

Compra del centro de supercomputación y el mercado favorable:

50.000 microprocesadores $\times 10$ euros/microprocesador $=500.000$ euros.

Compra del centro de supercomputación y mercado desfavorable:

20.000 microprocesadores $\times 10$ euros/microprocesador $=200.000$ euros. 
Contratar más ingenieros y el mercado favorable:

50.000 microprocesadores $\times 40$ euros/microprocesador $=2.000 .000$ euros.

Contratar más ingenieros y el mercado desfavorable:

20.000 microprocesadores $\times 40$ euros/microprocesador $=800.000$ euros .

\section{Costes fijos:}

Compra del centro de supercomputación $=2.000 .000$ euros.

Contratación y formación nuevos ingenieros $=1.000 .000$ euros.

El beneficio de cada rama lo obtiene restando los gastos de los ingresos:

Beneficio si compra el centro de supercomputación y el mercado es favorable:

$$
10.000 .000-500.00-2.000 .000=7.500 .000 \text { euros }
$$

Beneficio si compra el centro de supercomputación y el mercado es desfavorable:

$$
4.000 .000-200.000-2.000 .000=1.800 .000 \text { euros. }
$$

Beneficio si contrata más ingenieros y el mercado es favorable:

$$
10.000 .000-2.000 .000-1.000 .000=7.000 .000 \text { euros }
$$

Beneficio si contrata más ingenieros y el mercado es desfavorable:

$$
4.000 .000-800.000-1.000 .000=2.200 .000 \text { euros. }
$$

Paso 6 - Resuelva el árbol de decisión de derecha a izquierda. Dado que la etapa final es probabilista debe aplicar el criterio de la esperanza matemática con el objetivo de determinar el beneficio esperado de cada alternativa de decisión.

$$
\begin{aligned}
& (7.500 .000 \times 0,5)+(1.800 .000 \times 0,5)=4.650 .000 \text { euros. } \\
& (7.000 .000 \times 0,5)+(2.200 .000 \times 0,5)=4.600 .000 \text { euros. }
\end{aligned}
$$


Coloque los resultados en el árbol de decisión encima del nudo correspondiente.

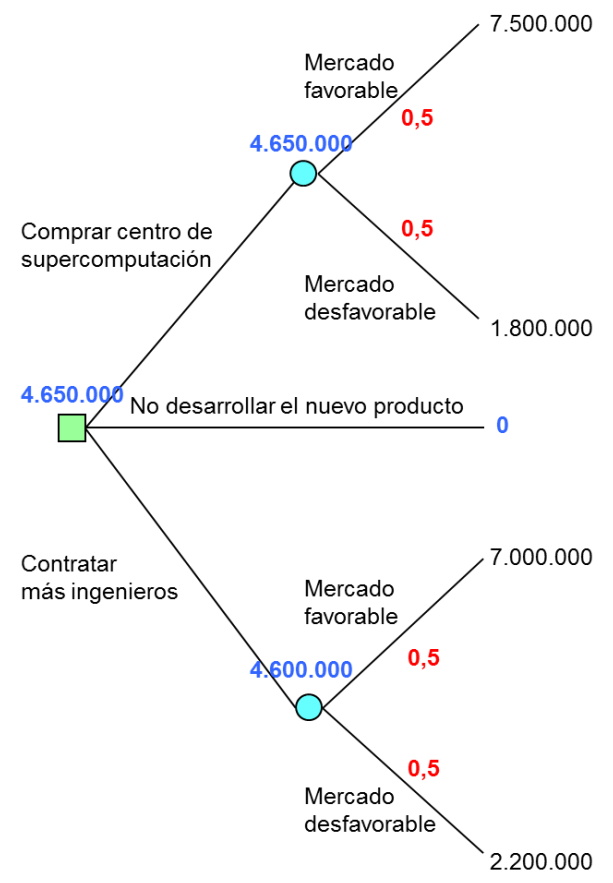

Resuelva la etapa anterior. Dado que esta primera etapa es determinista y que los valores que ha calculado son beneficios, debe elegir la alternativa cuyo beneficio sea mayor y colocar el resultado encima del nudo correspondiente.

En base al criterio del valor esperado, la decisión que debe tomar la dirección de la empresa la de comprar el centro de supercomputación, esperando obtener un beneficio de 4.650 .000 euros.

\section{Determine para qué rango de probabilidades de mercado favorable debe comprar el centro de supercomputación}

El árbol de decisión es el mismo del apartado anterior, siendo en este caso $\mathrm{p}$ la probabilidad a priori de que la demanda del mercado sea favorable y $(1-p)$ la probabilidad a priori de que la demanda sea desfavorable. 


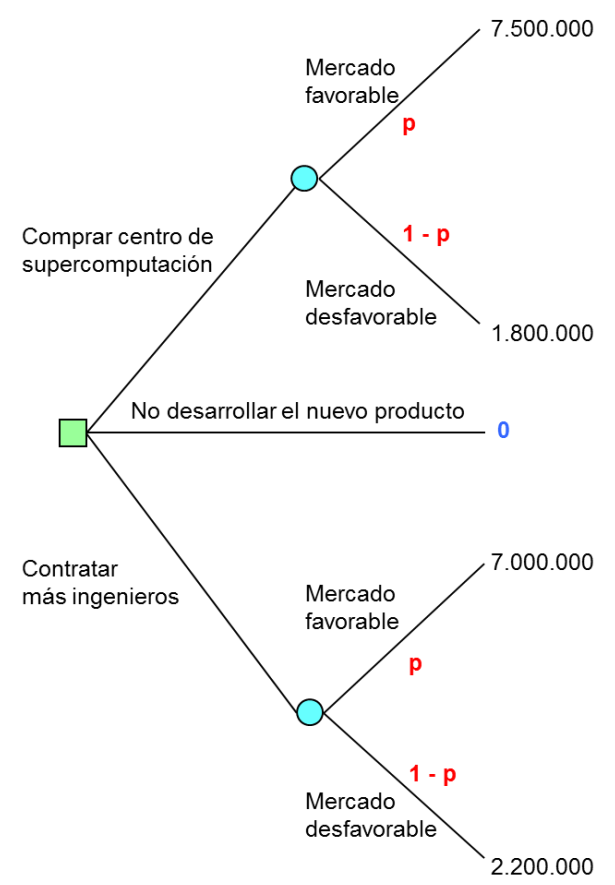

Resuelva seguidamente el árbol de decisión. Dado que la etapa final es probabilista debe aplicar el criterio de la esperanza matemática con el objetivo de determinar el beneficio esperado de cada alternativa de decisión.

$$
\begin{aligned}
& (7.500 .000 \times p)+(1.800 .000 \times(1-p)) \\
& (7.000 .000 \times p)+(2.200 .000 \times(1-p))
\end{aligned}
$$

Interesa comprar el centro de supercomputación siempre que el beneficio esperado de comprar dicho centro sea superior al de contratar más ingenieros y al de no desarrollar el nuevo producto:

$$
\begin{gathered}
(7.500 .000 \times p)+(1.800 .000 \times(1-p))>(7.000 .000 \times p)+(2.200 .000 \times(1-p)) \rightarrow p>0,444 \\
(7.500 .000 \times p)+(1.800 .000 \times(1-p))>0 \rightarrow p>0
\end{gathered}
$$

Interesa comprar el centro de supercomputación siempre que la probabilidad a priori de mercado favorable sea superior al $44,44 \%$.

3. Se han definido las ventas favorables como las que alcancen las $\mathbf{5 0 . 0 0 0}$ unidades. Es probable que dicha cifra sea demasiado optimista, halle el valor por el que cambiaría su decisión y contrataría más ingenieros

El árbol de decisión así como las probabilidades a priori de cada uno de los estados de la naturaleza son los mismos del primer apartado de este ejercicio. Definiendo VE como las ventas favorables, los beneficios en este caso son: 


\section{Ingresos:}

Mercado favorable:

VE microprocesadores $\times 200$ euros/microprocesador $=200$ VE euros

Mercado desfavorable:

20.000 microprocesadores $\times 200$ euros $/$ microprocesador $=4.000 .000$ euros

\section{Costes de fabricación:}

Compra del centro de supercomputación y mercado favorable:

VE microprocesadores $\times 10$ euros/microprocesador $=10$ VE euros

Compra del centro de supercomputación y mercado desfavorable:

20.000 microprocesadores $\times 10$ euros $/$ microprocesador $=200.000$ euros

Contratar ingenieros y mercado favorable:

VE microprocesadores $\times 40$ euros/microprocesador $=40$ VE euros

Contratar ingenieros y mercado desfavorable:

20.000 microprocesadores $\times 40$ euros $/$ microprocesador $=800.000$ euros

\section{Costes fijos:}

Compra del centro de supercomputación $=2.000 .000$ euros

Contratación y formación nuevos ingenieros $=1.000 .000$ euros

\section{Beneficio de cada rama del árbol:}

Beneficio si compra el centro de supercomputación y el mercado es favorable:

$$
200 \mathrm{VE}-10 \mathrm{VE}-2.000 .000=190 \mathrm{VE}-2.000 .000 \text { euros }
$$


Beneficio si compra el centro de supercomputación y el mercado es desfavorable:

$$
4.000 .000-200.000-2.000 .000=1.800 .000 \text { euros }
$$

Beneficio si contrata más ingenieros y el mercado es favorable:

$$
200 \mathrm{VE}-40 \mathrm{VE}-1.000 .000=160 \mathrm{VE}-1.000 .000 \text { euros }
$$

Beneficio si contrata más ingenieros y el mercado es desfavorable:

$$
4.000 .000-800.000-1.000 .000=2.200 .000 \text { euros }
$$

Resuelva seguidamente el árbol de decisión. Dado que la etapa final es probabilista debe aplicar el criterio de la esperanza matemática con el objetivo de determinar el beneficio esperado de cada alternativa de decisión.

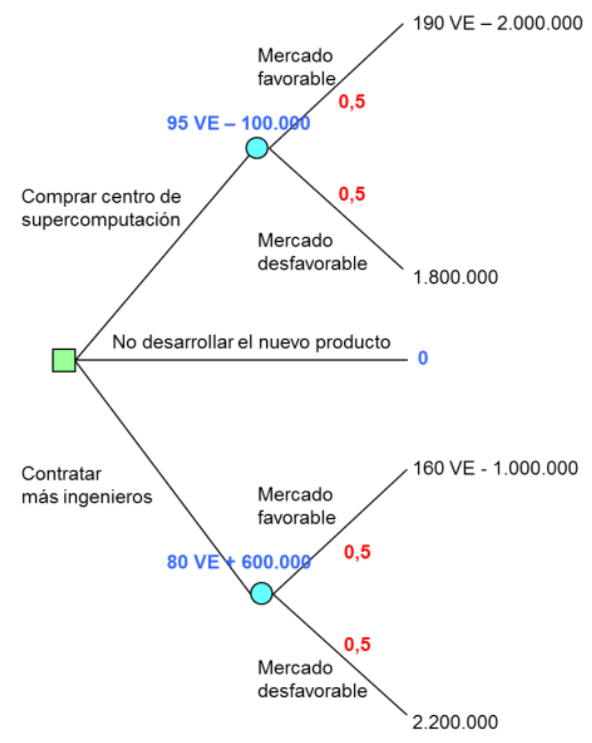

$$
\begin{aligned}
& ((190 \mathrm{VE}-2.000 .000) \times 0,5)+(1.800 .000 \times 0,5)=95 \mathrm{VE}-100.000 \\
& ((160 \mathrm{VE}-1.000 .000) \times 0,5)+(2.200 .000 \times 0,5)=80 \mathrm{VE}+600.000
\end{aligned}
$$

Contrataría más ingenieros cuando:

$$
80 \mathrm{VE}+600.000>95 \mathrm{VE}-100.000 \rightarrow \mathrm{VE}<46.666,66
$$

Contrataría más ingenieros cuando las ventas favorables sean inferiores a 46.666,66 microprocesadores. 


\section{Ejercicio 9}

El departamento de $I+D$ de una pequeña empresa está desarrollando un nuevo producto. El gerente de la empresa puede: vender dicho producto a una gran compañía multinacional por 100 millones de euros, poner en marcha una prueba de mercado antes de tomar una decisión, o bien, adelantar la campaña de marketing del nuevo producto con la finalidad de adelantarse a la competencia, confiando en que el desarrollo del mismo culminará con éxito.

Las pruebas de mercado del producto ascienden a 8 millones de euros, existiendo un $60 \%$ de probabilidades de que los resultados de las mismas sean favorables, en cuyo caso se estima que valor del nuevo producto asciende a 40 millones de euros. En caso de un resultado desfavorable pueden encontrase aplicaciones alternativas para el producto en uno de cada cinco casos, si bien el valor del mismo se reduce a 20 millones de euros.

En caso de que el resultado de las pruebas de mercado sea favorable, la probabilidad de que el producto tenga una buena acogida por parte de los clientes es tan solo del $60 \%$. Si se opta por comercializar el producto, los gastos de comercialización ascienden a 5 millones de euros.

La posibilidad de que el gerente adopte la tercera alternativa, adelantar la campaña de marketing del nuevo producto, se estiman en una entre cuatro. Sin embargo, los resultados esperados si hiciera esto con éxito son de ciento sesenta millones de euros. En caso de resultado desfavorable de las pruebas de mercado como siempre, existe la posibilidad de encontrar aplicaciones alternativas para el producto en uno de cada cinco casos, en cuyo caso el valor del mismo es de 80 millones de euros.

Esta tercera alternativa requiere llevar a cabo las pruebas de mercado así como la comercialización del producto, tanto sí el producto tiene éxito como sino. Indique la decisión que deberá tomar el gerente de la empresa.

\section{Solución:}

Paso 1 - Enumere las diferentes alternativas de decisión.

Vender dicho producto a una gran compañía multinacional.

Adelantar la campaña de marketing del nuevo producto.

Poner en marcha una prueba de mercado.

Paso 2 - Enumere para cada una de las alternativas de decisión, los estados de la naturaleza asociados a la misma.

\begin{tabular}{|c|c|}
\hline Alternativas & Estados de la naturaleza \\
\hline Vender & \\
\hline Marketing & $\begin{array}{c}\text { Resultado favorable de las pruebas } \\
\text { Resultado desfavorable de las pruebas }\end{array}$ \\
\hline Prueba & $\begin{array}{c}\text { Resultado favorable de las pruebas } \\
\text { Resultado desfavorable de las pruebas }\end{array}$ \\
\hline
\end{tabular}


Conocido el resultado de las pruebas de mercado, sea éste favorable o desfavorable, debe decidir si comercializa o no el producto.

\begin{tabular}{|c|c|c|}
\hline Alternativas & Estados de la naturaleza & Alternativas \\
\hline Vender & Favorable & $\begin{array}{c}\text { Comercializo } \\
\text { No comercializo }\end{array}$ \\
\hline \multirow{3}{*}{ Marketing } & Desfavorable & $\begin{array}{c}\text { Comercializo } \\
\text { No comercializo }\end{array}$ \\
\cline { 2 - 3 } & Favorable & $\begin{array}{c}\text { Comercializo } \\
\text { No comercializo }\end{array}$ \\
\cline { 2 - 3 } & Desfavorable & $\begin{array}{c}\text { Comercializo } \\
\text { No comercializo }\end{array}$ \\
\hline
\end{tabular}

Si el resultado de las pruebas de mercado es favorable y toma la decisión de comercializar el nuevo producto, los estados posibles de la naturaleza son, que el nuevo producto tenga buena acogida por parte de los clientes (tenga Éxito), o contrariamente que el producto no tenga una buena acogida (Fracaso).

Por su parte, si el resultado de las pruebas de mercado es desfavorable y toma la decisión de comercializar el nuevo producto, los estados posibles de la naturaleza son, que encuentre aplicaciones alternativas para el producto, o contrariamente que no las encuentre (No alternativas).

Paso 3 - Explicite el árbol de decisión.

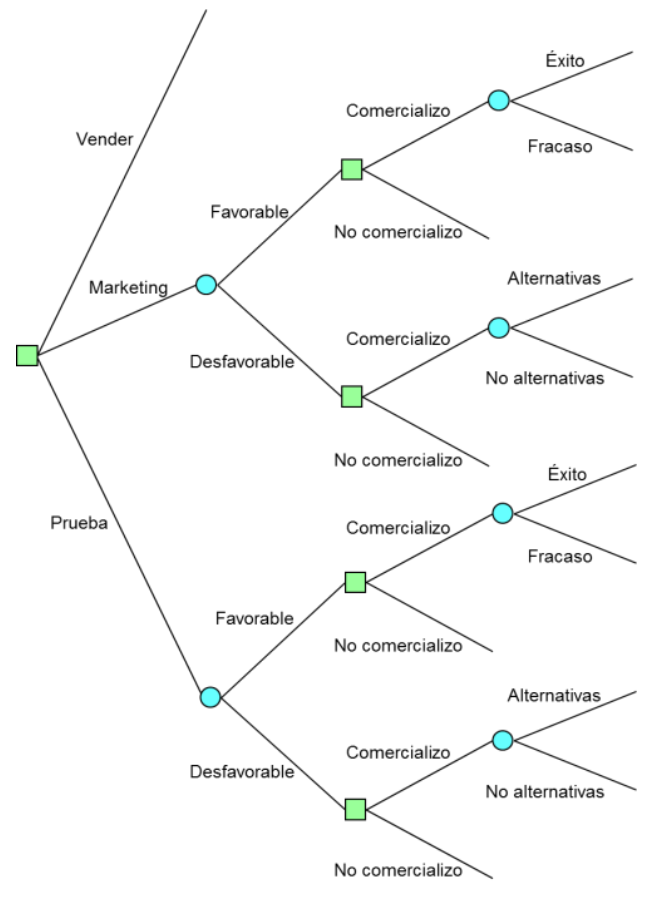


Paso 4 - Asigne las probabilidades a priori de cada uno de los estados de la naturaleza.

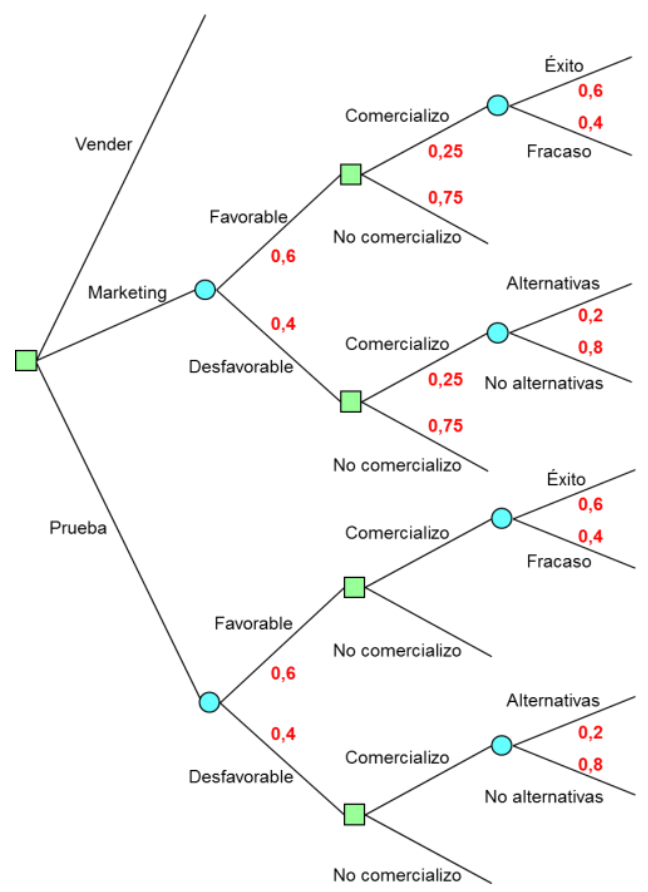

Paso 5 - Calcule el beneficio de cada una de las ramas del árbol.

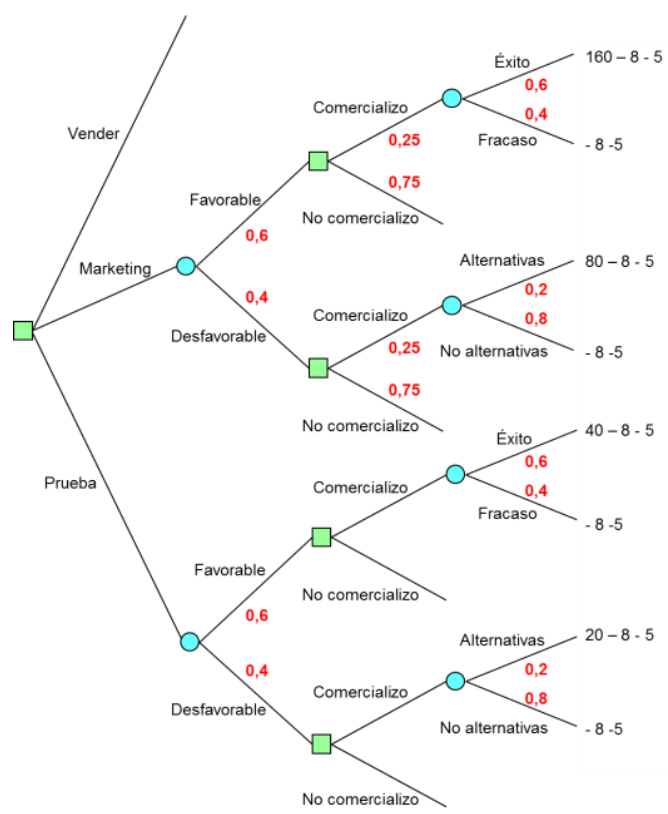


El beneficio de cada rama lo obtiene restando al valor del producto en cada rama, los gastos de 8 millones de euros de las pruebas de mercado, y los gastos de 5 millones de euros de la comercialización.

Paso 6 - Resuelva el árbol de decisión de derecha a izquierda. Dado que la etapa final es probabilista debe aplicar el criterio de la esperanza matemática con el objetivo de determinar el beneficio esperado de cada alternativa de decisión.

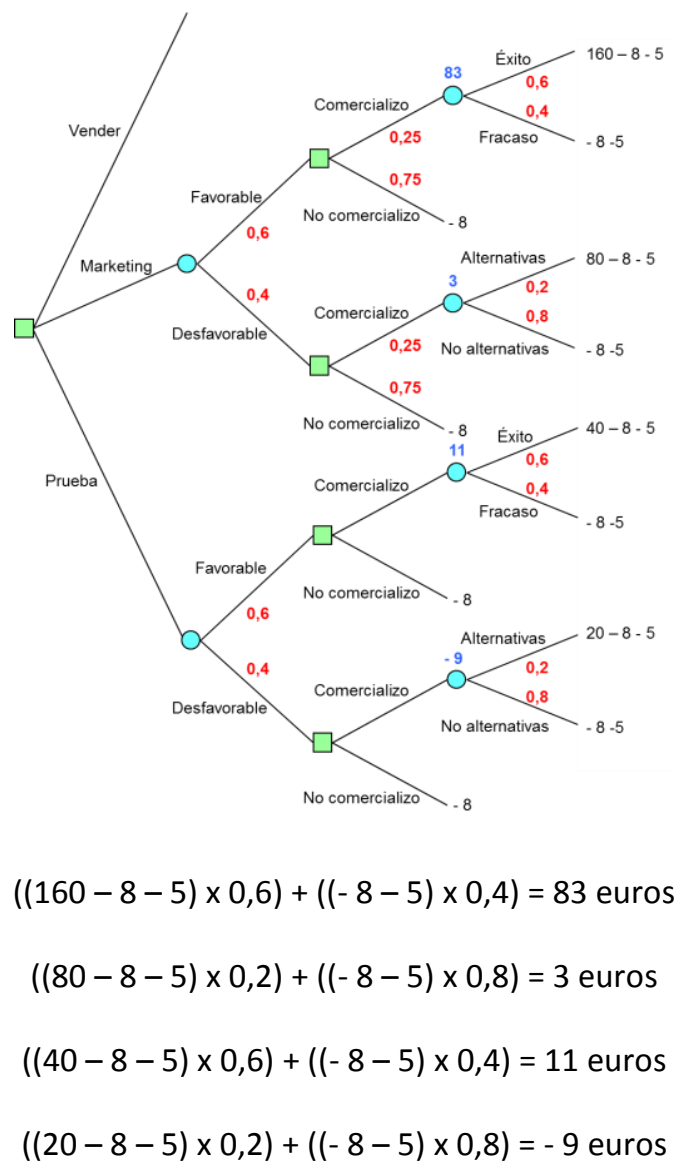

En caso de realizar las pruebas de mercado y no comercializar el nuevo producto, incurre en un gasto de 8 millones de euros de las pruebas de mercado.

Paso 7 - Resuelva la etapa anterior. Si es probabilista aplique el criterio del valor esperado, por el contrario, si es determinista y dado que los valores calculados son beneficios esperados, debe elegir la alternativa cuyo beneficio sea mayor. 
Problemas resueltos de teoría de la decisión

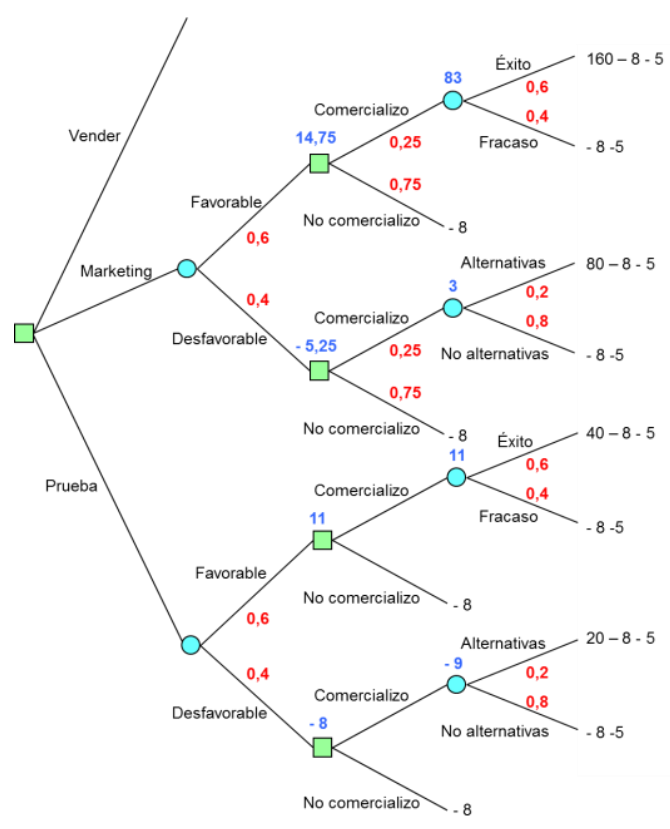

$(83 \times 0,25)+((-8) \times 0,75)=14,75$ euros

$(3 \times 0,25)+((-8) \times 0,75)=-5,25$ euros

Paso 8 - Resuelva la etapa anterior. Dado que se trata de una etapa probabilista debe aplicar el criterio de la esperanza matemática con el objetivo de determinar el beneficio esperado de cada alternativa de decisión. 


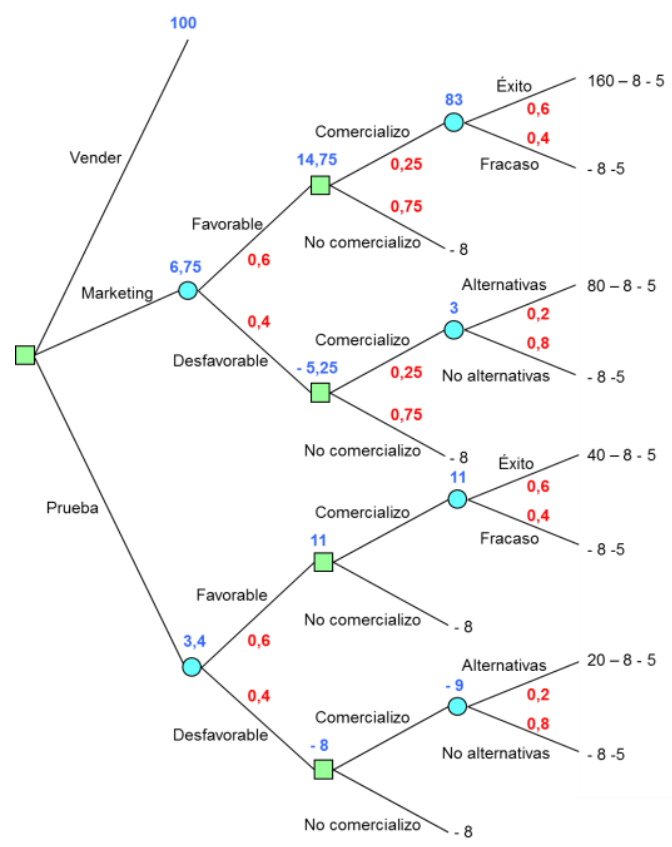

$(14,75 \times 0,6)+((-5,25) \times 0,4)=6,75$ euros

$(11 \times 0,6)+((-8) \times 0,4)=3,4$ euros

Finalmente resolviendo la última etapa, elige la alternativa cuyo beneficio sea mayor dado que la etapa es determinista y los valores calculados beneficios esperados.

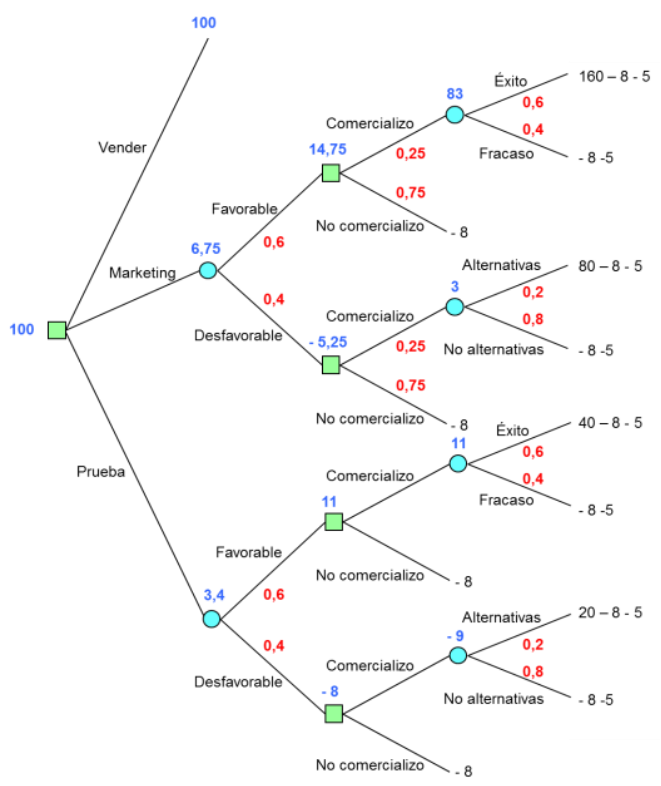

La decisión que debe tomar el gerente de la empresa es la de vender el nuevo producto a una gran compañía multinacional, esperando con ello obtener un beneficio de 100 millones de euros. 


\section{Ejercicio 10}

Una empresa cuyo objeto es la venta de coches de segunda mano cobra un $10 \%$ de comisión sobre las ventas. Dicha empresa ha recibido el pedido de un cliente de vender tres automóviles de su propiedad, el primero de ellos un flamante utilitario valorado en 10.000 euros, el segundo un deportivo valorado en 60.000 euros y el tercero un vehículo todoterreno $4 \times 4$ Turbo casi nuevo cuya valoración asciende a 100.000 euros. Las cláusulas pactadas en el pedido entre el cliente y la empresa establecen que obligatoriamente el utilitario debe ser vendido primero en el plazo de un mes, en caso contrario queda anulado el pedido. Vendido el utilitario, la empresa puede optar por vender el deportivo, el todoterreno, o cancelar el pedido. Por último, una vez vendido el segundo vehículo, la empresa podrá cancelar el pedido o vender el tercer coche. Los gastos de publicidad que estima la empresa serán necesarios para vender dichos automóviles así como la probabilidad de vender cada uno de ellos, vienen dados en la tabla siguiente:

\begin{tabular}{|c|c|c|}
\hline & Gastos publicidad & Probabilidad \\
\hline Utilitario & 3.000 euros & $40 \%$ \\
\hline Deportivo & 1.000 euros & $80 \%$ \\
\hline Todo terreno 4x4 Turbo & 2.000 euros & $60 \%$ \\
\hline
\end{tabular}

Determine si el gerente de la empresa debe o no aceptar el pedido que le formaliza el cliente.

\section{Solución:}

Paso 1 - Enumere las diferentes alternativas de decisión.

Aceptar el pedido que propone el cliente.

No aceptar el pedido que propone el cliente.

Paso 2 - Enumere para cada una de las alternativas de decisión, los estados de la naturaleza asociados a la misma.

\begin{tabular}{|c|c|}
\hline Alternativas & Estados de la naturaleza \\
\hline Aceptar & $\begin{array}{c}\text { Vende el utilitario } \\
\text { No vende el utilitario }\end{array}$ \\
\hline No aceptar & \\
\hline
\end{tabular}

Si consigue vender el utilitario, debe decidir si prueba vender el deportivo, prueba vender el $4 \times 4$, o cancela el pedido. 


\begin{tabular}{|c|c|c|}
\hline Alternativas & Estados de la naturaleza & Alternativas \\
\hline \multirow{2}{*}{ Aceptar } & Vende utilitario & $\begin{array}{c}\text { Prueba vender el deportivo } \\
\text { Prueba vender el } 4 \times 4 \\
\text { Cancela pedido }\end{array}$ \\
\cline { 2 - 3 } & No vende utilitario & \\
\hline No aceptar & & \\
\hline
\end{tabular}

Si prueba vender el deportivo, los estados posibles de la naturaleza son, que consiga o no la venta del deportivo. En caso de que venda el deportivo debe decidir si prueba vender el $4 \times 4$ o cancela el pedido. Si prueba vender el $4 \times 4$ puede ocurrir que lo venda o que no lo venda.

Por su parte, si prueba vender el $4 \times 4$, los estados posibles de la naturaleza son, que consiga o no la venta del mismo. En caso de que venda el $4 \times 4$ debe decidir si prueba vender el deportivo o cancela el pedido. Si prueba vender el deportivo puede suceder que lo venda o que no lo venda.

Paso 3 - Explicite el árbol de decisión.

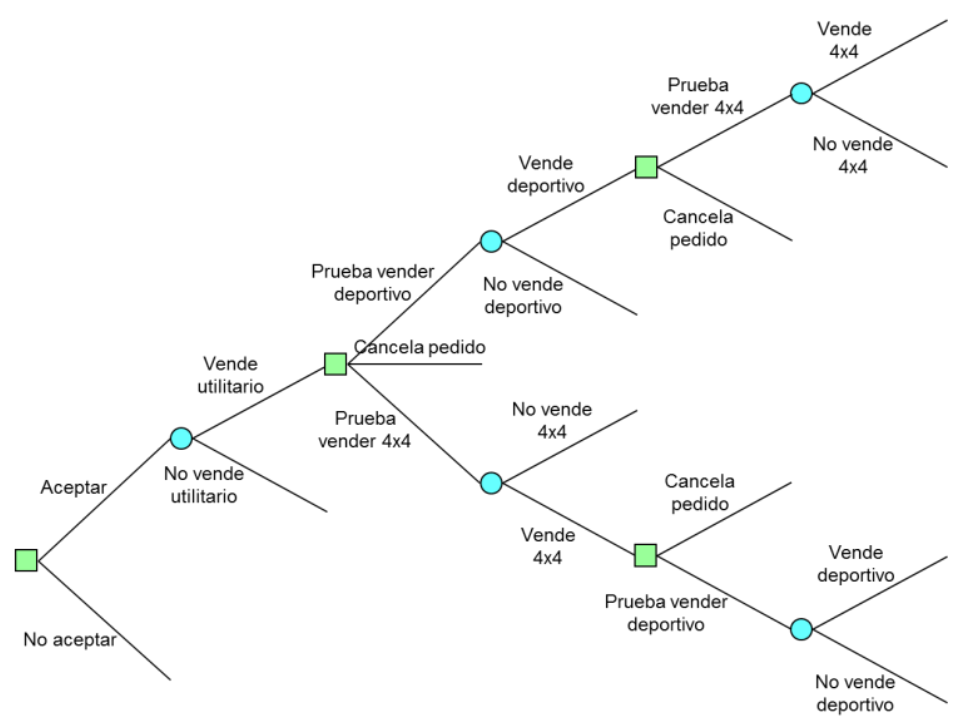


Paso 4 - Asigne las probabilidades a priori de cada uno de los estados de la naturaleza.

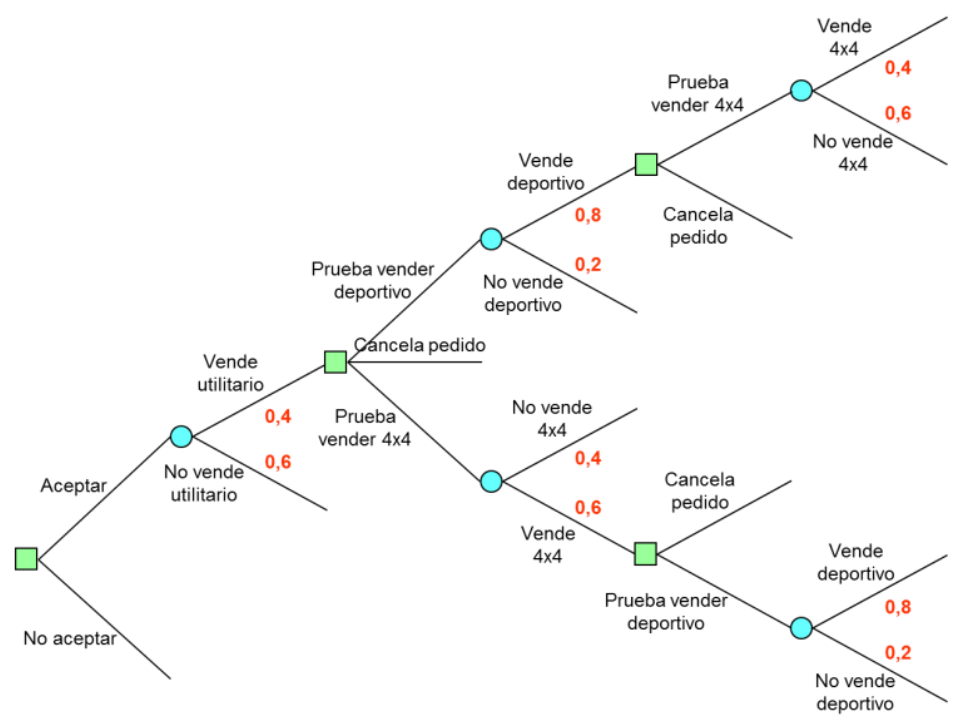

Paso 5 - Calcule el beneficio de cada una de las ramas del árbol.

El beneficio de cada rama lo obtiene restando los gastos de los ingresos. Los ingresos vienen dados por la comisión que cobra la empresa por la venta de los vehículos (10 \% sobre ventas), mientras que los gastos se reducen exclusivamente a los gastos de publicidad que estima la empresa necesarios para vender dichos automóviles.

Beneficio si vende el utilitario, el deportivo y el $4 \times 4$ :

$$
((10.000+60.000+100.000) \times 0,1)-(3.000+1.000+2.000)=11.000 \text { euros }
$$

Beneficio si vende el utilitario, el deportivo y no vende el 4x4:

$$
((10.000+60.000) \times 0,1)-(3.000+1.000+2.000)=1.000 \text { euros }
$$

Beneficio si vende el utilitario y el deportivo:

$$
((10.000+60.000) \times 0,1)-(3.000+1.000)=3.000 \text { euros }
$$

Beneficio si vende el utilitario y no vende el deportivo:

$$
(10.000 \times 0,1)-(3.000+1.000)=-3.000 \text { euros }
$$


Beneficio si vende el utilitario:

$$
(10.000 \times 0,1)-3.000=-2.000 \text { euros }
$$

Beneficio si vende el utilitario y no vende el $4 \times 4$ :

$$
(10.000 \times 0,1)-(3.000+2.000)=-4.000 \text { euros }
$$

Beneficio si vende el utilitario y el $4 \times 4$ :

$$
((10.000+100.000) \times 0,1)-(3.000+2.000)=6.000 \text { euros }
$$

Beneficio si vende el utilitario, el $4 \times 4$ y no vende el deportivo:

$$
((10.000+100.000) \times 0,1)-(3.000+1.000+2.000)=5.000 \text { euros }
$$

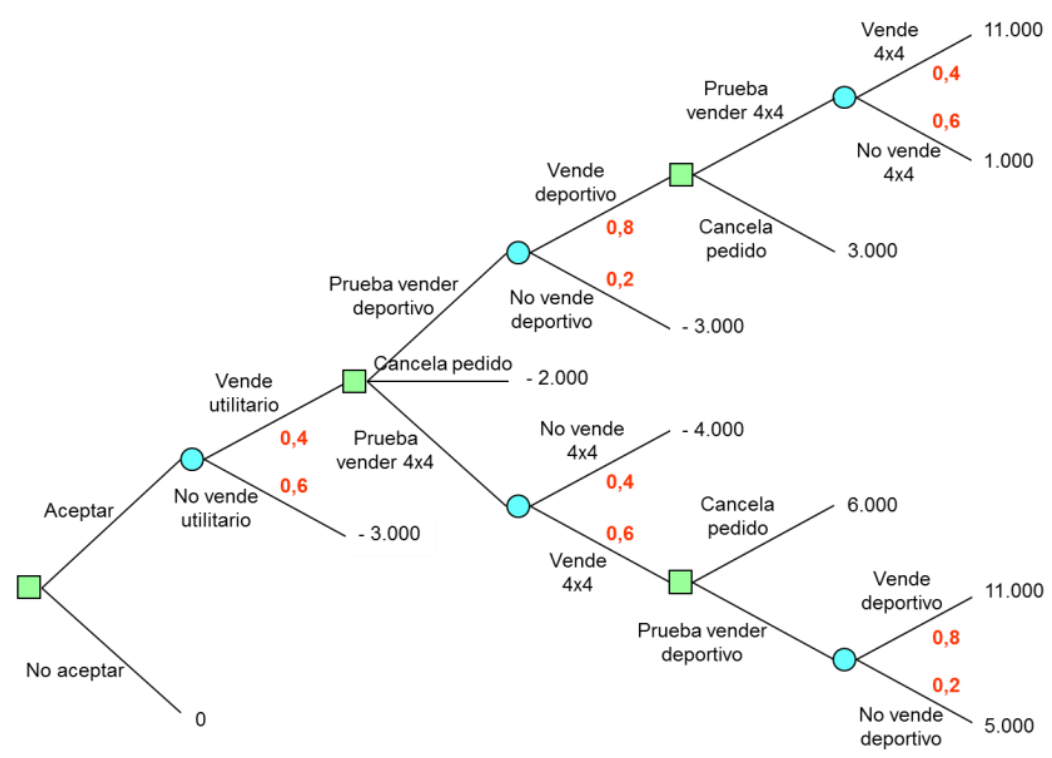


Paso 6 - Resuelva el árbol de decisión de derecha a izquierda. Dado que la etapa final es probabilista debe aplicar el criterio de la esperanza matemática con el objetivo de determinar el beneficio esperado de cada alternativa de decisión.

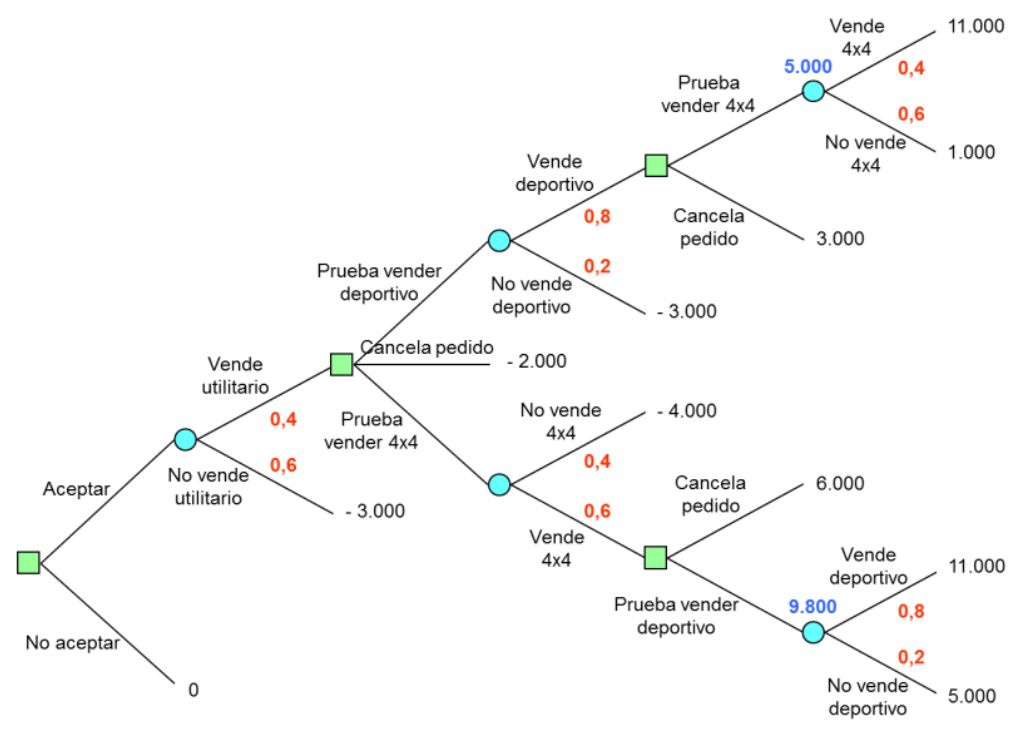

$$
\begin{aligned}
& (11.000 \times 0,4)+(1.000 \times 0,6)=5.000 \text { euros } \\
& (11.000 \times 0,8)+(5.000 \times 0,2)=9.800 \text { euros }
\end{aligned}
$$

Paso 7 - Resuelva la etapa anterior. Dado que es una etapa determinista y que los valores calculados son beneficios esperados, debe elegir la alternativa cuyo beneficio sea mayor.

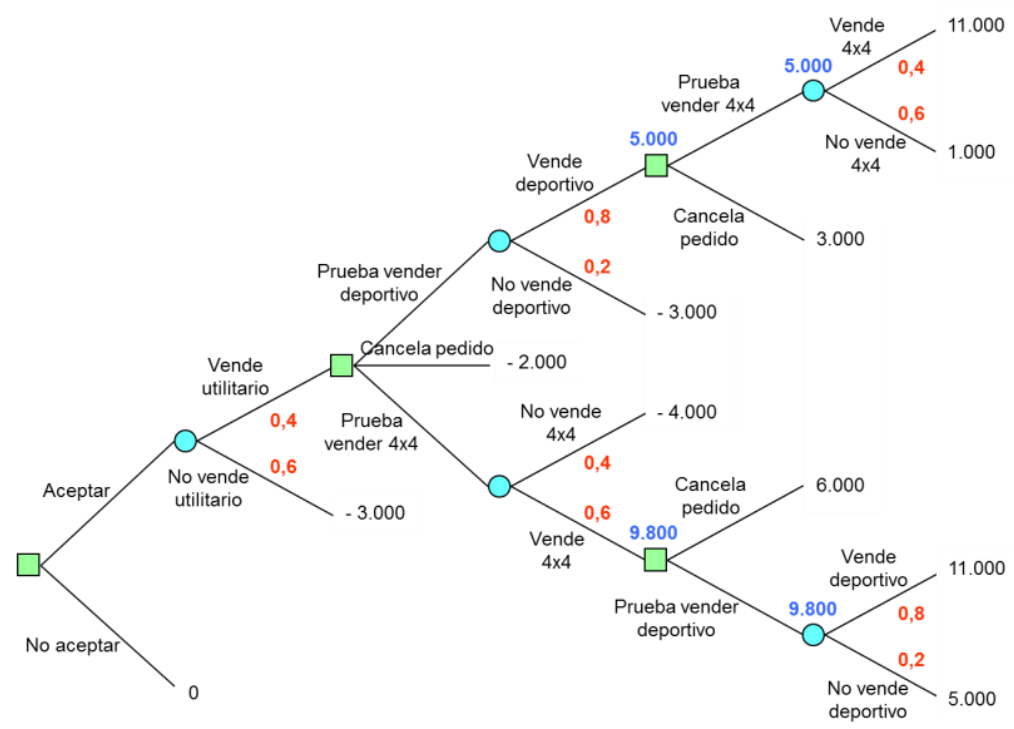


Paso 8 - Resuelva la etapa anterior. Dado que se trata de una etapa probabilista debe aplicar el criterio de la esperanza matemática con el objetivo de determinar el beneficio esperado de cada alternativa de decisión.

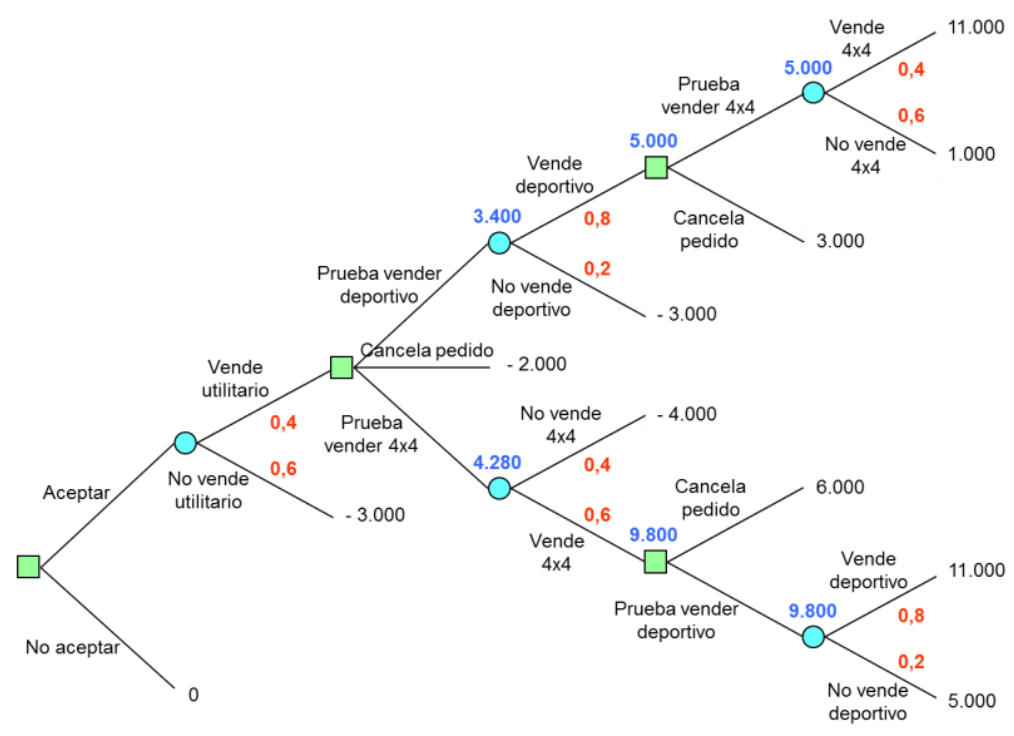

$(5.000 \times 0,8)+((-3.000) \times 0,2)=3.400$ euros

$((-4.000) \times 0,4)+(9.800 \times 0,6)=4.280$ euros

Paso 9 - Resuelva la etapa anterior. Al tratarse de una etapa determinista y que los valores calculados son beneficios esperados, debe elegir la alternativa cuyo beneficio sea mayor.

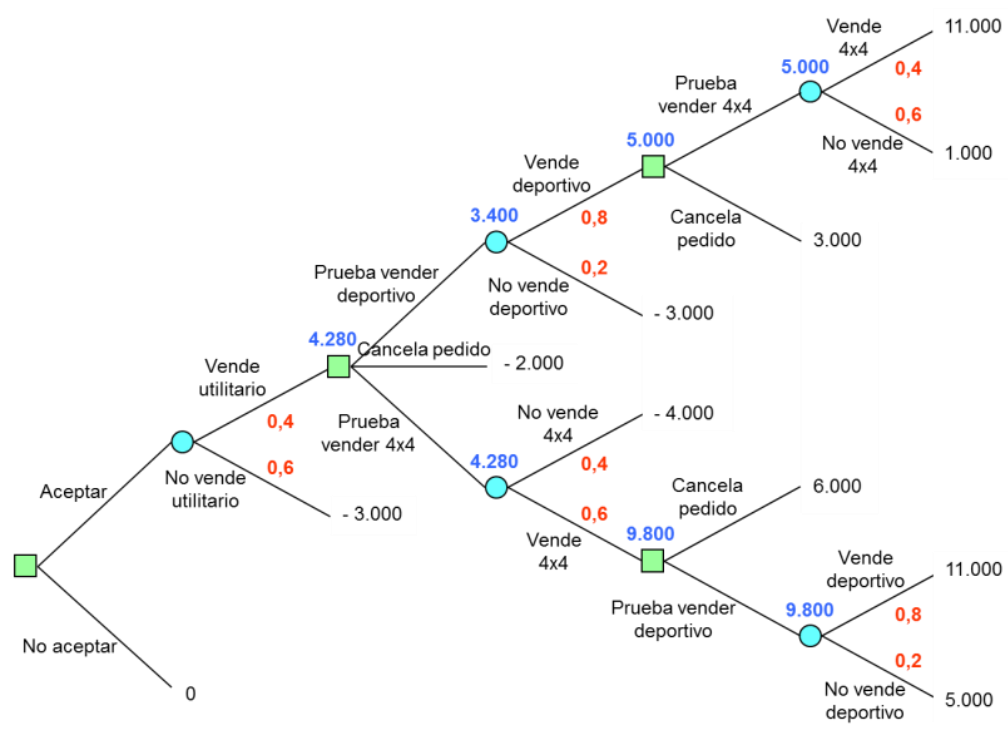


Paso 10 - Resuelva la etapa anterior. Por tratarse de una etapa probabilista debe aplicar el criterio de la esperanza matemática con el objetivo de determinar el beneficio esperado de cada alternativa de decisión.

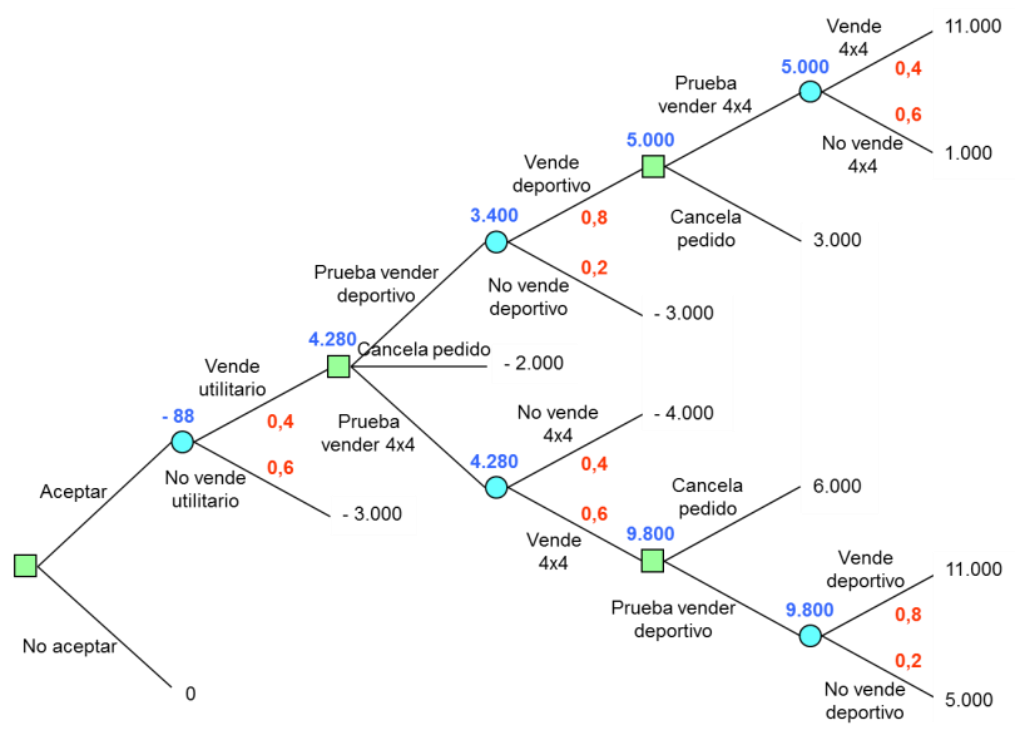

$(4.280 \times 0,4)+((-3.000) \times 0,6)=-88$ euros

Finalmente resolviendo la última etapa, elige la alternativa cuyo beneficio sea mayor dado que la etapa es determinista y los valores calculados beneficios esperados.

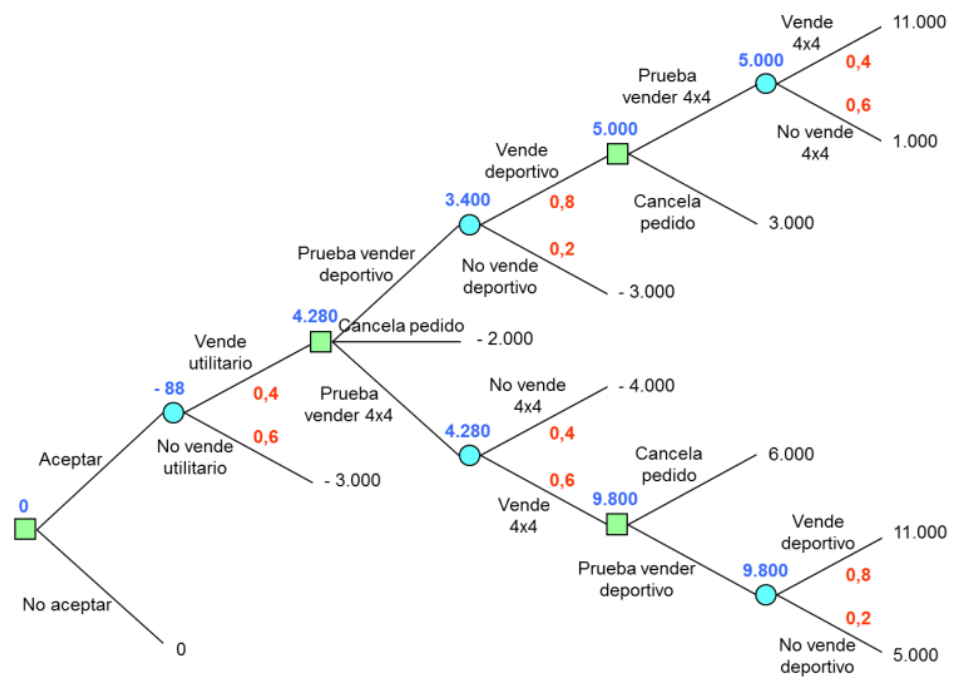

En base al criterio del valor esperado, la decisión que debe tomar el gerente de la empresa es la de no aceptar el pedido que le formaliza el cliente, esperando con ello obtener un beneficio de 0 euros. 


\section{Ejercicio 11}

El gerente de la empresa dedicada a la venta de coches de segunda mano del ejercicio anterior, conoce a un importante piloto de carreras que puede proporcionarle información cien por cien fiable de los automóviles que conseguirá vender, así como el orden en que logrará dichas ventas. Calcule lo que el gerente estaría dispuesto a pagar al piloto por proporcionarle dicha información.

\section{Solución:}

Paso 1 - Enumere las diferentes alternativas de decisión.

\section{Consultar al piloto.}

No consultar al piloto.

En caso de no consultar al piloto, el árbol de decisión se corresponde con el del ejercicio anterior, en el que el beneficio esperado es de 0 euros.

Paso 2 - Enumere todas y cada una de las informaciones que puede proporcionarle el piloto en caso de que usted le solicite dicha información.

\begin{tabular}{|c|c|}
\hline Alternativas & \multicolumn{1}{|c|}{ Información que puede proporcionar el piloto } \\
\hline \multirow{3}{*}{ Consultar } & \multicolumn{1}{c}{ No vende el utilitario } \\
& $\begin{array}{l}\text { Vende el utilitario, no vende el deportivo, vende el } 4 \times 4 \\
\text { Vende el utilitario, vende el deportivo, vende el } 4 \times 4 \\
\text { Vende el utilitario, vende el deportivo, no vende el } 4 \times 4 \\
\text { Vende el utilitario, no vende el deportivo, no vende el } 4 \times 4\end{array}$ \\
\hline
\end{tabular}

Paso 3 - Explicite el árbol de decisión. 


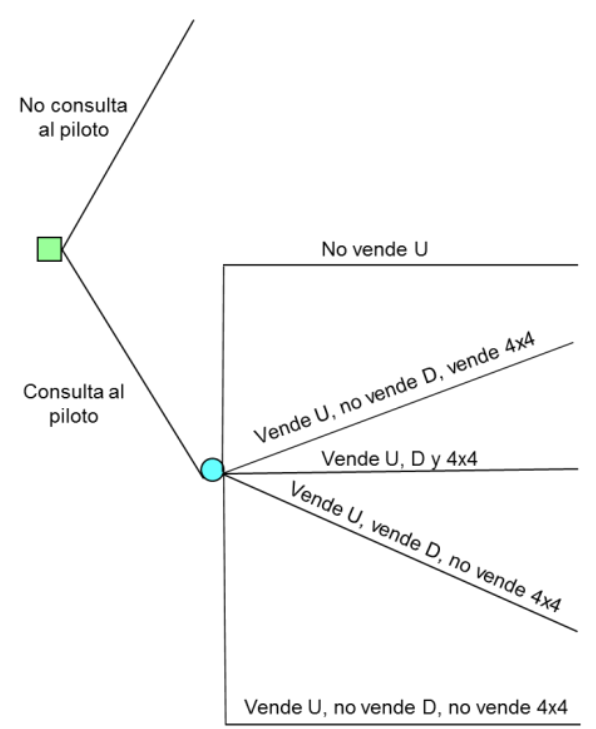

Donde U hace referencia al automóvil Utilitario, D al Deportivo, y 4x4 al vehículo todoterreno $4 \times 4$.

Paso 4 - Asigne las probabilidades a priori de cada uno de los estados de la naturaleza.

Probabilidad de no vender el utilitario $=(1-0,4)=0,6$

Probabilidad de vender el utilitario y no vender el deportivo y vender el $4 \times 4$ :

$$
0,4 \times(1-0,8) \times 0,6=0,048
$$

Probabilidad de vender el utilitario y vender el deportivo y vender el 4x4:

$$
0,4 \times 0,8 \times 0,6=0,192
$$

Probabilidad de vender el utilitario y vender el deportivo y no vender el $4 \times 4$ :

$$
0,4 \times 0,8 \times(1-0,6)=0,128
$$

Probabilidad de vender el utilitario y no vender el deportivo y no vender el $4 \times 4$ :

$$
0,4 \times(1-0,8) \times(1-0,6)=0,032
$$




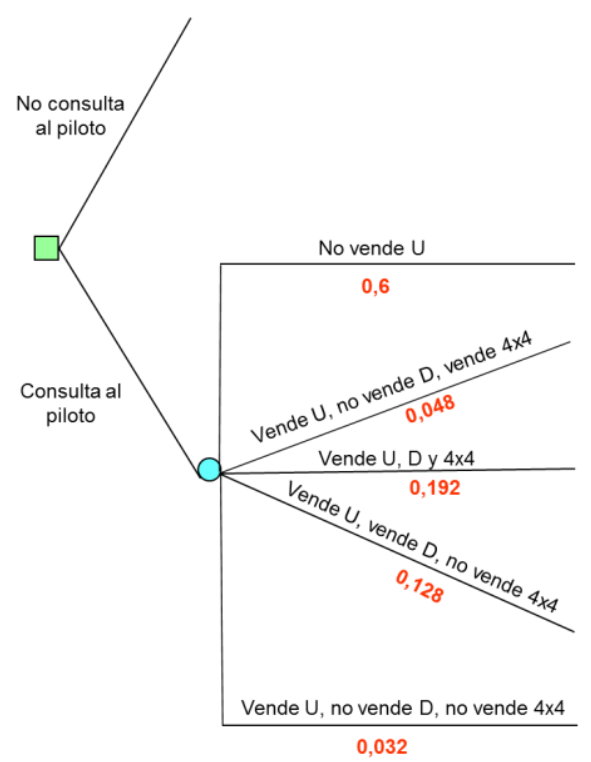

Paso 5 - Calcule el beneficio de cada una de las ramas del árbol.

Beneficio si no vende el utilitario $=0$ euros.

Beneficio si vende el utilitario, no vende el deportivo, y vende el $4 \times 4$ :

$$
((10.000+100.000) \times 0,1)-(3.000+2.000)=6.000 \text { euros }
$$

Beneficio si vende el utilitario, el deportivo, y el $4 \times 4$ :

$$
((10.000+60.000+100.000) \times 0,1)-(3.000+1.000+2.000)=11.000 \text { euros }
$$

Beneficio si vende el utilitario, el deportivo, y no vende el $4 \times 4$ :

$$
((10.000+60.000) \times 0,1)-(3.000+1.000)=3.000 \text { euros }
$$

Beneficio si vende el utilitario, no vende el deportivo, y no vende el $4 \times 4$ :

$$
(10.000 \times 0,1)-3.000=-2.000 \text { euros }
$$




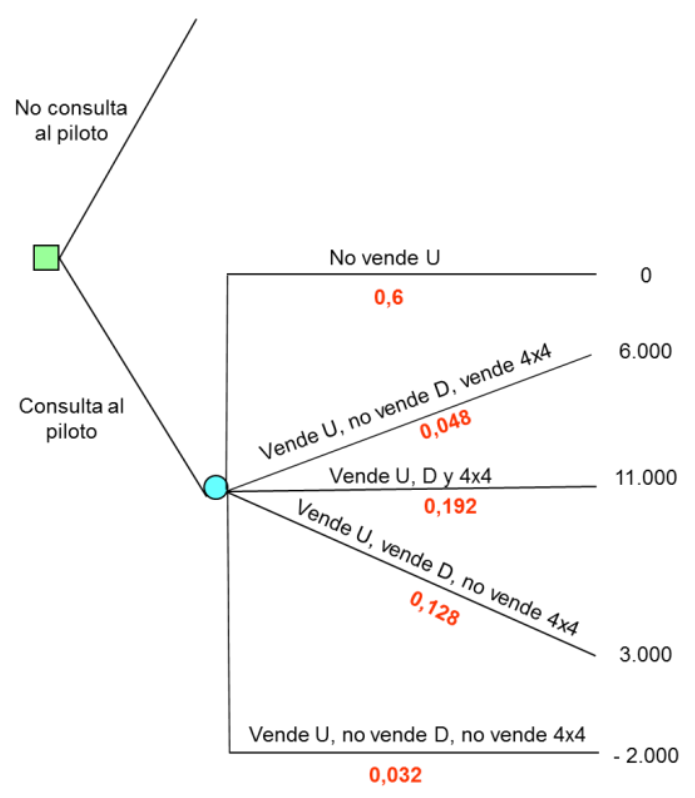

Paso 6 - Resuelva el árbol de decisión de derecha a izquierda. Dado que la etapa final es probabilista debe aplicar el criterio de la esperanza matemática con el objetivo de determinar el beneficio esperado.

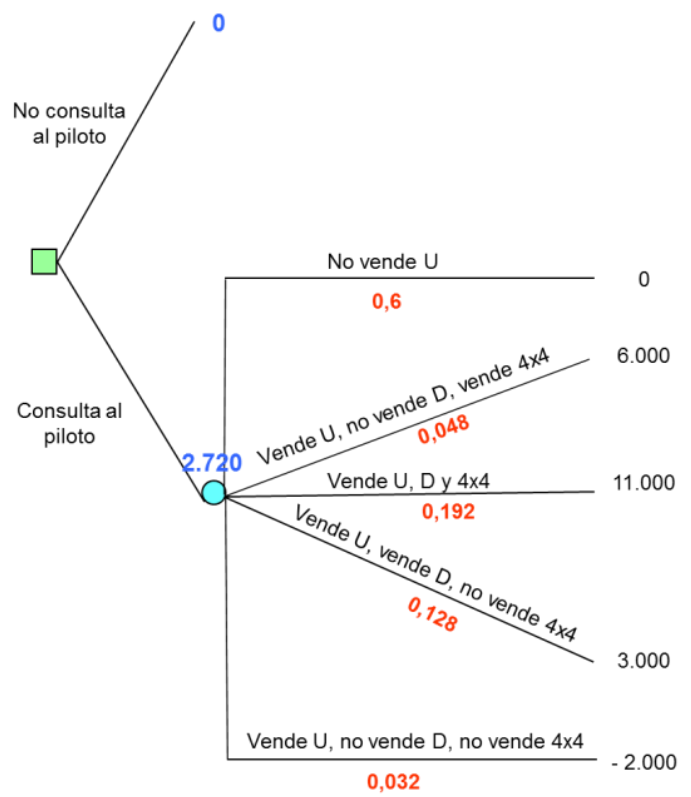




$$
(0 \times 0,6)+(6.000 \times 0,048)+(11.000 \times 0,192)+(3.000 \times 0,128)+(-2.000 \times 0,032)=2.720 \text { euros }
$$

Paso 7 - Resuelva la etapa anterior. Dado que es una etapa determinista y que los valores calculados son beneficios esperados, debe elegir la alternativa cuyo beneficio sea mayor.

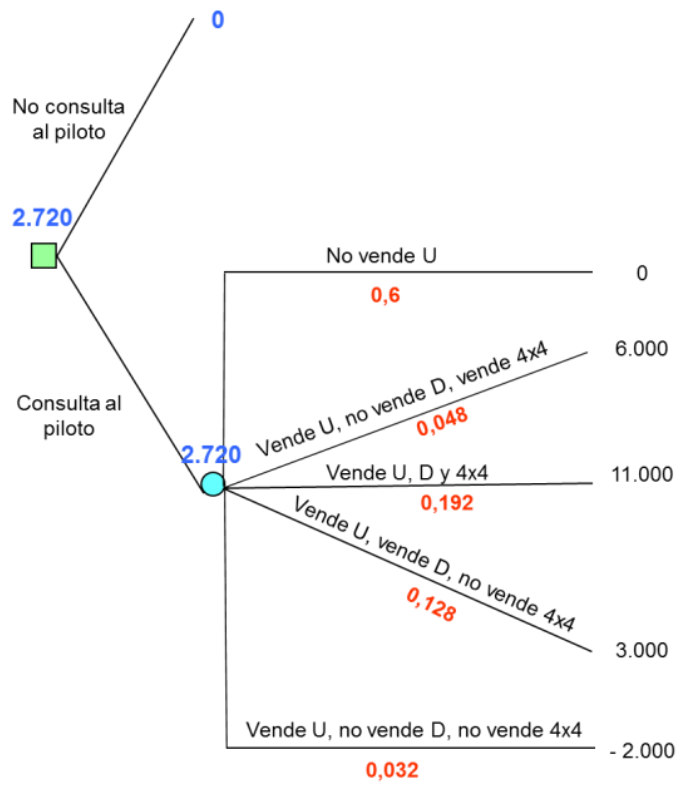

En base al criterio del valor esperado, la decisión que debe tomar el gerente de la empresa es la de consultar al piloto, esperando con ello obtener un beneficio de 2.720 euros.

El valor de la información que aporta el experto, viene dada por la diferencia de beneficios esperados, consultando al experto y sin consultar al experto. Este valor recibe el nombre de valor esperado de la información perfecta, dado que en éste caso el informador es fiable en un ciento por ciento.

Valor de la información perfecta $=2.720-0=2.720$ euros

Como máximo el gerente de la empresa puede pagar al experto 2.720 euros por su información, dado que es el valor de esperado de la misma. 


\section{Ejercicio 12}

El gerente de la empresa dedicada a la venta de coches de segunda mano del ejercicio número 10, está interesado en estudiar si vale la pena proponer a su cliente, que una vez vendido el utilitario le permita vender el deportivo y el todoterreno $4 \times 4$ turbo simultáneamente, en lugar de primero vender uno y después el otro, tal como especifica el pedido.

\section{Solución:}

Paso 1 - Enumere las diferentes alternativas de decisión.

Aceptar el nuevo pedido que propone el gerente al cliente.

No aceptar el nuevo pedido que propone el gerente al cliente.

Paso 2 - Enumere para cada una de las alternativas de decisión, los estados de la naturaleza asociados a la misma.

\begin{tabular}{|c|c|}
\hline Alternativas & Estados de la naturaleza \\
\hline Aceptar & $\begin{array}{c}\text { Vende el utilitario } \\
\text { No vende el utilitario }\end{array}$ \\
\hline No aceptar & \\
\hline
\end{tabular}

Si consigue vender el utilitario, debe decidir si prueba vender el deportivo y el $4 \times 4$ simultáneamente, 0 cancela el pedido.

\begin{tabular}{|c|c|c|}
\hline Alternativas & Estados de la naturaleza & Alternativas \\
\hline \multirow{2}{*}{ Aceptar } & Vende utilitario & $\begin{array}{c}\text { Prueba vender el deportivo y el } 4 \times 4 \text { simultáneamente } \\
\text { Cancela pedido }\end{array}$ \\
\cline { 2 - 3 } & No vende utilitario & \\
\hline No aceptar & & \\
\hline
\end{tabular}

Si prueba vender el deportivo y el 4x4 simultáneamente, los estados posibles de la naturaleza son:

- Que venda el deportivo y venda el $4 \times 4$

- Que no venda el deportivo y si venda el $4 \times 4$

- Que venda el deportivo y no venda el $4 \times 4$

- Que no venda el deportivo y no venda el $4 \times 4$ 
Paso 3 - Explicite el árbol de decisión.

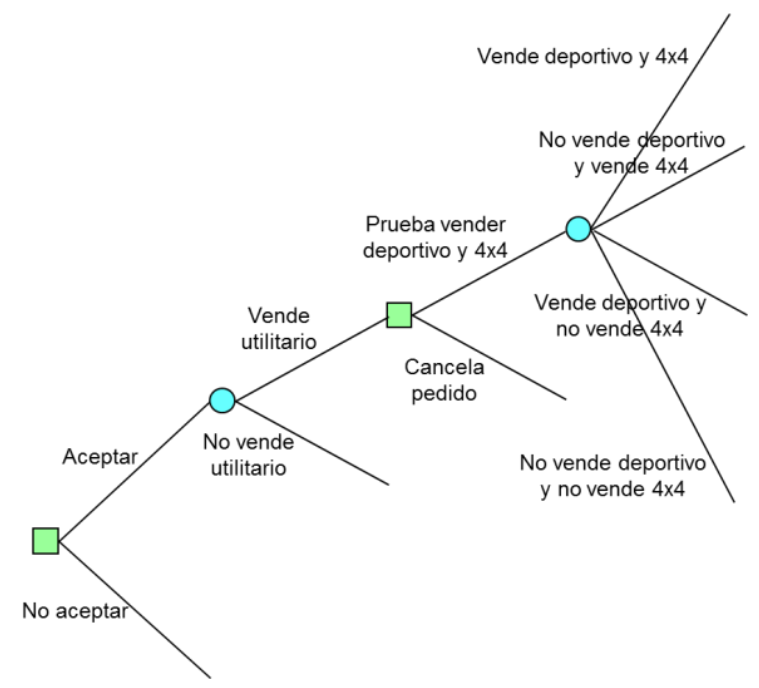

Paso 4 - Asigne las probabilidades a priori de cada uno de los estados de la naturaleza.

Probabilidad de vender el deportivo y vender el $4 \times 4$ :

$$
0,8 \times 0,6=0,48
$$

Probabilidad de no vender el deportivo y vender el $4 \times 4$ :

$$
(1-0,8) \times 0,6=0,12
$$

Probabilidad de vender el deportivo y no vender el $4 \times 4$ :

$$
0,8 \times(1-0,6)=0,32
$$

Probabilidad de no vender el deportivo y no vender el $4 \times 4$ :

$$
(1-0,8) \times(1-0,6)=0,08
$$




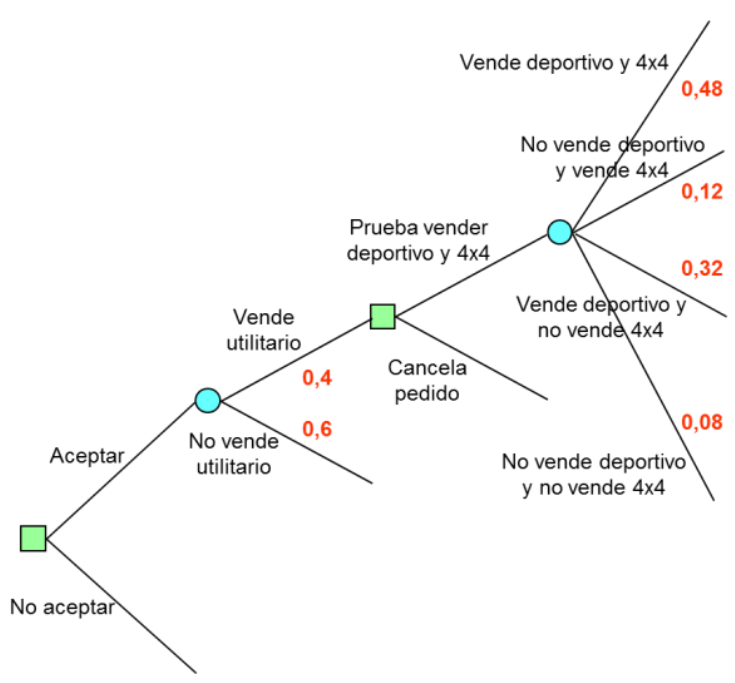

Paso 5 - Calcule el beneficio de cada una de las ramas del árbol.

Beneficio si vende el utilitario, el deportivo y el $4 \times 4$ :

$$
((10.000+60.000+100.000) \times 0,1)-(3.000+1.000+2.000)=11.000 \text { euros }
$$

Beneficio si vende el utilitario, no vende el deportivo y vende el $4 \times 4$ :

$$
((10.000+100.000) \times 0,1)-(3.000+1.000+2.000)=1.000 \text { euros }
$$

Beneficio si vende el utilitario, vende el deportivo y no vende el $4 \times 4$ :

$$
((10.000+60.000) \times 0,1)-(3.000+1.000+2.000)=1.000 \text { euros }
$$

Beneficio si vende el utilitario, no vende el deportivo y no vende el $4 \times 4$ :

$$
(10.000 \times 0,1)-(3.000+1.000+2.000)=-5.000 \text { euros }
$$

Beneficio si vende el utilitario:

$$
(10.000 \times 0,1)-3.000=-2.000 \text { euros. }
$$




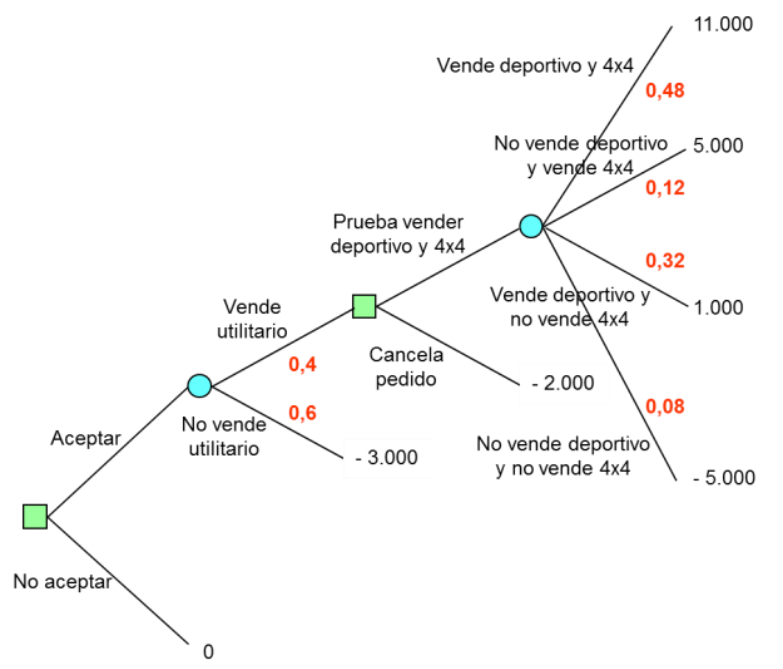

Paso 6 - Resuelva el árbol de decisión de derecha a izquierda. Dado que la etapa final es probabilista debe aplicar el criterio de la esperanza matemática con el objetivo de determinar el beneficio esperado.

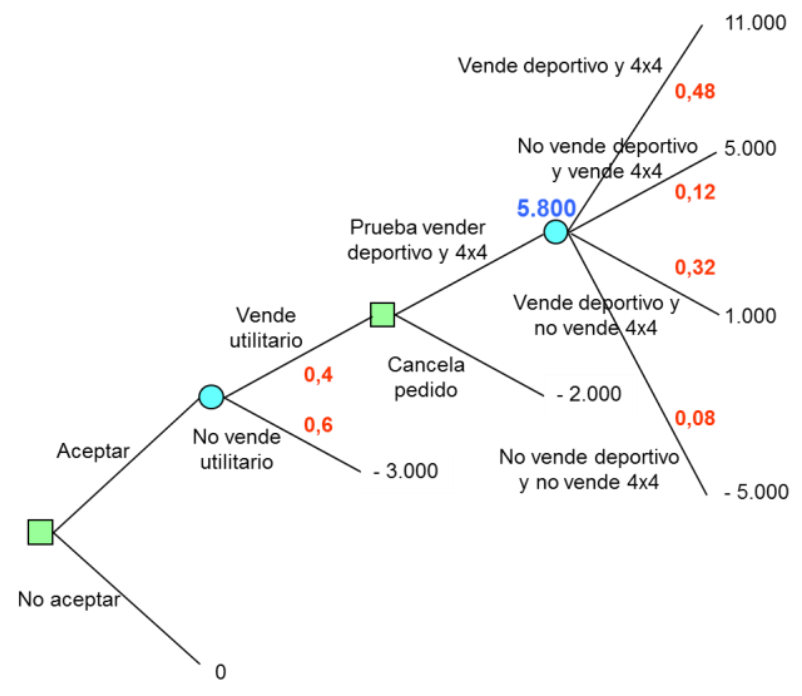

$(11.000 \times 0,48)+(5.000 \times 0,12)+(1.000 \times 0,32)+((-5.000) \times 0,08)=5.800$ euros 
Paso 7 - Resuelva la etapa anterior. Dado que es una etapa determinista y que los valores calculados son beneficios esperados, debe elegir la alternativa cuyo beneficio sea mayor.

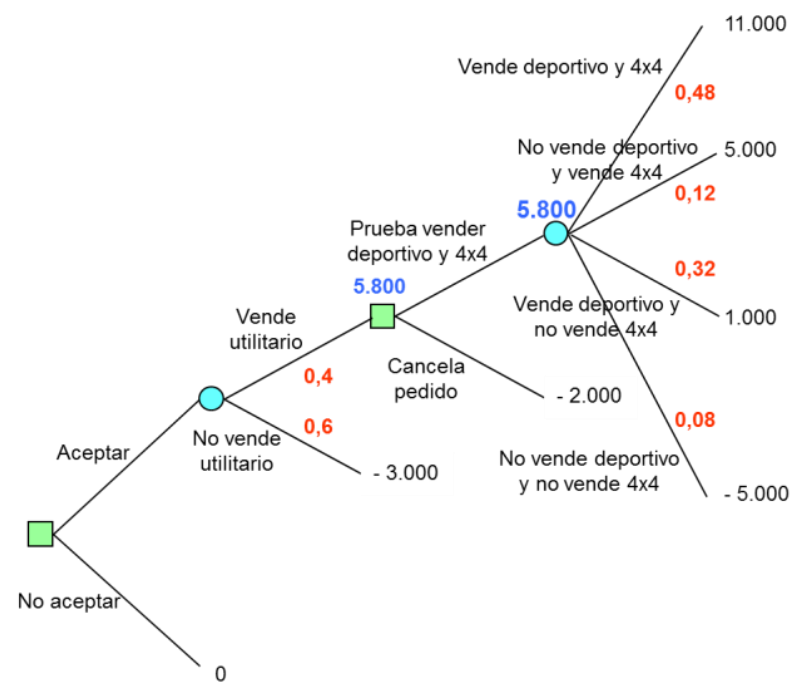

Paso 8 - Resuelva la etapa anterior. Dado que se trata de una etapa probabilista debe aplicar el criterio de la esperanza matemática con el objetivo de determinar el beneficio esperado.

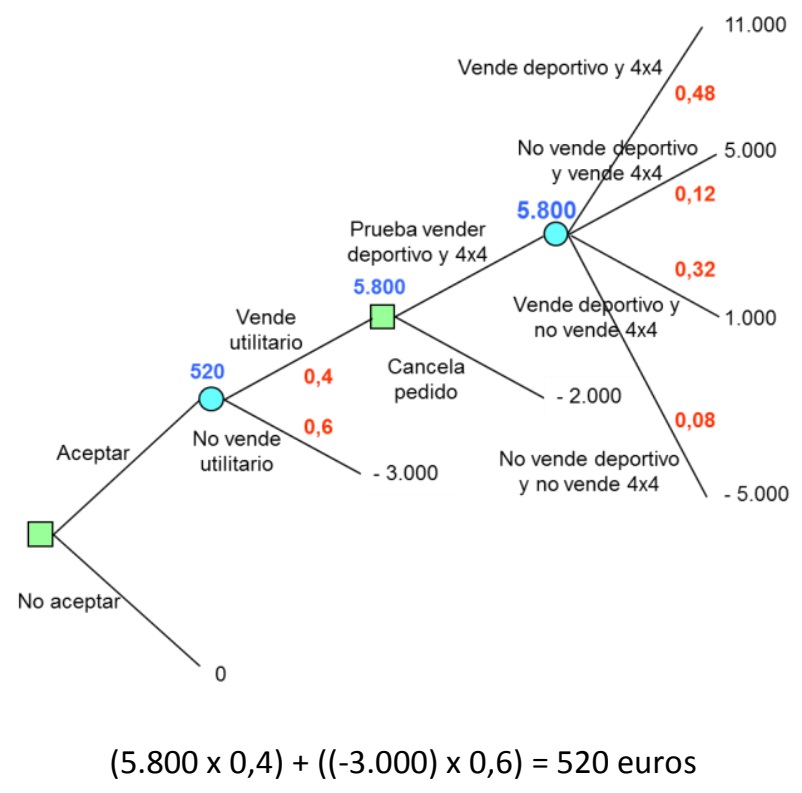


Paso 9 - Resuelva la etapa anterior. Al tratarse de una etapa determinista y que los valores calculados son beneficios esperados, debe elegir la alternativa cuyo beneficio sea mayor.

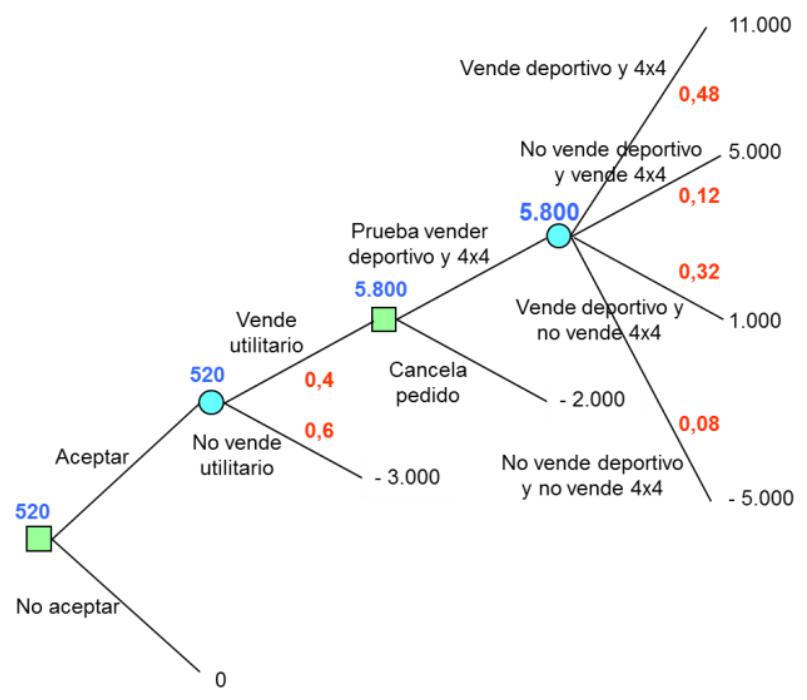

En base al criterio del valor esperado, si vale la pena que el gerente de la empresa proponga a su cliente, que una vez vendido el utilitario le permita vender el deportivo y el todoterreno $4 \times 4$ turbo simultáneamente, en lugar de primero vender uno y después el otro, tal como especifica el pedido del cliente. Con la nueva propuesta de pedido se espera obtener un beneficio de 520 euros, mientras que con la propuesta de pedido inicial formulada por el cliente (ver ejercicio 10) de una vez vendido el utilitario, vender primero un automóvil y después el otro, el beneficio esperado era de 0 euros. 


\section{Ejercicio 13}

El director de un restaurante de comida lenta está estudiando la posibilidad de ampliar su negocio, para ello está dispuesto a llevar a cabo las reformas que sean necesarias. En concreto está analizando tres mejoras posibles, la primera consistiría en ofrecer además del servicio de restauración, un nuevo servicio como hostal con un total de 8 habitaciones con baño. La segunda mejora se limita a incrementar el número de mesas del restaurante, para ello tiene la posibilidad de usar el segundo piso del local que está ocupando en la actualidad. La tercera mejora se resumiría en dejarlo todo intacto tal como está ahora el restaurante. La tabla siguiente muestra los beneficios que estima el director para cada una de las tres posibles mejoras, así como las probabilidades a priori de que la demanda sea alta o media, según la mejora que ponga en marcha:

\begin{tabular}{|c|c|c|c|c|}
\hline Mejora & Demanda Alta & $p$ & Demanda media & $p$ \\
\hline 1 & 200.000 euros & 0.6 & 70.000 euros & 0.4 \\
\hline 2 & 180.000 euros & 0.4 & 160.000 euros & 0.6 \\
\hline 3 & 150.000 euros & 0.2 & 140.000 euros & 0.8 \\
\hline
\end{tabular}

\section{Solución:}

Paso 1 - Enumere las diferentes alternativas de decisión.

\section{Mejora 1.}

Mejora 2.

Mejora 3.

Paso 2 - Enumere para cada una de las alternativas de decisión, los estados de la naturaleza asociados a la misma.

\begin{tabular}{|c|c|}
\hline Alternativas & Estados de la naturaleza \\
\hline Mejora 1 & $\begin{array}{c}\text { Demanda alta } \\
\text { Demanda media }\end{array}$ \\
\hline Mejora 2 & $\begin{array}{c}\text { Demanda alta } \\
\text { Demanda media }\end{array}$ \\
\hline Mejora 3 & Demanda alta \\
Demanda media
\end{tabular}


Paso 3 - Explicite el árbol de decisión.

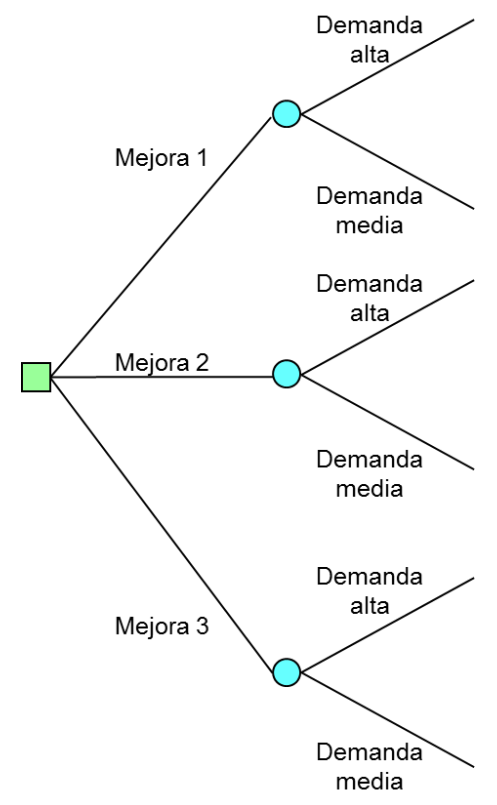

Paso 4 - Asigne las probabilidades a priori de cada uno de los estados de la naturaleza.

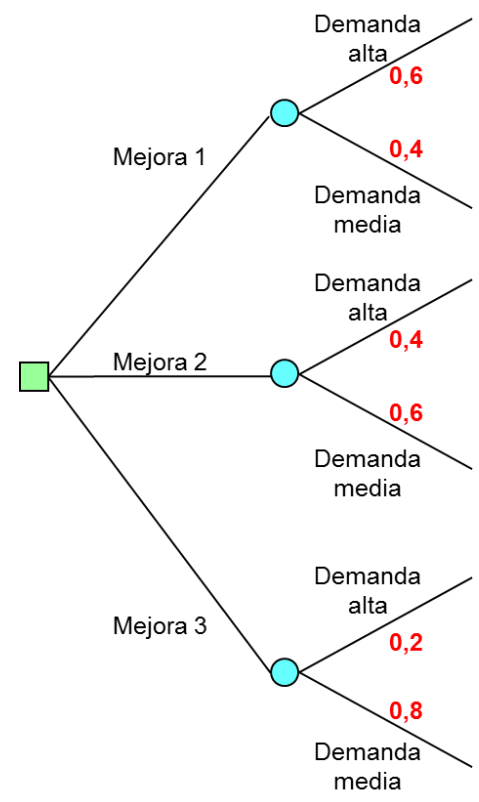


Paso 5 - Calcule el beneficio de cada una de las ramas del árbol.

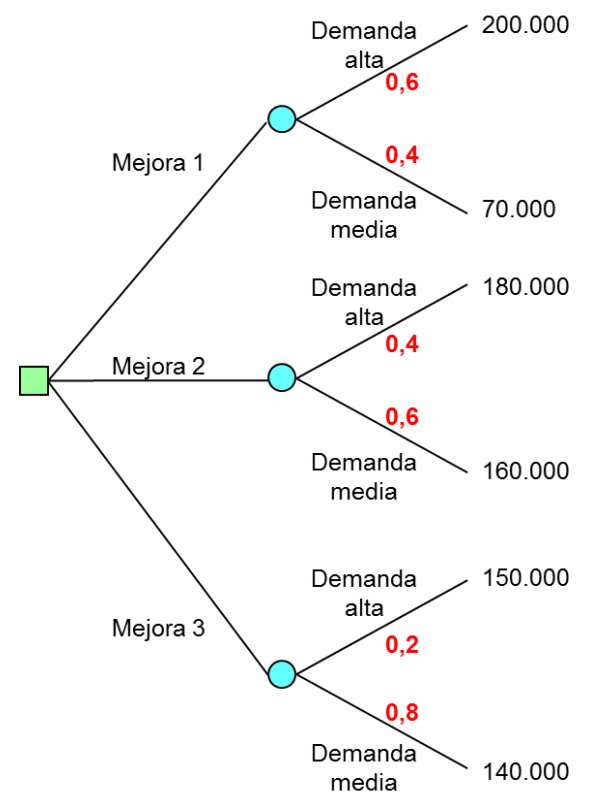

Paso 6 - Resuelva el árbol de decisión de derecha a izquierda. Dado que la etapa final es probabilista debe aplicar el criterio de la esperanza matemática con el objetivo de determinar el beneficio esperado.

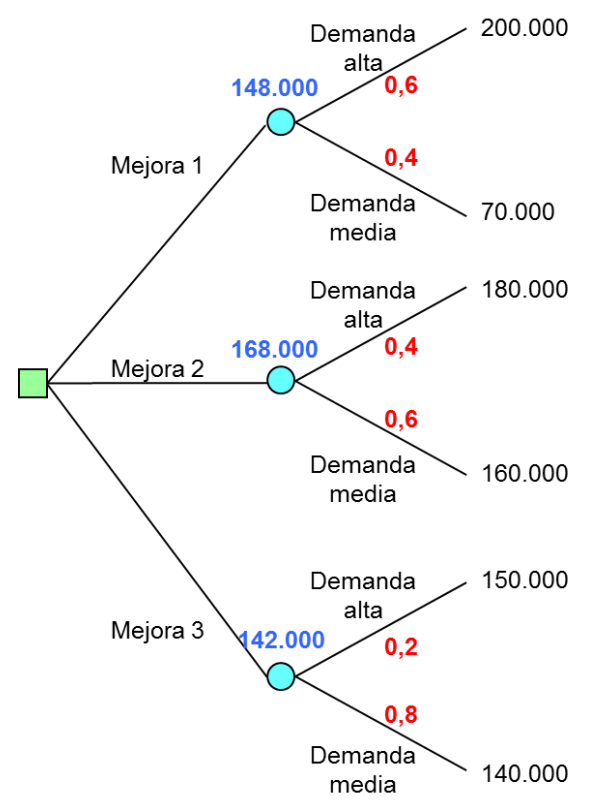




$$
\begin{aligned}
& (200.000 \times 0,6)+(70.000 \times 0,4)=148.000 \text { euros } \\
& (180.000 \times 0,4)+(16.000 \times 0,6)=168.000 \text { euros } \\
& (150.000 \times 0,2)+(140.000 \times 0,8)=142.000 \text { euros }
\end{aligned}
$$

Paso 7 - Resuelva la etapa anterior. Dado que esta primera etapa es determinista y que los valores que ha calculado son beneficios, debe elegir la alternativa cuyo beneficio sea mayor y colocar el resultado encima del nudo correspondiente.

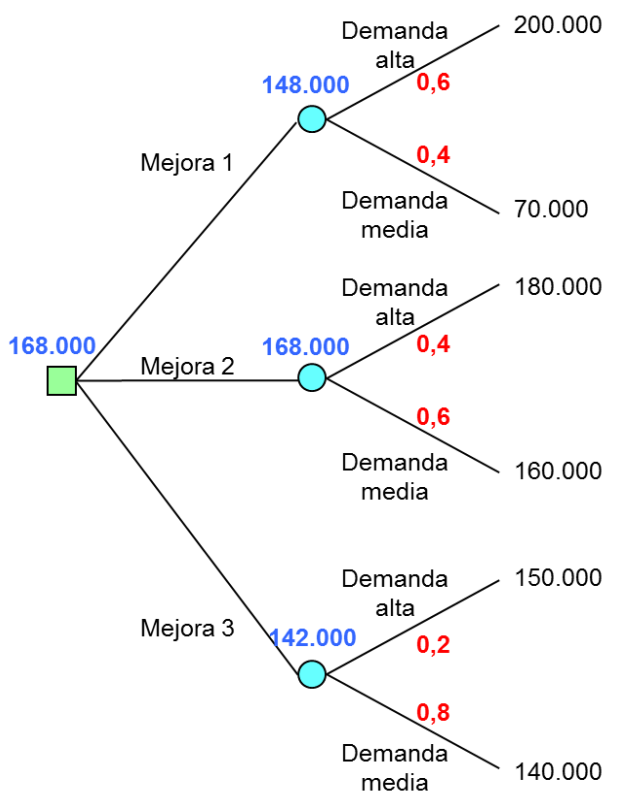

La decisión que debe tomar el director del restaurante es la de poner en marcha la segunda mejora, consistente en incrementar el número de mesas del restaurante, empleando para ello el segundo piso del local en que está ubicado el restaurante, esperando obtener un beneficio de 168.000 euros. 


\section{Ejercicio 14}

Una empresa está estudiando la construcción de una nueva fábrica que le permita incrementar su capacidad productiva para hacer frente al incremento de la demanda previsto para los próximos años. Las alternativas de localización de la misma son las ciudades de Sevilla, Soria, Valencia, y Orense. Los beneficios estimados para cada alternativa a lo largo de los próximos años se recogen en la tabla.

\begin{tabular}{|c|c|c|c|}
\cline { 2 - 4 } \multicolumn{1}{c|}{} & \multicolumn{3}{c|}{ Incremento de la demanda } \\
\cline { 2 - 4 } \multicolumn{1}{c|}{} & Moderado & Elevado & Muy elevado \\
\hline Sevilla & 100.000 & 400.000 & 650.000 \\
\hline Soria & 140.000 & 350.000 & 450.000 \\
\hline Valencia & 150.000 & 570.000 & 1.000 .000 \\
\hline Orense & 200.000 & 500.000 & 950.000 \\
\hline
\end{tabular}

Determine la ubicación óptima de la nueva planta:

1. Siguiendo los criterios optimista, pesimista y Laplace.

2. Si la probabilidad de un incremento moderado de la demanda es del $60 \%$, de un incremento elevado es del $30 \%$, y de un incremento muy elevado es del $10 \%$.

\section{Solución:}

\subsection{Determine la ubicación óptima de la nueva planta siguiendo el criterio optimista}

Maximizar \{Máximo \{Beneficio\}\}

\begin{tabular}{|c|c|c|c|c|}
\cline { 2 - 5 } \multicolumn{1}{c|}{} & Moderado & Elevado & Muy elevado & Máximo \{Beneficio\} \\
\hline Sevilla & 100.000 & 400.000 & 650.000 & 650.000 \\
\hline Soria & 140.000 & 350.000 & 450.000 & 450.000 \\
\hline Valencia & 150.000 & 570.000 & 1.000 .000 & 1.000 .000 \\
\hline Orense & 200.000 & 500.000 & 950.000 & 950.000 \\
\hline
\end{tabular}

Maximizar \{Máximo \{Beneficio\}\}

Máx. $\{650.000,450.000,1.000 .000,950.000\}=1.000 .000$ euros

La decisión óptima siguiendo el criterio optimista es la de construir la nueva planta en Valencia. 


\subsection{Determine la ubicación óptima de la nueva planta siguiendo el criterio pesimista}

\begin{tabular}{|c|c|c|c|c|}
\cline { 2 - 5 } \multicolumn{4}{c|}{ Maximizar \{Mínimo \{Beneficio\}\} } \\
\cline { 2 - 5 } \multicolumn{1}{c|}{} & Moderado & Elevado & Muy elevado & Máximo \{Beneficio\} \\
\hline Sevilla & 100.000 & 400.000 & 650.000 & 100.000 \\
\hline Soria & 140.000 & 350.000 & 450.000 & 140.000 \\
\hline Valencia & 150.000 & 570.000 & 1.000 .000 & 150.000 \\
\hline Orense & 200.000 & 500.000 & 950.000 & 200.000 \\
\hline
\end{tabular}

Maximizar $\{$ Mínimo \{Beneficio\}\}

Máx. $\{100.000,140.000,150.000,200.000\}=200.000$ euros

La decisión óptima siguiendo el criterio pesimista es la de construir la nueva planta en Orense.

\subsection{Determine la ubicación óptima de la nueva planta siguiendo el criterio de Laplace}

Criterio de Laplace $\rightarrow$ Criterio equiprobable $\rightarrow$ Todos los estados de la naturaleza tienen la misma probabilidad. En este caso los estados de la naturaleza posibles son tres:

- Incremento moderado de la demanda.

- Incremento elevado de la demanda.

- Incremento muy elevado de la demanda.

Dado que los estados de la naturaleza son tres y que todos deben tener la misma probabilidad (criterio de Laplace), la probabilidad a priori de cada uno de ellos es del $100 / 3=33,33 \%$.

\begin{tabular}{|c|c|c|c|c|}
\cline { 2 - 5 } \multicolumn{1}{c|}{} & Moderado & Elevado & Muy elevado & Valor esperado $\mathrm{E}[\mathrm{x}]$ \\
\hline Sevilla & 100.000 & 400.000 & 650.000 & 383.333 \\
\hline Soria & 140.000 & 350.000 & 450.000 & 313.333 \\
\hline Valencia & 150.000 & 570.000 & 1.000 .000 & 573.333 \\
\hline Orense & 200.000 & 500.000 & 950.000 & 550.000 \\
\cline { 2 - 5 } & $33.33 \%$ & $33.33 \%$ & $33.33 \%$ & \multicolumn{1}{c}{} \\
\cline { 2 - 5 } & \multicolumn{2}{c}{} & & \multicolumn{2}{c}{} &
\end{tabular}

Maximizar Beneficio esperado\}

Máx. $\{383.333,313.333,573.333,550.000\}=573.333$ euros

La decisión óptima siguiendo el criterio Laplace es la de construir la nueva planta en Valencia. 


\section{Si la probabilidad de un incremento moderado de la demanda es del $60 \%$, de un incremento} elevado es del $30 \%$, y de un incremento muy elevado es del $10 \%$

En este caso debe aplicarse el criterio de la esperanza matemática.

\begin{tabular}{|c|c|c|c|c|}
\cline { 2 - 5 } \multicolumn{1}{c|}{} & Moderado & Elevado & Muy elevado & Máximo \{Beneficio\} \\
\hline Sevilla & 100.000 & 400.000 & 650.000 & 250.000 \\
\hline Soria & 140.000 & 350.000 & 450.000 & 234.000 \\
\hline Valencia & 150.000 & 570.000 & 1.000 .000 & 361.000 \\
\hline Orense & 200.000 & 500.000 & 950.000 & 365.000 \\
\hline & $60 \%$ & $30 \%$ & $10 \%$ & \multicolumn{1}{c}{} \\
\cline { 2 - 5 } & \multicolumn{3}{c}{}
\end{tabular}

Maximizar $\{$ Beneficio esperado\}

Máx. $\{245.000,234.000,361.000,365.000\}=365.000$ euros

La decisión óptima siguiendo el criterio de la esperanza matemática, con las probabilidades a priori dadas en el enunciado del ejercicio, es la de construir la nueva planta en Orense. 


\title{
Ejercicio 15
}

Una empresa, con el fin de fabricar una nueva línea de productos, está analizando la reforma de su planta actual. La demanda de la nueva línea de productos puede ser favorable o desfavorable. Si la empresa efectúa una reforma profunda de la planta actual, el beneficio estimado en el caso de que la demanda de la nueva línea de productos sea favorable es de 500.000 euros, mientras que si la demanda es desfavorable el beneficio estimado asciende tan solo a 100.000 euros. En el caso de que la reforma que se efectúe en la planta sea moderada, si la demanda es favorable se estiman unos beneficios de 400.000 euros, mientras que si es desfavorable los beneficios estimados son de 250.000 euros. La probabilidad a priori de que la demanda sea favorable o desfavorable es la misma. Obviamente, ni que decir tiene, que la empresa tiene la opción de no poner en marcha la nueva línea de productos.

1. Determine la decisión que debe tomar el empresario.

2. Antes de tomar su decisión, el empresario puede obtener información adicional contratando una firma de investigación de mercado para llevar a cabo un estudio de la demanda. ¿Cuánto estaría dispuesto a pagar por la información exacta?

\section{Solución:}

\section{Determine la decisión que debe tomar el empresario}

Paso 1 - Enumere las diferentes alternativas de decisión.

\author{
Hacer una reforma profunda. \\ Hacer una reforma moderada.
}

No reformar nada.

Paso 2 - Enumere para cada una de las alternativas de decisión, los estados de la naturaleza asociados a la misma.

\begin{tabular}{|c|c|}
\hline Alternativas & Estados de la naturaleza \\
\hline Hacer una reforma profunda & $\begin{array}{c}\text { Demanda favorable } \\
\text { Demanda desfavorable }\end{array}$ \\
\hline Hacer una reforma moderada & $\begin{array}{c}\text { Demanda favorable } \\
\text { Demanda desfavorable }\end{array}$ \\
\hline No reformar & \\
\hline
\end{tabular}


Paso 3 - Explicite el árbol de decisión.

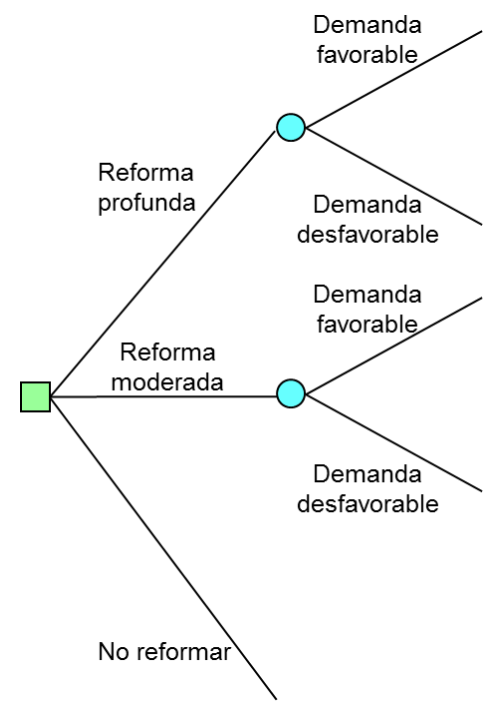

Paso 4 - Asigne las probabilidades a priori de cada uno de los estados de la naturaleza.

Según el enunciado del ejercicio, la probabilidad a priori de que la demanda sea favorable o desfavorable es la misma.

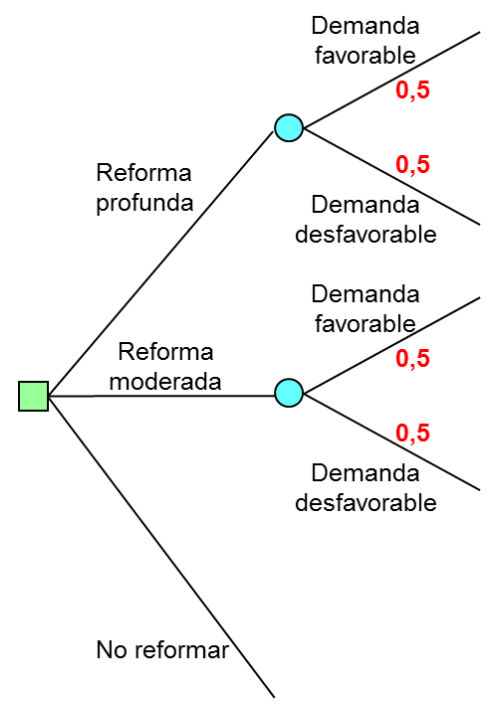


Paso 5 - Calcule el beneficio de cada una de las ramas del árbol.

Los beneficios esperados vienen dados en el enunciado del ejercicio.

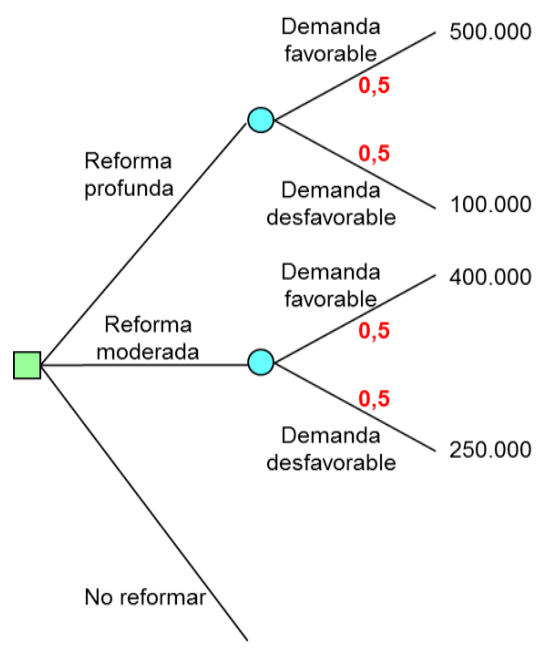

Paso 6 - Resuelva el árbol de decisión de derecha a izquierda. Dado que la etapa final es probabilista debe aplicar el criterio de la esperanza matemática con el objetivo de determinar el beneficio esperado.

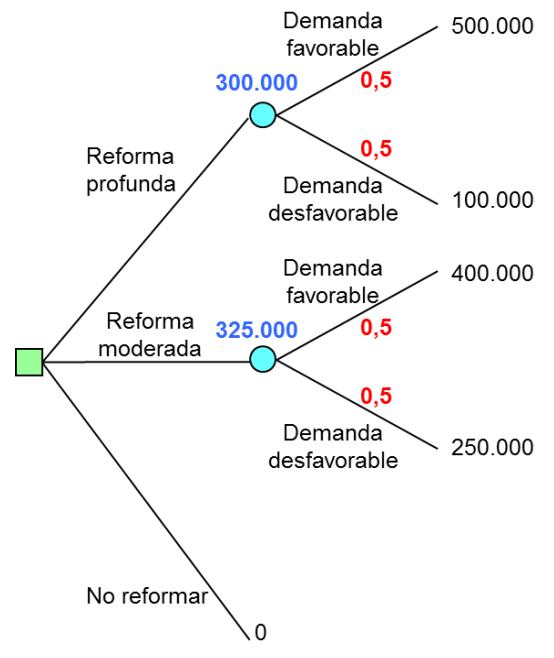

$$
\begin{aligned}
& (500.000 \times 0,5)+(100.000 \times 0,5)=300.000 \text { euros } \\
& (400.000 \times 0,5)+(250.000 \times 0,5)=325.000 \text { euros }
\end{aligned}
$$


Paso 7 - Resuelva la etapa anterior. Dado que esta primera etapa es determinista y que los valores que ha calculado son beneficios, debe elegir la alternativa cuyo beneficio sea mayor y colocar el resultado encima del nudo correspondiente.

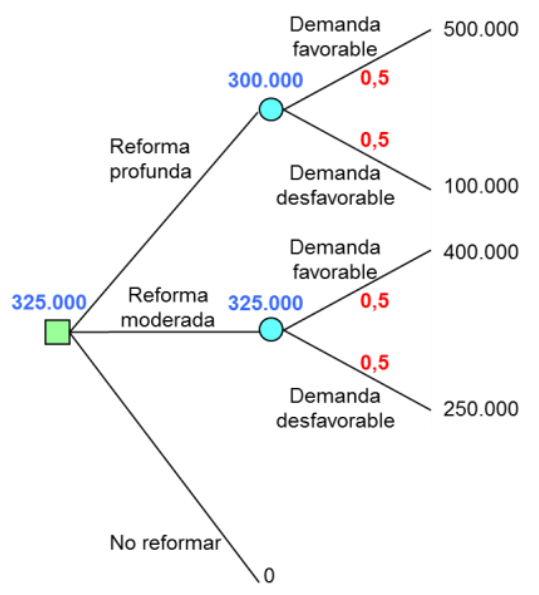

La decisión que debe tomar el empresario es la de llevar a cabo una reforma moderada, esperando obtener un beneficio de 325.000 euros.

2. Antes de tomar su decisión, el empresario puede obtener información adicional contratando una firma de investigación de mercado para llevar a cabo un estudio de la demanda. ¿Cuánto estaría dispuesto a pagar por la información exacta?

Paso 1 - Enumere las diferentes alternativas de decisión.

Obtener información adicional sobre la demanda.

NO obtener información adicional sobre la demanda.

En el caso de que opte por no reunir información adicional, debe decidir si hace una reforma profunda, moderada, o por el contrario no realiza ninguna reforma. 
Paso 2 - Enumere para cada una de las alternativas de decisión, los estados de la naturaleza asociados a la misma.

\begin{tabular}{|c|c|c|}
\hline \multicolumn{2}{|c|}{ Alternativas } & Estados de la naturaleza \\
\hline \multicolumn{2}{|c|}{ Con información } & $\begin{array}{l}\text { Información demanda favorable } \\
\text { Información demanda desfavorable }\end{array}$ \\
\hline \multirow{3}{*}{$\begin{array}{c}\text { Sin } \\
\text { información }\end{array}$} & $\begin{array}{l}\text { Reforma } \\
\text { profunda }\end{array}$ & $\begin{array}{c}\text { Demanda favorable } \\
\text { Demanda desfavorable }\end{array}$ \\
\hline & $\begin{array}{l}\text { Reforma } \\
\text { moderada }\end{array}$ & $\begin{array}{c}\text { Demanda favorable } \\
\text { Demanda desfavorable }\end{array}$ \\
\hline & No reformar & $\begin{array}{c}\text { Demanda favorable } \\
\text { Demanda desfavorable }\end{array}$ \\
\hline
\end{tabular}

Obtenida la información, sea ésta favorable o desfavorable, debe decidir si lleva a cabo una reforma profunda, moderada, o por el contrario no realiza ninguna reforma en la planta actual, tras lo cual la demanda podrá ser favorable o desfavorable.

Paso 3 - Explicite el árbol de decisión.

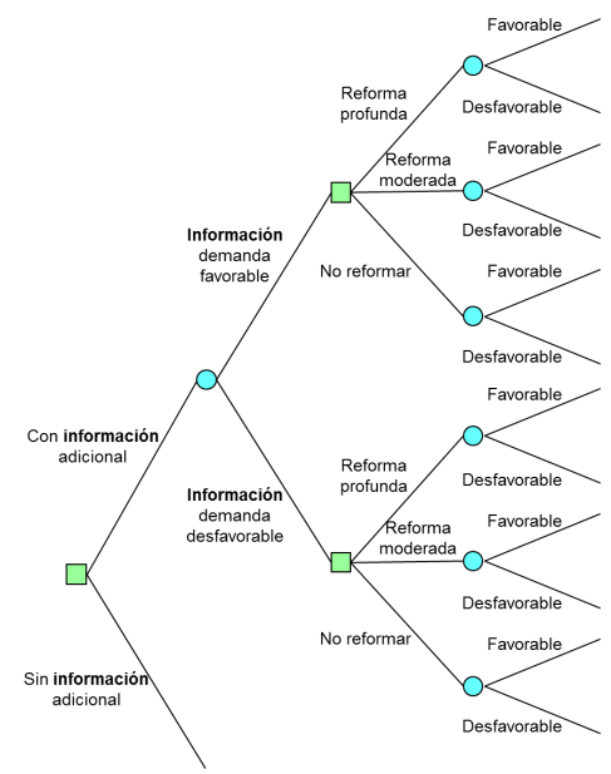

Paso 4 - Asigne las probabilidades a priori de cada uno de los estados de la naturaleza.

Dado que la información proporcionada por la compañía de investigación de mercados es exacta, según indica el enunciado, las probabilidades a posteriori (probabilidades condicionales) vienen dadas por: 
$\mathrm{P}$ (Demanda favorable / Información demanda favorable) = 1

$\mathrm{P}($ Demanda desfavorable / Información demanda favorable $)=0$

$\mathrm{P}($ Demanda favorable / Información demanda desfavorable $)=0$

$\mathrm{P}($ Demanda desfavorable / Información demanda desfavorable $)=1$

De donde, la probabilidad a priori de cada uno de los acontecimientos:

$\mathrm{P}($ Información demanda favorable $)=[\mathrm{P}$ (Demanda favorable $) \times \mathrm{P}$ (Información demanda favorable $/$ Demanda favorable $)]+[P($ Demanda desfavorable $) \times \mathrm{P}($ Información demanda favorable / Demanda desfavorable $)]=[0,5 \times 1]+[0,5 \times 0]=0,5$

$\mathrm{P}($ Información demanda desfavorable $)=[\mathrm{P}($ Demanda favorable $) \times \mathrm{P}($ Información demanda desfavorable / Demanda favorable $)]+[\mathrm{P}($ Demanda desfavorable $) \times \mathrm{P}($ Información demanda desfavorable / Demanda desfavorable) $]=[0,5 \times 0]+[0,5 \times 1]=0,5$

Obviamente, dado que el informador es $100 \%$ fiable, las probabilidades a priori de que la información sea demanda favorable o desfavorable, se corresponde con las probabilidades a priori de que la demanda sea favorable o desfavorable, respectivamente.

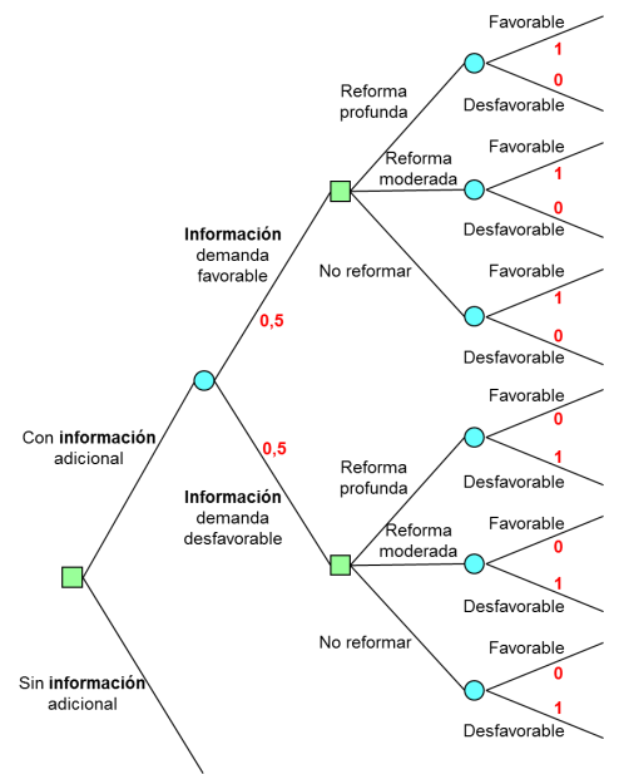


Paso 5 - Calcule el beneficio de cada una de las ramas del árbol.

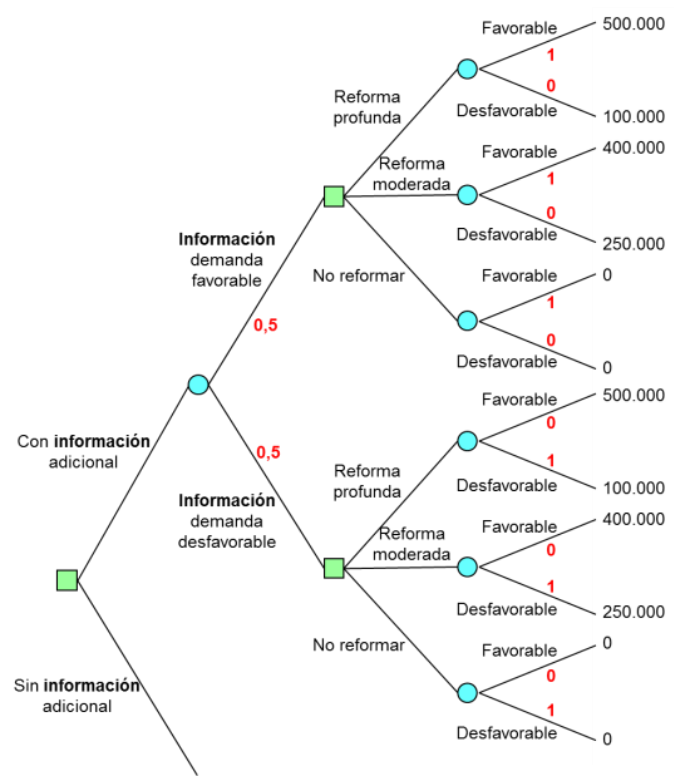

Paso 6 - Resuelva el árbol de decisión de derecha a izquierda. Dado que la etapa final es probabilista debe aplicar el criterio de la esperanza matemática con el objetivo de determinar el beneficio esperado de cada alternativa de decisión.

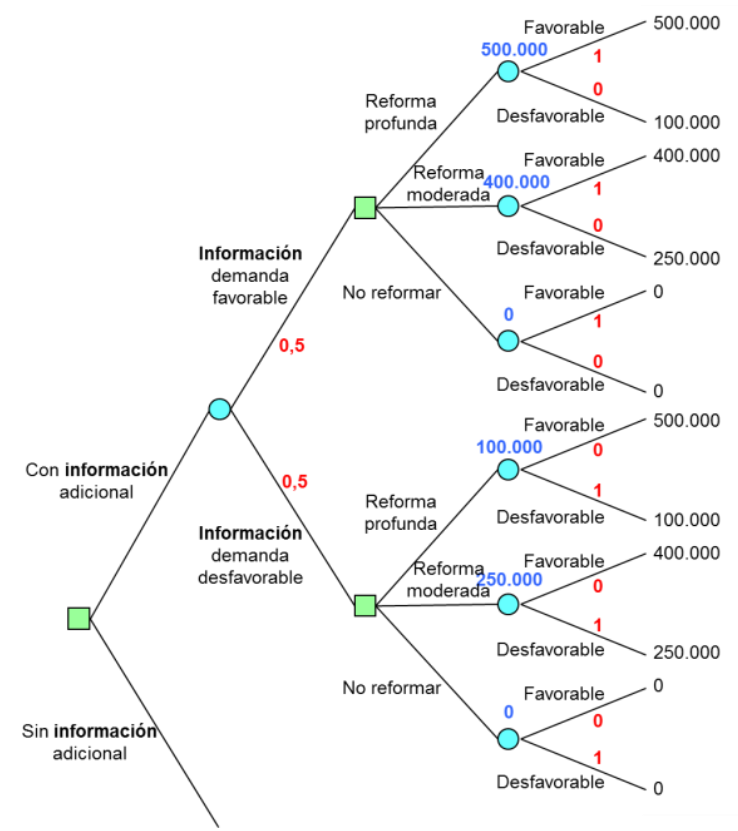




$$
\begin{aligned}
& (500.000 \times 1)+(100.000 \times 0)=500.000 \text { euros } \\
& (400.000 \times 1)+(250.000 \times 0)=400.000 \text { euros } \\
& (500.000 \times 0)+(100.000 \times 1)=100.000 \text { euros } \\
& (400.000 \times 0)+(250.000 \times 1)=250.000 \text { euros }
\end{aligned}
$$

Paso 7 - Resuelva la etapa anterior. Dado que dicha etapa es determinista y que los valores que ha calculado son beneficios, debe elegir la alternativa cuyo beneficio sea mayor y colocar el resultado encima del nudo correspondiente.

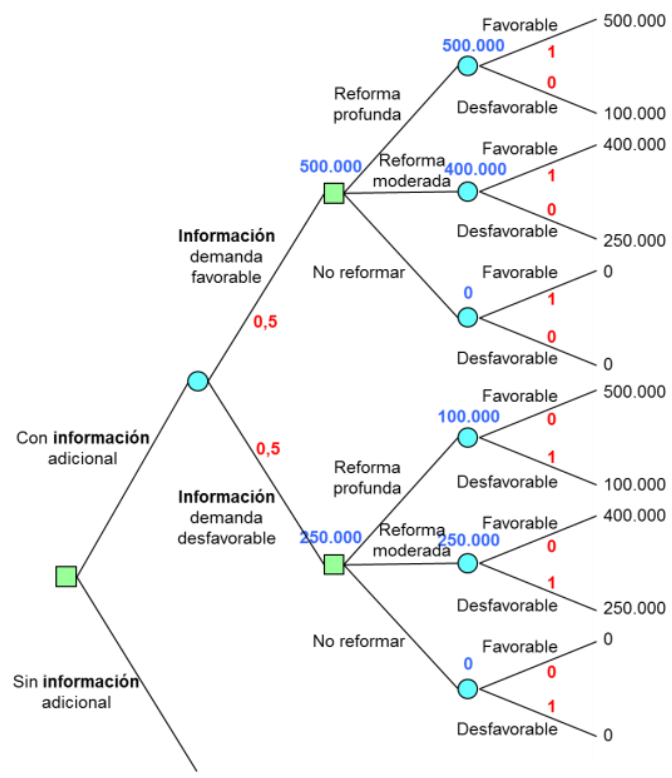

Paso 8 - Resuelva las dos últimas etapas. La etapa penúltima es probabilista por lo que debe aplicar el criterio de la esperanza matemática con el objetivo de determinar el beneficio esperado.

$$
(500.000 \times 0,5)+(250.000 \times 0,5)=375.000 \text { euros }
$$

El beneficio esperado sin reunir información adicional lo ha determinado en el apartado anterior de este mismo ejercicio, resultando un beneficio de 325.000 euros.

La última etapa es determinista, debe pues elegir la alternativa cuyo beneficio sea mayor y colocar el resultado encima del nudo correspondiente. 


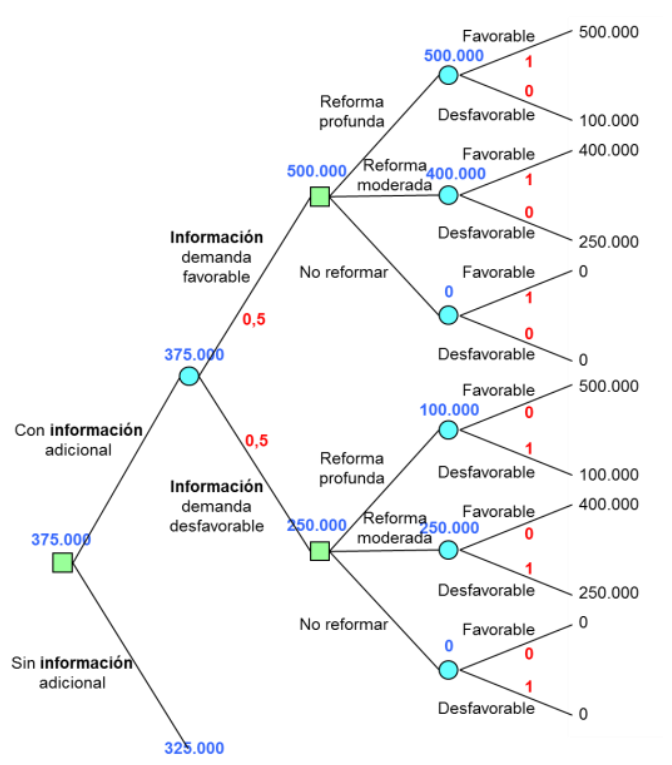

La decisión que debe tomar el empresario es solicitar información adicional, esperando obtener un beneficio de 375.000 euros. Si dicha información resulta favorable debe hacer una reforma profunda de la planta, en caso contrario debe realizar una reforma moderada.

El beneficio esperado con información adicional es de 375.000 euros, mientras que el beneficio esperado sin información adicional asciende a 325.000 euros, de donde el valor de la información aportada por la compañía de investigación de mercados es de:

$$
375.000-325.000=50.000 \text { euros }
$$

Como máximo el empresario estaría dispuesto a pagar 50.000 euros por la información aportada por la compañía de investigación de mercados. 


\section{Ejercicio 16}

El departamento de investigación y desarrollo de una empresa pretende diseñar un nuevo sistema de comunicación, para ello puede adoptar tres estrategias posibles de diseño. Cuanto mejor sea la estrategia de diseño menor será el coste variable, según el responsable del departamento de investigación y desarrollo, la estimación de costes para cada una de las estrategias es la siguiente:

Estrategia basada en baja tecnología y costes reducidos, consistente en contratar a ingenieros becarios en prácticas. Esta opción tiene un coste fijo de 10.000 euros y unos costes variables unitarios de 1,7, 1,6 y 1,5 euros, con unas probabilidades del $40 \%, 35 \%$, y 25\%, respectivamente.

La segunda estrategia se fundamenta en la subcontratación, recurriendo a personal externo cualificado de alta calidad, lo que conduce a unos costes fijos de 100.000 euros y unos costes variables unitarios de 1,4, 1,3 y 1,2 euros, con unas probabilidades del 60\%, 25\%, y 15\%, respectivamente.

Por último, la tercera estrategia se apoya en alta tecnología, para ello se utilizará el mejor personal de la empresa así como la última tecnología en diseño asistido por computador electrónico. Este enfoque tiene un coste fijo de 250.000 euros y unos costes variables unitarios de 1,1 y 1 euro, con unas probabilidades del $75 \%$ y $25 \%$, respectivamente.

Conociendo que la demanda prevista es de 500.000 unidades, determine la decisión que deberá adoptar el responsable del departamento de investigación y desarrollo.

\section{Solución:}

Paso 1 - Enumere las diferentes alternativas de decisión.

Adoptar la estrategia basada en baja tecnología.

Adoptar la estrategia basada en subcontratación.

Adoptar la estrategia basada en alta tecnología.

Paso 2 - Enumere para cada una de las alternativas de decisión, los estados de la naturaleza asociados a la misma.

\begin{tabular}{|c|c|}
\hline Alternativas & Estados de la naturaleza \\
\hline \multirow{2}{*}{ Baja tecnología } & 1,7 euros / unidad \\
& 1,6 euros / unidad \\
& 1,5 euros / unidad \\
\hline \multirow{2}{*}{ Subcontratación } & 1,4 euros / unidad \\
& 1,3 euros / unidad \\
& 1,2 euros / unidad \\
\hline \multirow{2}{*}{ Alta tecnología } & 1,1 euros / unidad \\
& 1,0 euros / unidad \\
\hline
\end{tabular}


Paso 3 - Explicite el árbol de decisión.

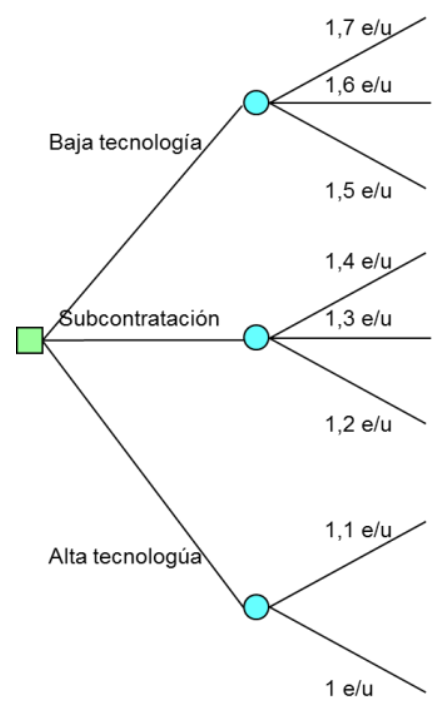

Paso 4 - Asigne las probabilidades a priori de cada uno de los estados de la naturaleza.

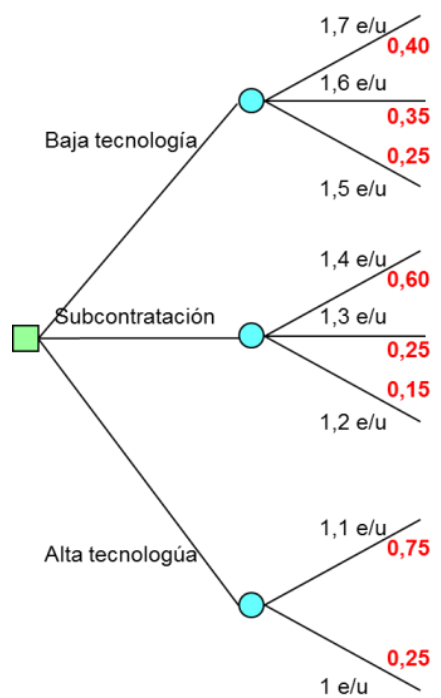

Paso 5 - Calcule el coste de cada una de las ramas del árbol.

$$
\begin{aligned}
& 10.000+(500.000 \times 1,7)=860.000 \\
& 10.000+(500.000 \times 1,6)=810.000 \\
& 10.000+(500.000 \times 1,5)=760.000
\end{aligned}
$$


$100.000+(500.000 \times 1,4)=800.000$

$100.000+(500.000 \times 1,3)=750.000$

$100.000+(500.000 \times 1,2)=700.000$

$250.000+(500.000 \times 1,1)=800.000$

$250.000+(500.000 \times 1,0)=750.000$

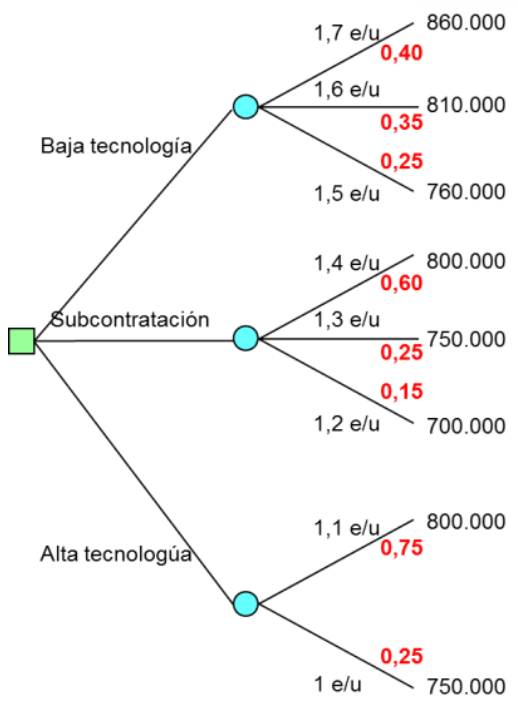

Paso 6 - Resuelva el árbol de decisión de derecha a izquierda. Dado que la etapa final es probabilista debe aplicar el criterio de la esperanza matemática con el objetivo de determinar el coste esperado.

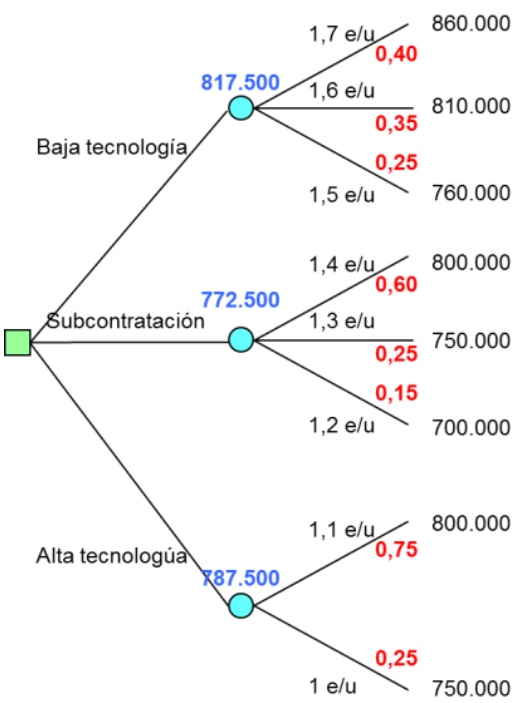




$$
\begin{gathered}
(860.000 \times 0,40)+(810.000 \times 0,35)+(760.000 \times 0,25)=817.500 \text { euros } \\
(800.000 \times 0,60)+(750.000 \times 0,25)+(700.000 \times 0,15)=772.500 \text { euros } \\
(800.000 \times 0,75)+(750.000 \times 0,25)=787.500 \text { euros }
\end{gathered}
$$

Paso 7 - Resuelva la etapa anterior. Dado que esta primera etapa es determinista y que los valores que ha calculado son costes, debe elegir la alternativa cuyo coste sea menor y colocar el resultado encima del nudo correspondiente.

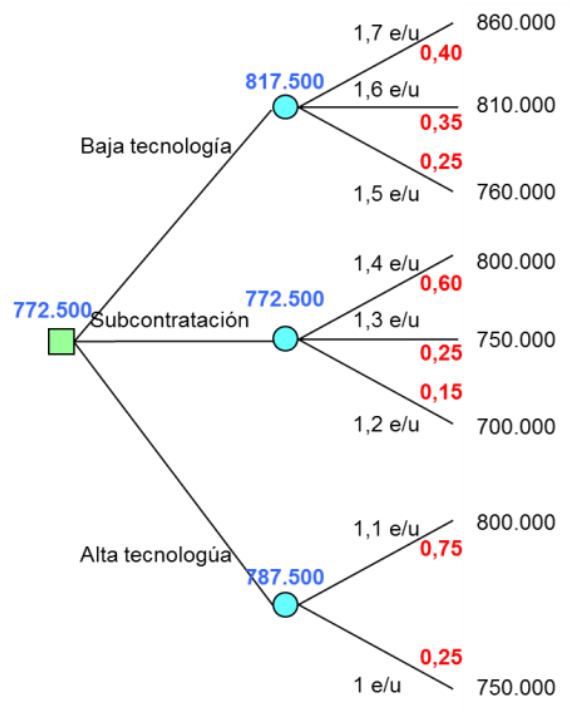

La decisión que debe tomar el responsable del departamento de investigación y desarrollo es la de adoptar la estrategia basada en la subcontratación, recurriendo a personal externo cualificado de alta calidad, esperando que los costes asciendan a 772.500 euros. 


\section{Ejercicio 17}

Una empresa está estudiando la compra de unos terrenos en los que es probable que haya gas. Si encuentra gas, la empresa podrá enajenar los terrenos obteniendo un beneficio de 125.000 .000 de euros, o bien explotarlos ella misma en cuyo caso los beneficios dependerán de la demanda, si ésta es alta los beneficios serán de 200.000.000 de euros, en caso contrario, si la demanda es baja los beneficios solo alcanzarán los 75.000 .000 de euros. La probabilidad a priori de que la demanda sea alta o baja, es exactamente la misma. En el caso de no encontrar gas en dichos terrenos, la empresa soportará unas pérdidas de 50.000 .000 de euros, si bien la probabilidad de encontrar gas según los expertos es del 70\%. Determine si la empresa debe o no adquirir los terrenos.

\section{Solución:}

Paso 1 - Enumere las diferentes alternativas de decisión.

\section{Comprar los terrenos.}

No comprar los terrenos.

Paso 2 - Enumere para cada una de las alternativas de decisión, los estados de la naturaleza asociados a la misma.

\begin{tabular}{|c|c|}
\hline Alternativas & Estados de la naturaleza \\
\hline Comprar los terrenos & $\begin{array}{c}\text { Hay Gas en los terrenos } \\
\text { No hay Gas en los terrenos }\end{array}$ \\
\hline No comprar los terrenos & \\
\hline
\end{tabular}

Si compra los terrenos y en ellos encuentra gas, debe decidir si revende los terrenos o si por el contrario la empresa prefiere explotar el gas contenido en dichos terrenos, en cuyo caso, la demanda de gas podrá ser alta o baja.

Paso 3 - Explicite el árbol de decisión.

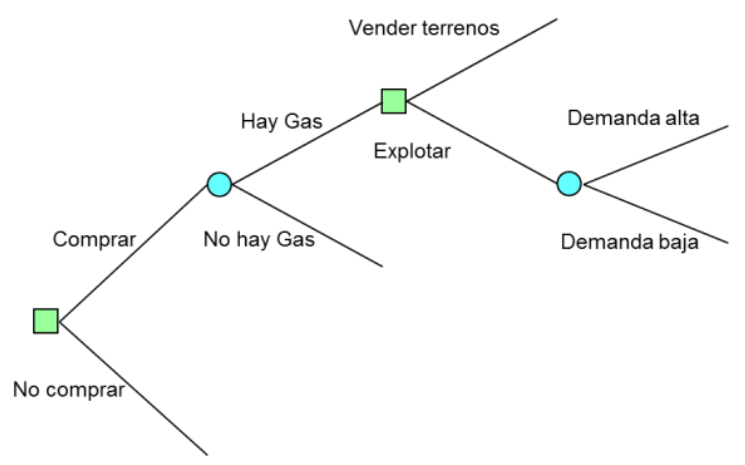


Paso 4 - Asigne las probabilidades a priori de cada uno de los estados de la naturaleza.

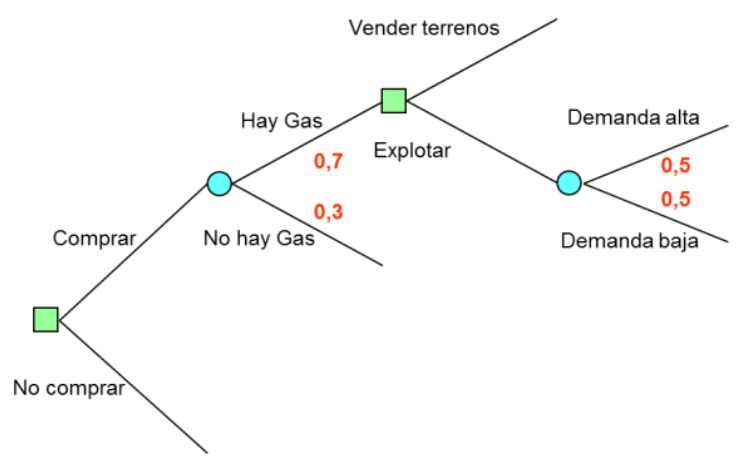

Paso 5 - Calcule el beneficio de cada una de las ramas del árbol.

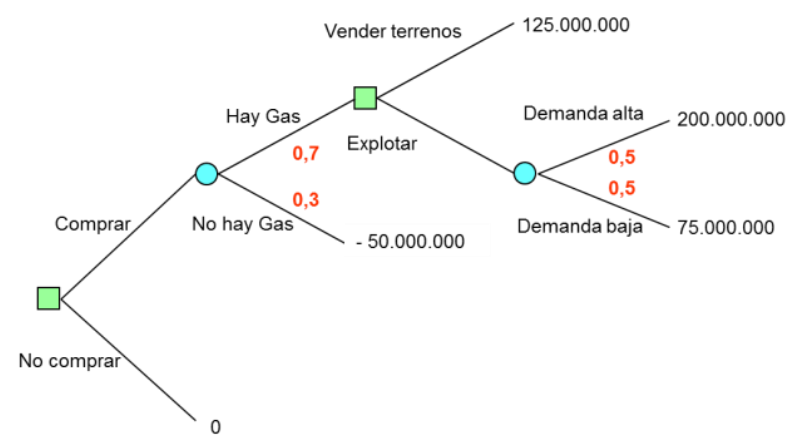

Paso 6 - Resuelva el árbol de decisión de derecha a izquierda. Dado que la etapa final es probabilista debe aplicar el criterio de la esperanza matemática con el objetivo de determinar el beneficio esperado.

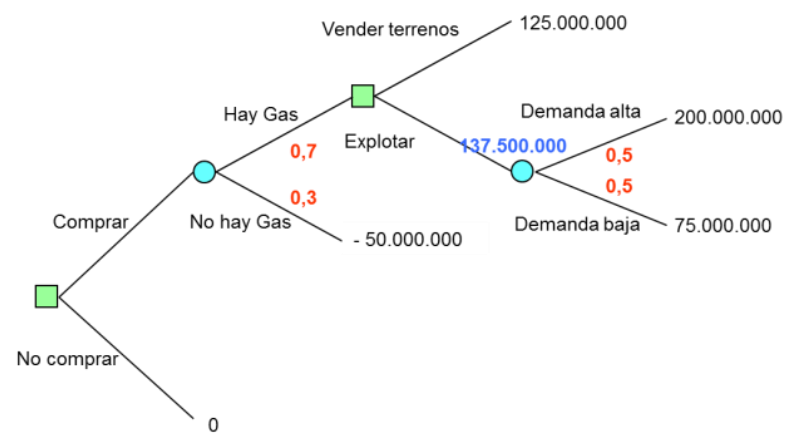

$(200.000 .000 \times 0,5)+(75.000 .000 \times 0,5)=137.500 .000$ euros 
Paso 7 - Resuelva la etapa anterior. Dado que dicha etapa es determinista y que los valores que ha calculado son beneficios, debe elegir la alternativa cuyo beneficio sea mayor y colocar el resultado encima del nudo correspondiente.

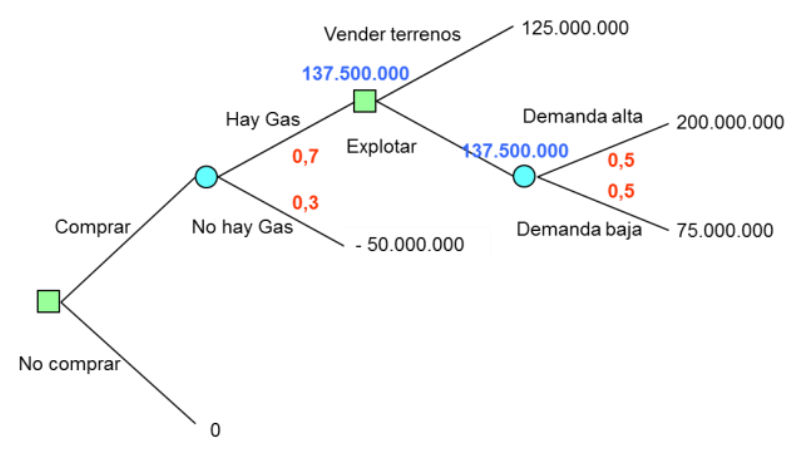

Paso 8 - Resuelva las dos últimas etapas. La etapa penúltima es probabilista por lo que debe aplicar el criterio de la esperanza matemática con el objetivo de determinar el beneficio esperado.

$$
(137.500 .000 \times 0,7)+((-50.000 .000) \times 0,3)=81.250 .000 \text { euros }
$$

Finalmente resolviendo la última etapa, elige la alternativa cuyo beneficio sea mayor dado que la etapa es determinista y los valores calculados beneficios esperados.

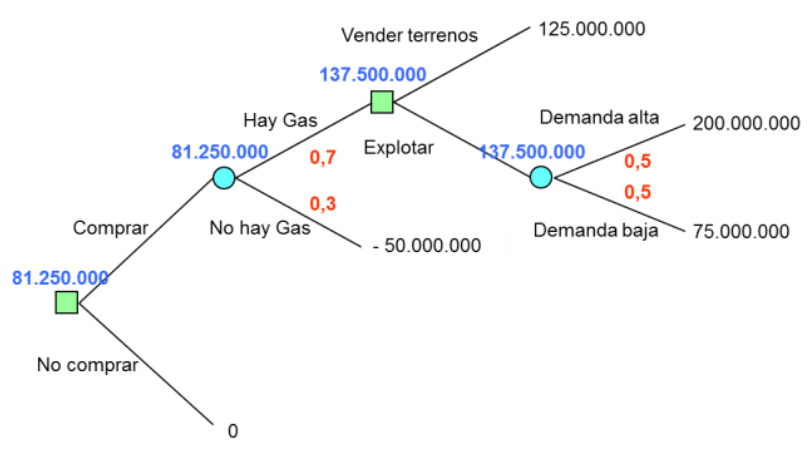

La decisión que debe tomar la empresa es la de comprar los terrenos, esperando obtener unos beneficios de 81.250 .000 euros. Si en los terrenos se encuentra gas, la decisión que deberá adoptar la empresa es la de explotar el gas contenido en dichos terrenos. 


\section{Ejercicio 18}

La siguiente matriz muestra los beneficios para cada alternativa de decisión, así como las probabilidades a priori de cada estado de la naturaleza.

\begin{tabular}{|l|c|c|c|c|}
\cline { 2 - 5 } \multicolumn{1}{c|}{} & \multicolumn{4}{c|}{ Estados de la naturaleza } \\
\cline { 2 - 5 } \multicolumn{1}{c|}{} & Estado 1 & Estado 2 & Estado 3 & Estado 4 \\
\hline Alternativa 1 & 100 & 90 & -20 & -45 \\
\hline Alternativa 2 & 85 & 80 & 10 & -20 \\
\hline Alternativa 3 & 0 & 70 & 90 & 60 \\
\hline Alternativa 4 & -30 & 0 & 40 & 65 \\
\hline Alternativa 5 & -35 & -10 & 85 & 120 \\
\hline & $15 \%$ & $30 \%$ & $10 \%$ & $45 \%$ \\
\hline
\end{tabular}

Determine la mejor decisión aplicando los criterios:

1. Pesimista.

2. Optimista.

3. Laplace.

4. Pesimista y Laplace a la matriz de costes de oportunidad.

5. Beneficio máximo esperado.

6. Calcule el valor esperado de la información perfecta.

\section{Solución:}

\section{Criterio pesimista}

Maximizar $\{$ Mínimo $\{$ Beneficio $\}\}=$ Minimizar $\{$ Máxima $\{$ Pérdida $\}\}$

\begin{tabular}{|c|c|c|c|c|c|}
\cline { 2 - 5 } \multicolumn{1}{c|}{} & \multicolumn{4}{c|}{ Estados de la naturaleza } & Mínimo \\
\cline { 2 - 5 } \multicolumn{1}{c|}{} & Estado 1 & Estado 2 & Estado 3 & Estado 4 & \{Beneficio\} \\
\hline Alternativa 1 & 100 & 90 & -20 & -45 & -45 \\
\hline Alternativa 2 & 85 & 80 & 10 & -20 & -20 \\
\hline Alternativa 3 & 0 & 70 & 90 & 60 & 0 \\
\hline Alternativa 4 & -30 & 0 & 40 & 65 & -30 \\
\hline Alternativa 5 & -35 & -10 & 85 & 120 & -35 \\
\hline
\end{tabular}

Maximizar $\{$ Mínimo $\{$ Beneficio $\}\}=$ Máx. $\{-45,-20,0,-30,-35\}=0$

Minimizar $\{$ Máxima $\{$ Pérdida $\}=$ Mín. $\{-45,-20,0,-30,-35\}=0$

La decisión óptima siguiendo el criterio pesimista es la alternativa 3. 


\section{Criterio optimista}

Maximizar \{Máximo \{Beneficio\}\}

\begin{tabular}{|c|c|c|c|c|c|}
\cline { 2 - 5 } \multicolumn{1}{c|}{} & \multicolumn{4}{c|}{ Estados de la naturaleza } & Mínimo \\
\cline { 2 - 5 } \multicolumn{1}{c|}{} & Estado 1 & Estado 2 & Estado 3 & Estado 4 & Beneficio\} \\
\hline Alternativa 1 & 100 & 90 & -20 & -45 & 100 \\
\hline Alternativa 2 & 85 & 80 & 10 & -20 & 85 \\
\hline Alternativa 3 & 0 & 70 & 90 & 60 & 90 \\
\hline Alternativa 4 & -30 & 0 & 40 & 65 & 65 \\
\hline Alternativa 5 & -35 & -10 & 85 & 120 & 120 \\
\hline
\end{tabular}

Maximizar \{Máximo \{Beneficio\}\}

Máx. $\{100,85,90,65,120\}=120$

La decisión óptima siguiendo el criterio optimista es la alternativa 5.

\section{Criterio Laplace}

Criterio de Laplace (Criterio equiprobable): Todos los estados de la naturaleza tienen la misma probabilidad. En este caso los estados de la naturaleza posibles son cuatro: estado 1, estado 2, estado 3 y estado 4. Dado que los estados de la naturaleza son cuatro y que todos deben tener la misma probabilidad (criterio de Laplace), la probabilidad a priori de cada uno de ellos es del $100 / 4=25 \%$.

\begin{tabular}{|c|c|c|c|c|c|}
\cline { 2 - 5 } \multicolumn{1}{c|}{} & \multicolumn{4}{c|}{ Estados de la naturaleza } & Valor esperado \\
\cline { 2 - 5 } \multicolumn{1}{c|}{} & Estado 1 & Estado 2 & Estado 3 & Estado 4 & E[x] \\
\hline Alternativa 1 & 100 & 90 & -20 & -45 & 31,25 \\
\hline Alternativa 2 & 85 & 80 & 10 & -20 & 38,75 \\
\hline Alternativa 3 & 0 & 70 & 90 & 60 & 55,00 \\
\hline Alternativa 4 & -30 & 0 & 40 & 65 & 18,75 \\
\hline Alternativa 5 & -35 & -10 & 85 & 120 & 40,00 \\
\hline
\end{tabular}

Maximizar $\{$ Beneficio esperado\}

Máx. $\{31,38,55,18,40\}=55,00$

La decisión óptima siguiendo el criterio Laplace es la alternativa 3. 


\section{Pesimista y Laplace a la matriz de costes de oportunidad}

Coste de oportunidad: es el coste de no haber elegido la alternativa óptima. Por ejemplo, si se diera el estado 1 resulta evidente que la alternativa óptima que debiera haberse elegido es la alternativa 1 dado que es la que proporciona el máximo beneficio si se da el estado 1, ahora bien, suponga que en lugar de haber elegido la alternativa 1 usted ha elegido la alternativa 2, en este caso en lugar de obtener un beneficio de 100 su beneficio será tan solo de 85, es decir, ha dejado de ganar $85-100=-15$ por no haber elegido la alternativa óptima, éste es pues su coste de oportunidad, en este caso presentado como ejemplo.

\section{Matriz de costes de oportunidad}

\begin{tabular}{|c|c|c|c|c|}
\cline { 2 - 5 } \multicolumn{1}{c|}{} & \multicolumn{4}{c|}{ Estados de la naturaleza } \\
\cline { 2 - 5 } \multicolumn{1}{c|}{} & Estado 1 & Estado 2 & Estado 3 & Estado 4 \\
\hline Alternativa 1 & 0 & 90 & -110 & -165 \\
\hline Alternativa 2 & -15 & -10 & -80 & -140 \\
\hline Alternativa 3 & -100 & -20 & 0 & -60 \\
\hline Alternativa 4 & -130 & -90 & -50 & -55 \\
\hline Alternativa 5 & -135 & -100 & -5 & 0 \\
\hline & $15 \%$ & $30 \%$ & $10 \%$ & $45 \%$ \\
\cline { 2 - 5 } & & & & \\
\end{tabular}

Aplicando el criterio pesimista a la matriz de costes de oportunidad, resulta:

Maximizar $\{$ Mínimo $\{$ Beneficio $\}\}=$ Minimizar $\{$ Máxima $\{$ Pérdida $\}\}$

\begin{tabular}{|c|c|c|c|c|c|}
\hline & \multicolumn{4}{|c|}{ Estados de la naturaleza } & \multirow{2}{*}{$\begin{array}{c}\text { Mínimo } \\
\{\text { Beneficio\} }\end{array}$} \\
\hline & Estado 1 & Estado 2 & Estado 3 & Estado 4 & \\
\hline Alternativa 1 & 0 & 90 & -110 & -165 & -165 \\
\hline Alternativa 2 & -15 & -10 & -80 & -140 & -140 \\
\hline Alternativa 3 & -100 & -20 & 0 & -60 & -100 \\
\hline Alternativa 4 & -130 & -90 & -50 & -55 & -130 \\
\hline Alternativa 5 & -135 & -100 & -5 & 0 & -135 \\
\hline
\end{tabular}

Maximizar $\{$ Mínimo $\{$ Beneficio\}\}

Máx. $\{-165,-140,-100,-130,-135\}=-100$

Minimizar \{Máxima \{Pérdida\}\}

Mín. $\{-165,-140,-100,-130,-135\}=-100$

La decisión óptima siguiendo el criterio pesimista es la alternativa 3. 
Por su parte, aplicando el criterio de Laplace a la matriz de costes de oportunidad:

Criterio de Laplace (Criterio equiprobable): Todos los estados de la naturaleza tienen la misma probabilidad. Dado que en este caso los estados de la naturaleza son cuatro, y que todos deben tener la misma probabilidad (criterio de Laplace), la probabilidad $a$ priori de cada uno de ellos es del $100 / 4=$ $25 \%$.

\begin{tabular}{|l|c|c|c|c|c|}
\cline { 2 - 5 } \multicolumn{1}{c|}{} & \multicolumn{4}{c|}{ Estados de la naturaleza } & Valor esperado \\
\cline { 2 - 5 } \multicolumn{1}{c|}{} & Estado 1 & Estado 2 & Estado 3 & Estado 4 & \\
\hline Alternativa 1 & 0 & 90 & -110 & -165 & $-46,25$ \\
\hline Alternativa 2 & -15 & -10 & -80 & -140 & $-61,25$ \\
\hline Alternativa 3 & -100 & -20 & 0 & -60 & $-45,00$ \\
\hline Alternativa 4 & -130 & -90 & -50 & -55 & $-81,25$ \\
\hline Alternativa 5 & -135 & -100 & -5 & 0 & $-60,00$ \\
\hline & $25 \%$ & $25 \%$ & $25 \%$ & $25 \%$ & \multicolumn{1}{c|}{} \\
\cline { 2 - 5 } & & & \multicolumn{3}{c}{}
\end{tabular}

Minimizar $\{$ Coste esperado\}

Mín. $\{46,61,45,81,60\}=45,00$

La decisión óptima siguiendo el criterio Laplace es la alternativa 3.

\section{Beneficio máximo esperado}

\section{Maximizar \{Beneficio esperado\}}

\begin{tabular}{|l|c|c|c|c|c|}
\cline { 2 - 5 } \multicolumn{1}{c|}{} & \multicolumn{4}{c|}{ Estados de la naturaleza } & Valor esperado \\
\cline { 2 - 5 } \multicolumn{1}{c|}{} & Estado 1 & Estado 2 & Estado 3 & Estado 4 & E[x] \\
\hline Alternativa 1 & 100 & 90 & -20 & -45 & 19,75 \\
\hline Alternativa 2 & 85 & 80 & 10 & -20 & 28,75 \\
\hline Alternativa 3 & 0 & 70 & 90 & 60 & 57,00 \\
\hline Alternativa 4 & -30 & 0 & 40 & 65 & 28,75 \\
\hline Alternativa 5 & -35 & -10 & 85 & 120 & 54,25 \\
\hline & $25 \%$ & $25 \%$ & $25 \%$ & $25 \%$ & \multicolumn{1}{c}{} \\
\cline { 2 - 5 } & & \multicolumn{3}{c}{}
\end{tabular}

Maximizar Beneficio esperado\}

Máx. $\{19,28,57,28,54\}=57,00$

La decisión óptima siguiendo el criterio optimista es la alternativa 3. 


\section{Calcule el valor esperado de la información perfecta}

Paso 1 - Enumere las diferentes alternativas de decisión.

Obtener información adicional sobre los estados de la naturaleza.

NO obtener información adicional sobre los estados de la naturaleza.

En el caso de que opte por no reunir información adicional, debe decidir que alternativa resulta óptima.

Paso 2 - Enumere para cada una de las alternativas de decisión, los estados de la naturaleza asociados a la misma.

\begin{tabular}{|c|c|c|}
\hline \multicolumn{2}{|c|}{ Alternativas } & Estados de la naturaleza \\
\hline \multicolumn{2}{|c|}{ Con información } & Estado de la naturaleza 1, 2, 3 o 4 \\
\hline \multirow{5}{*}{ Sin información } & Alternativa 1 & Estado de la naturaleza 1, 2, 3 o 4 \\
\hline & Alternativa 2 & Estado de la naturaleza 1, 2, 3 o 4 \\
\hline & Alternativa 3 & Estado de la naturaleza 1, 2, 3 o 4 \\
\hline & Alternativa 4 & Estado de la naturaleza 1, 2, 3 o 4 \\
\hline & Alternativa 5 & Estado de la naturaleza $1,2,3 \circ 4$ \\
\hline
\end{tabular}

Obtenida la información, debe decidir que alternativa lleva a cabo, tras lo cual los estados de la naturaleza pueden ser: estado 1 , estado 2 , estado 3 , o estado 4 .

Paso 3 - Explicite el árbol de decisión.

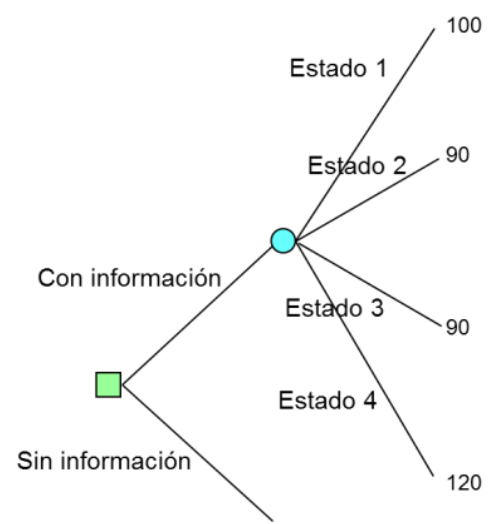

Dado que la información es perfecta, no es necesario explicitar todo el árbol. Por ejemplo, si el informador dice que ocurrirá el estado 1, al tratarse de información perfecta (informador 100\% fiable), la alternativa elegida será la 1 dado que es la que proporciona el beneficio mayor para el estado 1, y así sucesivamente para el resto de casos en que el informador diga que se cumplirá el estado 2, 3, o 4. 
Paso 4 - Asigne las probabilidades a priori de cada uno de los estados de la naturaleza.

La probabilidad a priori de cada estado de la naturaleza viene dada en el enunciado del ejercicio.

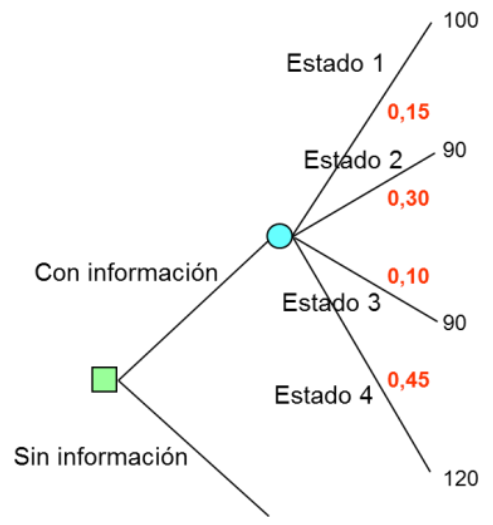

Paso 5 - Resuelva el árbol de decisión de derecha a izquierda. Dado que la etapa final es probabilista debe aplicar el criterio de la esperanza matemática con el objetivo de determinar el beneficio esperado de cada alternativa de decisión.

$$
(100 \times 0,15)+(90 \times 0,30)+(90 \times 0,10)+(120 \times 0,45)=105
$$

Coloque el resultado encima del nudo correspondiente.

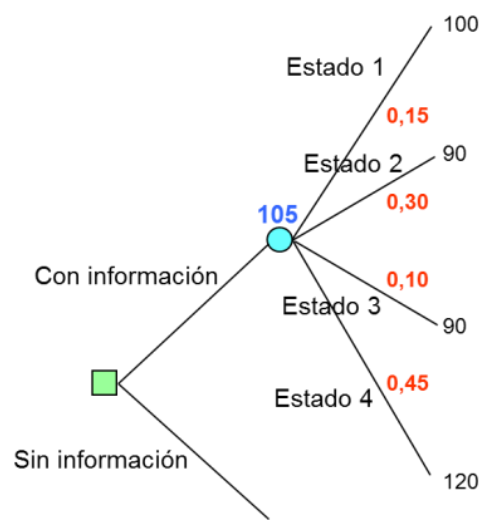


Paso 6 - Resuelva la última etapa, dado que es determinista debe elegir la decisión cuyo beneficio sea mayor. El beneficio esperado sin información lo ha obtenido en el apartado anterior (apartado 5) de este mismo ejercicio.

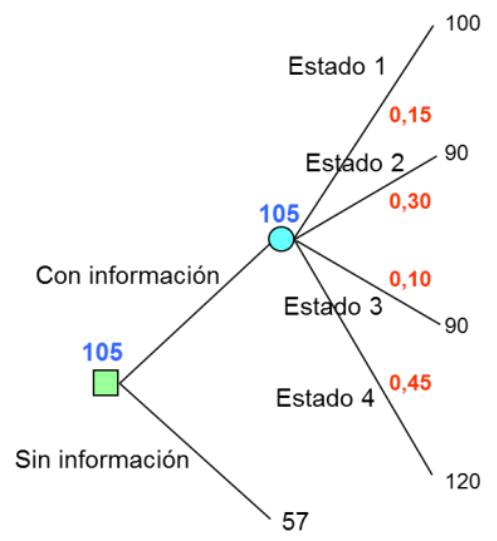

La decisión que debe tomar el empresario es solicitar información adicional, esperando obtener un beneficio de 105 unidades monetarias.

El beneficio esperado con información adicional es de 105, mientras que el beneficio esperado sin información adicional asciende a 57, de donde el valor de la información perfecta asciende a:

$$
105-57=48 \text { unidades monetarias }
$$

Como máximo estaría dispuesto a pagar 48 por dicha información. 


\section{Ejercicio 19}

Una empresa está considerando la posibilidad de contratar un experto en ingeniería industrial para la planificación de su estrategia de operaciones. Una adecuada planificación supondría a la empresa unos beneficios de 1.000 .000 de euros, mientras que si la planificación no fuera correctamente elaborada, la empresa estima unas pérdidas de 400.000 euros. El director industrial estima que la probabilidad de que el experto realice una adecuada planificación es del 75\%. Antes de contratar al experto, la empresa tiene la opción de realizar unas pruebas para determinar la idoneidad del candidato, dichas pruebas tienen una fiabilidad del $80 \%$ a la hora de determinar el éxito potencial del candidato en la realización de la planificación de las operaciones de la empresa. Determine la decisión óptima para la empresa, así como el coste que puede asumir la empresa por realizar la prueba de idoneidad.

\section{Solución:}

Paso 1 - Enumere las diferentes alternativas de decisión.

Contratar al experto.

NO contratar al experto.

Hacer pruebas para determinar la idoneidad del candidato.

Paso 2 - Enumere para cada una de las alternativas de decisión, los estados de la naturaleza asociados a la misma.

\begin{tabular}{|c|c|}
\hline Alternativas & Estados de la naturaleza \\
\hline Contratar al experto & $\begin{array}{c}\text { Planificación correcta } \\
\text { Planificación incorrecta }\end{array}$ \\
\hline No contratar al experto & $\begin{array}{c}\text { Candidato idóneo } \\
\text { Candidato no idóneo }\end{array}$ \\
\hline
\end{tabular}

Obtenida la información de la prueba, sea ésta que el candidato es o no idóneo, debe decidir si contrata o no contrata al experto, tras lo cual la planificación podrá ser correcta o incorrecta. 
Paso 3 - Explicite el árbol de decisión.

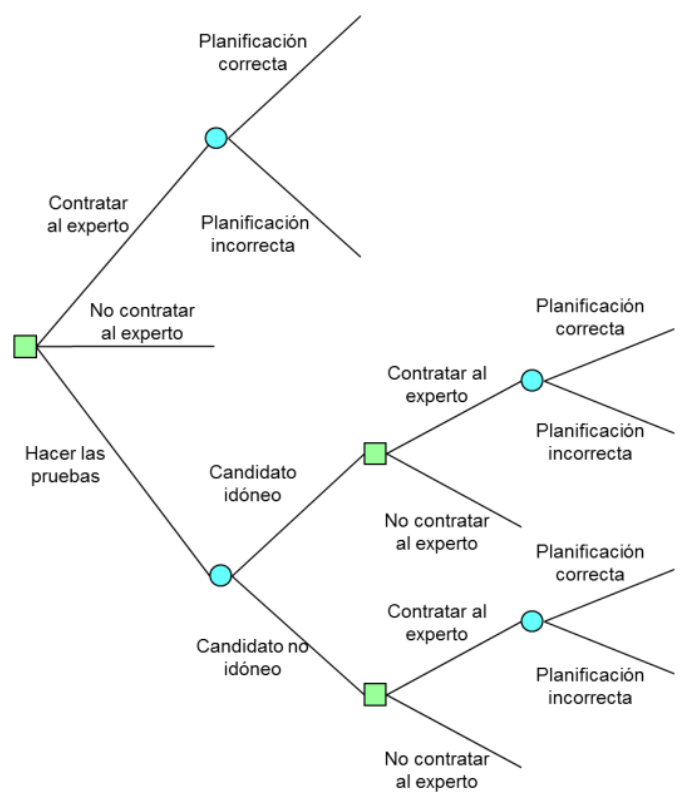

Paso 4 - Asigne las probabilidades de cada uno de los estados de la naturaleza. En este caso se trata de probabilidades a posteriori, por lo que debe utilizar el teorema de Bayes para calcular dichas probabilidades.

Para la aplicación del teorema de Bayes puede utilizar el árbol que se muestra seguidamente. Los estados de la naturaleza son que la planificación sea o no correcta, y los acontecimientos, que el candidato es idóneo o no.

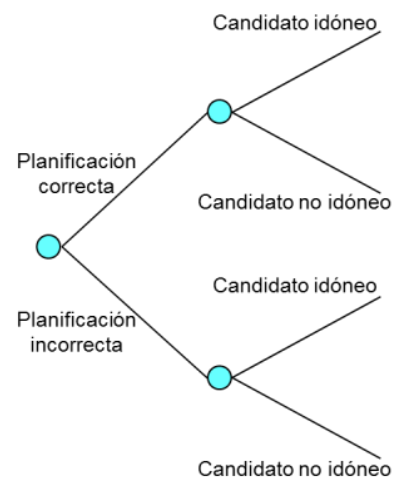


La probabilidad a priori de que la planificación sea correcta es del 75\%, según el enunciado del ejercicio. De igual forma, según señala el enunciado del ejercicio, las probabilidades condicionales vienen dadas por los siguientes valores:

$$
\begin{gathered}
P(\text { Candidato idóneo / Planificación correcta })=0,8 \\
P(\text { Candidato no idóneo / Planificación correcta })=0,2 \\
P(\text { Candidato idóneo / Planificación incorrecta })=0,2 \\
P(\text { Candidato no idóneo / Planificación incorrecta })=0,8
\end{gathered}
$$

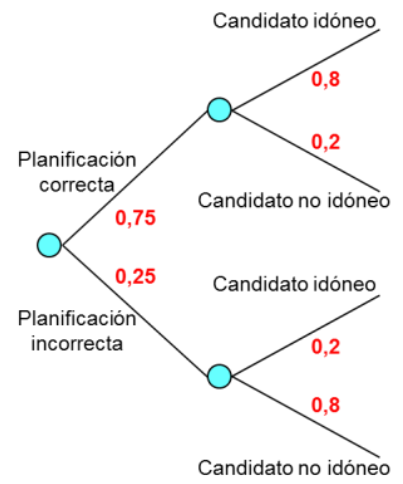

De donde, la probabilidad a priori de cada uno de los acontecimientos:

$\mathrm{P}($ Candidato idóneo $)=[\mathrm{P}($ Planificación correcta $) \times \mathrm{P}($ Candidato idóneo / Planificación correcta $)]+$ $[P($ Planificación incorrecta) $\times \mathrm{P}($ Candidato idóneo / Planificación incorrecta $)]=[0,75 \times 0,8]+[0,25 \times 0,2]$ $=0,65$

$\mathrm{P}($ Candidato no idóneo $)=[\mathrm{P}($ Planificación correcta $) \times \mathrm{P}($ Candidato no idóneo $/$ Planificación correcta $)]+$ $[\mathrm{P}$ (Planificación incorrecta) $\times \mathrm{P}($ Candidato no idóneo / Planificación incorrecta) $]=[0,75 \times 0,2]+[0,25 \times$ $0,8]=0,35$

A continuación, mediante la aplicación del teorema de Bayes determine las probabilidades a posteriori de cada uno de los estados de la naturaleza.

$$
\begin{gathered}
\mathrm{P}(\text { Planificación correcta / Candidato idóneo })=\frac{\mathrm{P}(\text { Planificac ión correcta }) \times \mathrm{P}(\text { Candidato idóneo } / \text { Planificac ión correcta })}{\mathrm{P}(\text { Candidato idóneo })} \\
\mathrm{P}(\text { Planificación correcta / Candidato idóneo })=\frac{0,75 \times 0,8}{0,65}=0,923
\end{gathered}
$$


$\mathrm{P}($ Planificac ión incorrecta / Candidato idóneo $)=\frac{\mathrm{P}(\text { Planificación incorrecta }) \times \mathrm{P}(\text { Candidato idóneo } / \text { Planificación incorrecta })}{\mathrm{P}(\text { Candidato idóneo })}$

$\mathrm{P}($ Planificación incorrecta / Candidato idóneo $)=\frac{0,25 \times 0,2}{0,65}=0,077$

$\mathrm{P}($ Planificac ión correcta / Candidato no idóneo $)=\frac{\mathrm{P}(\text { Planificac ión correcta }) \times \mathrm{P}(\text { Candidato no idóneo } / \text { Planificac ión correcta })}{\mathrm{P}(\mathrm{C} \text { ) }}$ $\mathrm{P}($ Candidato no idóneo $)$

$\mathrm{P}($ Planificación correcta / Candidato no idóneo $)=\frac{0,75 \times 0,2}{0,35}=0,429$

$\mathrm{P}($ Planificac ión incorrecta / Candidato no idóneo $)=\frac{\mathrm{P}(\text { Planificac ión incorrecta }) \times \mathrm{P}(\text { Candidato no idóneo } / \text { Planificac ión incorrecta })}{\mathrm{P}(\mathrm{C} \text { ) }}$ $\mathrm{P}($ Candidato no idóneo $)$

$\mathrm{P}($ Planificación incorrecta / Candidato no idóneo $)=\frac{0,25 \times 0,8}{0,35}=0,571$

\section{De donde, el árbol de decisión incluyendo las probabilidades:}

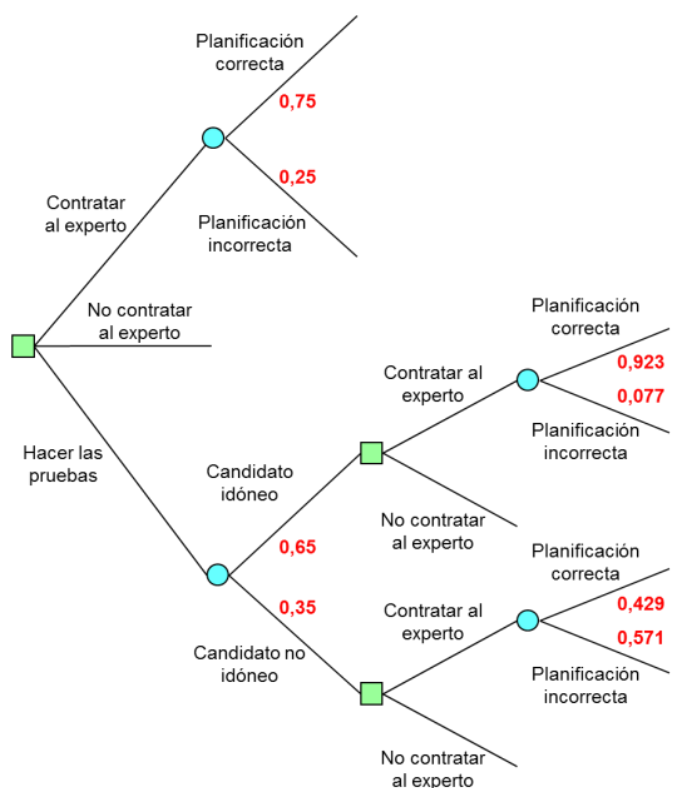


Paso 5 - Calcule el beneficio de cada una de las ramas del árbol.

Los beneficios esperados en cada caso, vienen dados en el enunciado del ejercicio: una planificación correcta supone unos beneficios estimados de 1.000 .000 de euros, mientras que una planificación incorrecta presume unas pérdidas de 400.000 euros.

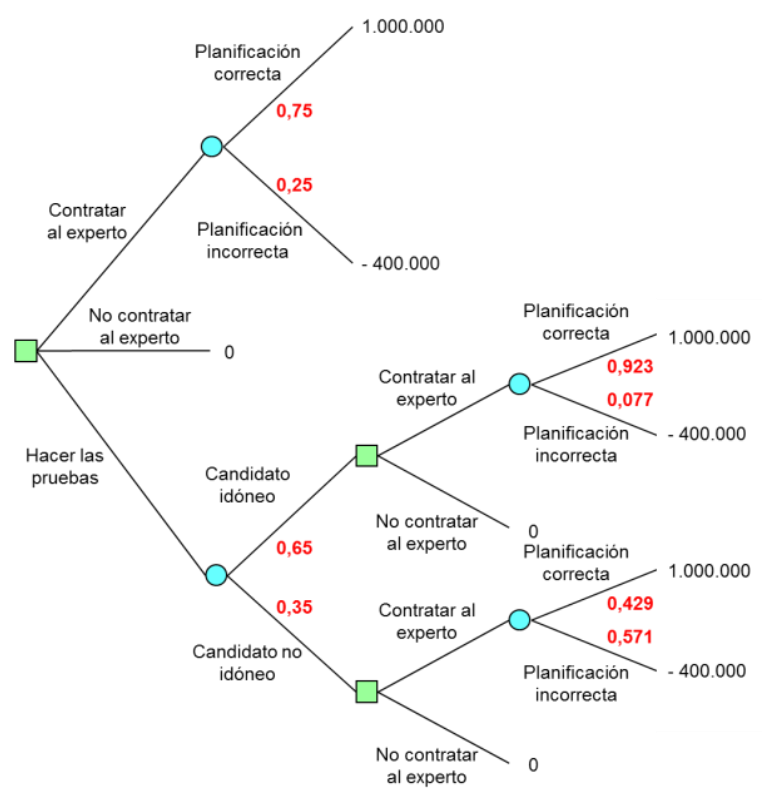

Paso 6 - Resuelva el árbol de decisión de derecha a izquierda. Dado que la etapa final es probabilista debe aplicar el criterio de la esperanza matemática con el objetivo de determinar el beneficio esperado de cada alternativa de decisión.

$$
\begin{gathered}
(1.000 .000 \times 0,75)+((-400.000) \times 0,25)=650.000 \text { euros } \\
(1.000 .000 \times 0,923)+((-400.000) \times 0,077)=892.200 \text { euros } \\
(1.000 .000 \times 0,429)+((-400.000) \times 0,571)=200.600 \text { euros }
\end{gathered}
$$

Coloque estos resultados en el árbol de decisión encima del nudo correspondiente. 


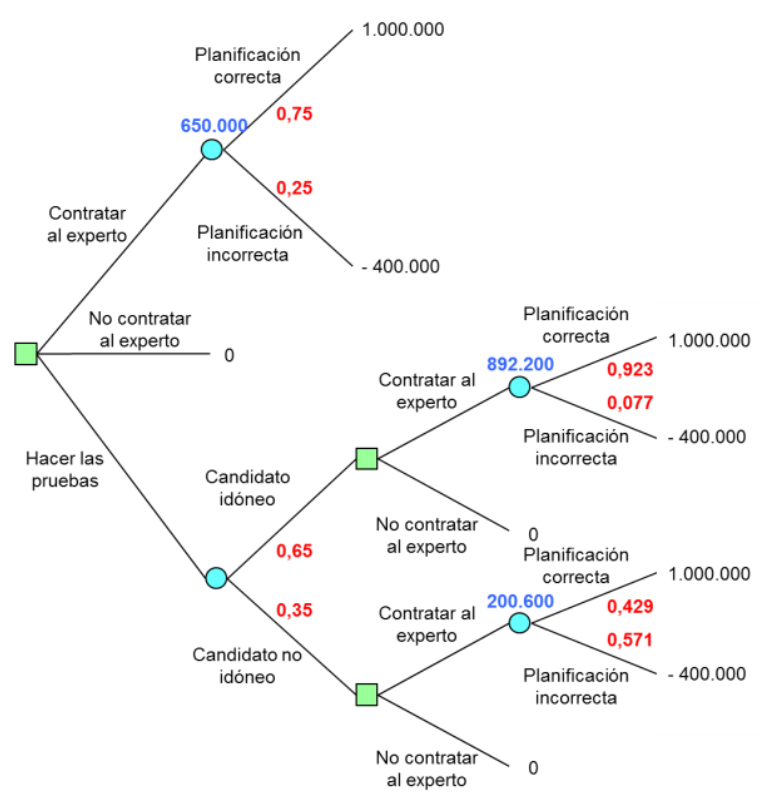

Paso 7 - Resuelva la etapa anterior. Dado que dicha etapa es determinista y que los valores que ha calculado son beneficios, debe elegir la alternativa cuyo beneficio sea mayor y colocar el resultado encima del nudo correspondiente.

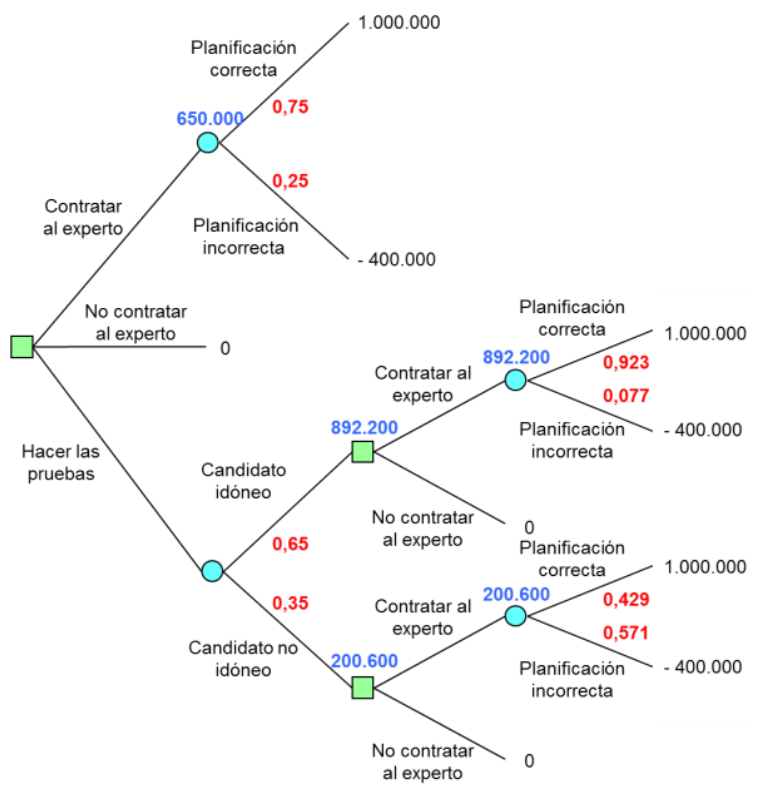


Paso 8 - Resuelva las dos últimas etapas. La penúltima etapa es probabilista por lo que debe aplicar el criterio de la esperanza matemática con el objetivo de determinar el beneficio esperado.

$$
(892.200 \times 0,65)+(200.600 \times 0,35)=650.140 \text { euros }
$$

La última etapa es determinista, debe pues elegir la alternativa cuyo beneficio sea mayor y colocar el resultado encima del nudo correspondiente.

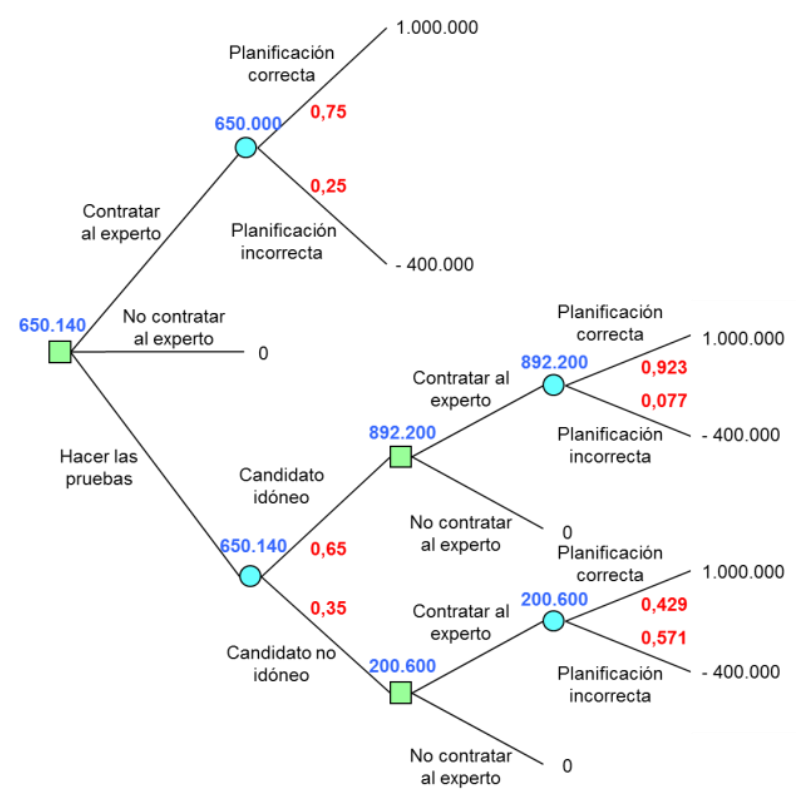

La decisión óptima para la empresa es la de hacer las pruebas para determinar la idoneidad del candidato, en caso de que el candidato sea idóneo debe contratarlo, por el contrario, si el candidato no es idóneo también debe contratarlo. Con esta decisión el beneficio esperado es de 650.140 euros.

El valor de la información = 650.140 - 650.000 = 140 euros es el valor de la información que aportan las pruebas para determinar la idoneidad del candidato. El coste que puede asumir la empresa por realizar las pruebas de idoneidad es de cómo máximo 140 euros. 


\section{Ejercicio 20}

Una empresa está considerando ampliar sus instalaciones para hacer frente a la demanda de sus productos. Las alternativas de que dispone la empresa son: construir una nueva fábrica, ampliar la fábrica actual, o no hacer nada. Existe un 30\% de probabilidades de que la demanda prevista para los próximos años aumente, un $60 \%$ de probabilidades de que se mantenga igual, y un $10 \%$ de probabilidades de que entre en recesión. Determine la opción más rentable para la empresa, siendo los beneficios estimados los que muestra la tabla.

\begin{tabular}{|c|c|c|c|}
\cline { 2 - 4 } \multicolumn{1}{c|}{} & \multicolumn{3}{c|}{ Demanda } \\
\cline { 2 - 4 } \multicolumn{1}{c|}{} & Aumenta & Estable & Disminuye \\
\hline Construir fábrica nueva & 8.000 .000 & 5.000 .000 & -5.000 .000 \\
\hline Ampliar fábrica actual & 6.500 .000 & 2.000 .000 & -3.000 .000 \\
\hline No hacer nada & 2.000 .000 & 1.000 .000 & -2.000 .000 \\
\hline
\end{tabular}

\section{Solución:}

Paso 1 - Enumere las diferentes alternativas de decisión.

Construir una nueva fábrica.

Ampliar la fábrica actual.

No hacer nada.

Paso 2 - Enumere para cada una de las alternativas de decisión, los estados de la naturaleza asociados a la misma.

\begin{tabular}{|c|c|}
\hline Alternativas & Estados de la naturaleza \\
\hline Construir fábrica nueva & $\begin{array}{l}\text { Demanda aumenta } \\
\text { Demanda estable } \\
\text { Demanda disminuye }\end{array}$ \\
\hline Ampliar fábrica & $\begin{array}{l}\text { Demanda aumenta } \\
\text { Demanda estable } \\
\text { Demanda disminuye }\end{array}$ \\
\hline No hacer nada & $\begin{array}{l}\text { Demanda aumenta } \\
\text { Demanda estable } \\
\text { Demanda disminuye }\end{array}$ \\
\hline
\end{tabular}


Paso 3 - Explicite el árbol de decisión.

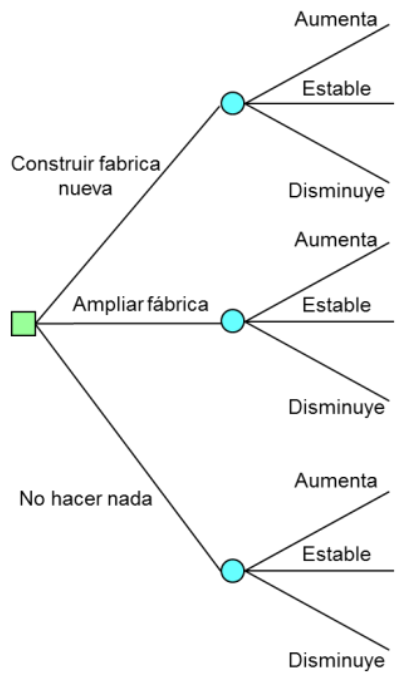

Paso 4 - Asigne las probabilidades a priori de cada uno de los estados de la naturaleza.

La probabilidad a priori de cada nivel de demanda viene dada en el enunciado del ejercicio: demanda aumente $30 \%$ de probabilidades, demanda se mantenga estable $60 \%$ de posibilidades, y demanda disminuya $10 \%$ de eventualidades.

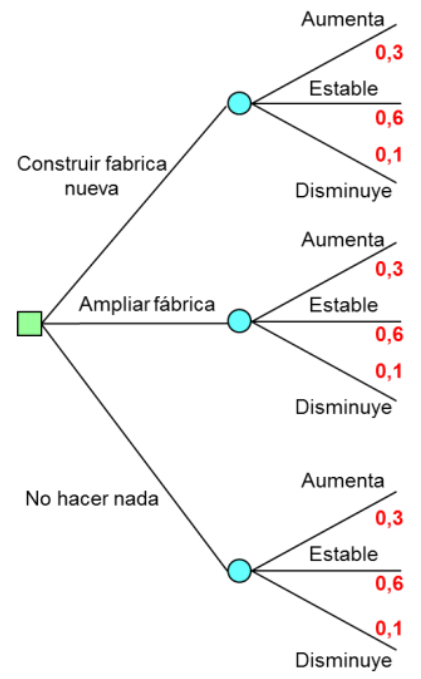


Paso 5 - Calcule el beneficio de cada una de las ramas del árbol.

El beneficio esperado para cada alternativa de decisión y nivel de demanda, viene dado en la tabla del enunciado del ejercicio.

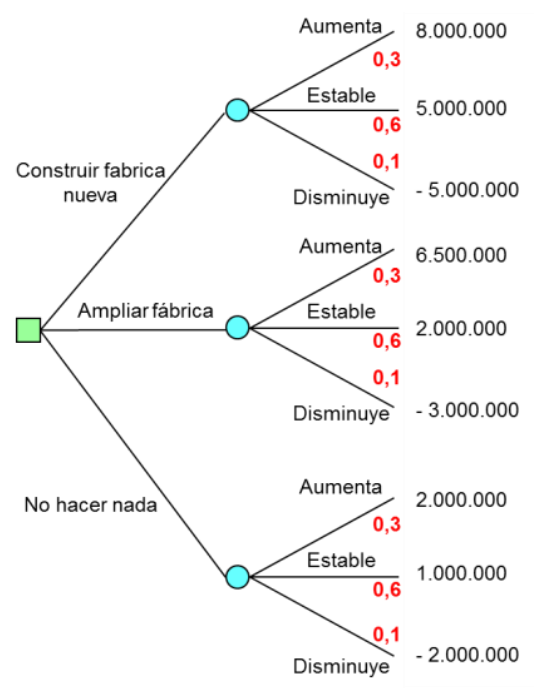

Paso 6 - Resuelva el árbol de decisión de derecha a izquierda. Dado que la etapa final es probabilista debe aplicar el criterio de la esperanza matemática con el objetivo de determinar el beneficio esperado.

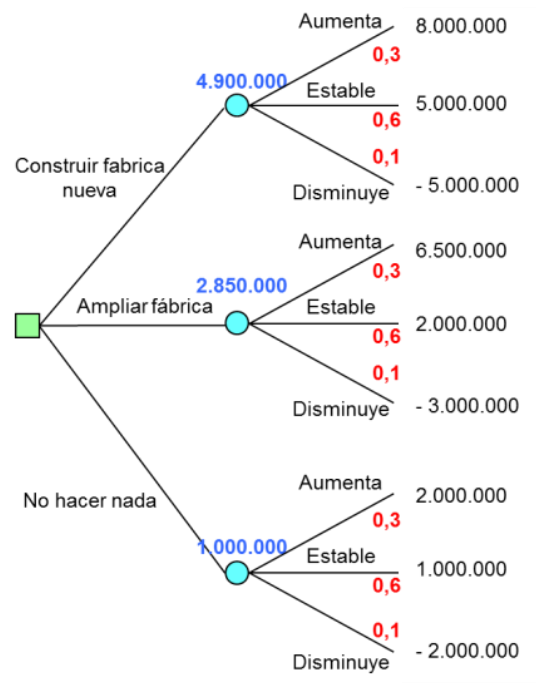




$$
\begin{aligned}
& (8.000 .000 \times 0,3)+(5.000 .000 \times 0,6)+((-5.000 .000) \times 0,1)=4.900 .000 \text { euros } \\
& (6.500 .000 \times 0,3)+(2.000 .000 \times 0,6)+((-3.000 .000) \times 0,1)=2.850 .000 \text { euros } \\
& (2.000 .000 \times 0,3)+(1.000 .000 \times 0,6)+((-2.000 .000) \times 0,1)=1.000 .000 \text { euros }
\end{aligned}
$$

Paso 7 - Resuelva la etapa anterior. Dado que esta primera etapa es determinista y que los valores que ha calculado son beneficios, debe elegir la alternativa cuyo beneficio sea mayor y colocar el resultado encima del nudo correspondiente.

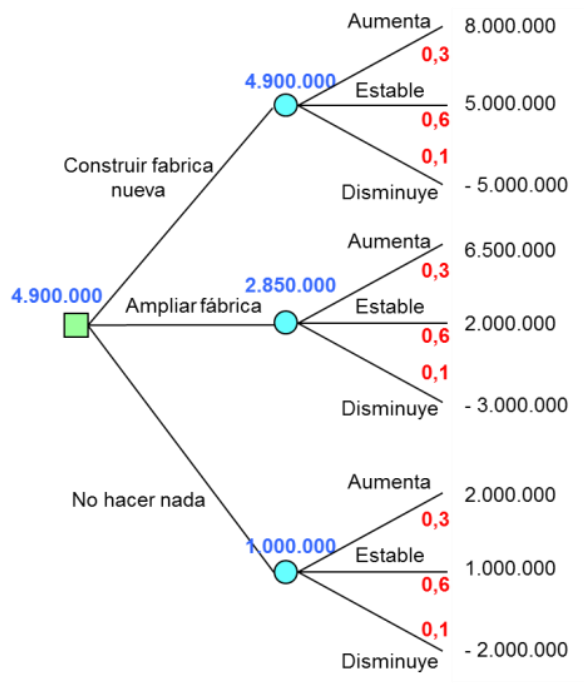

La opción más rentable para la empresa es la de construir una nueva fábrica, esperando alcanzar unos beneficios de 4.900 .000 euros. 


\section{Ejercicio 21}

Una empresa está estudiando el contrato de 600 euros semanales que tiene con su proveedor de servicios de mantenimiento. Desde la firma del contrato la media es de 2,5 averías semanales, entrañando cada fallo un coste de reparación de 1.000 euros. Las averías semanales de la empresa, antes de la firma del contrato, se muestran en la tabla.

\begin{tabular}{|c|c|c|c|c|c|c|c|}
\hline Averías & 0 & 1 & 2 & 3 & 4 & 5 & 6 \\
\hline Semanas que hubo estas averías & 9 & 10 & 12 & 16 & 24 & 18 & 11 \\
\hline
\end{tabular}

Ayude a la empresa a decidir si le conviene o no la renovación del contrato de mantenimiento con su actual proveedor.

\section{Solución:}

Paso 1 - Asigne las probabilidades a priori de cada uno de los estados de la naturaleza. La probabilidad (frecuencia relativa) de cada estado de la naturaleza viene dado por:

$$
\text { Frecuencia relativa }=\frac{\text { Frecuencia absoluta }}{\text { Número de casos }}
$$

Siendo el total de casos estudiados:

$$
9+10+12+16+24+18+11=100 \text { semanas }
$$

Así por ejemplo, en base a la historia pasada, la probabilidad de que en esta empresa se produzcan cero averías en una semana cualquiera es de:

$$
\text { Frecuencia relativa }=\frac{\text { Frecuencia absoluta }}{\text { Número de casos }}=\frac{9}{100} \frac{\text { semanas }}{\text { semanas }}=0,09 \rightarrow 9 \%
$$

\begin{tabular}{|c|c|c|c|c|c|c|c|}
\hline Averías & 0 & 1 & 2 & 3 & 4 & 5 & 6 \\
\hline Semanas & 9 & 10 & 12 & 16 & 24 & 18 & 11 \\
\hline Probabilidad & 0.09 & 0.10 & 0.12 & 0.16 & 0.24 & 0.18 & 0.11 \\
\hline
\end{tabular}

Paso 2 - Calcule el coste del mantenimiento antes y después de la firma del contrato con el proveedor de mantenimiento.

Aplicando el criterio de la esperanza matemática, el número esperado de averías por semana antes de la firma del contrato:

$$
(0 \times 0,09)+(1 \times 0,10)+(2 \times 0,12)+(3 \times 0,16)+(4 \times 0,24)+(5 \times 0,18)+(6 \times 0,11)=3,34 \text { averías/semana }
$$


Coste de las reparaciones antes de la firma del contrato:

3,34 averías/semana x 1.000 euros/avería = 3.340 euros/semana

Coste del servicio de mantenimiento actual tras la firma del contrato:

Coste del servicio + Coste de las reparaciones $=$

600 euros/semana $+(2,5$ averías/semana $\times 1.000$ euros/avería $)=3.100$ euros/semana

A la empresa le conviene renovar el contrato de mantenimiento con su actual proveedor, dado que con él se ahorra:

$$
3340-3100=240 \text { euros/semana }
$$




\section{Ejercicio 22}

Una empresa tiene dos opciones:

1. Producir la nueva línea de productos de la que acaba de dar a conocer los prototipos.

2. Antes de iniciar la producción, pedir a los ingenieros de producto que lleven a cabo un análisis del valor de la nueva línea de productos.

Con la primera opción la empresa esperar alcanzar unas ventas de 300.000 unidades con una probabilidad del 30\%, y de 150.000 unidades con una probabilidad del $70 \%$, siendo el precio unitario de venta de 600 euros. Por el contrario, si recurre a realizar el análisis del valor de la nueva línea de productos, las ventas esperadas son de 225.000 unidades con una probabilidad del 40\%, y de 140.000 unidades con una probabilidad del 60\%, siendo en este caso el precio unitario de venta de 900 euros. La empresa estima que el análisis del valor le ocasionará unos costes de 100.000 euros. Indique la decisión óptima que debe tomar la empresa.

\section{Solución:}

Paso 1 - Enumere las diferentes alternativas de decisión.

Producir la nueva línea de productos.

Análisis del valor de la nueva línea de productos.

Paso 2 - Enumere para cada una de las alternativas de decisión, los estados de la naturaleza asociados a la misma.

\begin{tabular}{|c|c|}
\hline Alternativas & Estados de la naturaleza \\
\hline Producir & $\begin{array}{l}\text { Vender } 300.000 \text { unidades } \\
\text { Vender } 150.000 \text { unidades }\end{array}$ \\
\hline Análisis del valor & $\begin{array}{l}\text { Vender } 225.000 \text { unidades } \\
\text { Vender } 140.000 \text { unidades }\end{array}$ \\
\hline
\end{tabular}

Paso 3 - Explicite el árbol de decisión.

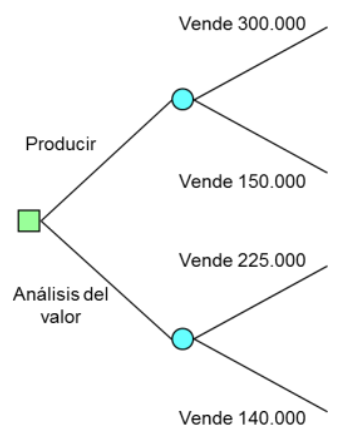


Paso 4 - Asigne las probabilidades a priori de cada uno de los estados de la naturaleza.

La probabilidad a priori de cada nivel de demanda viene dada en el enunciado del ejercicio: probabilidad del $30 \%$ de que la demanda sea de 300.000 unidades, probabilidad del $70 \%$ de que la demanda sea de 150.000 unidades, probabilidad del $40 \%$ de que la demanda sea de 225.000 unidades, y probabilidad del $60 \%$ de que la demanda sea de 140.000 unidades.

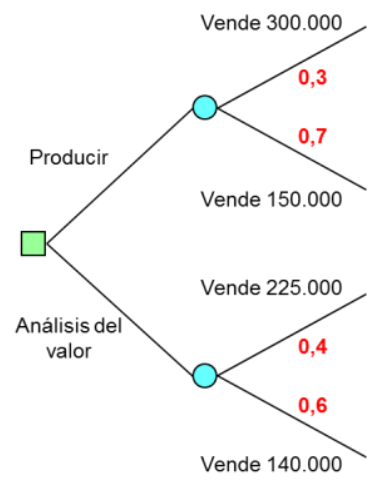

Paso 5 - Calcule el beneficio de cada una de las ramas del árbol.

300.000 unidades $\times 600$ euros/unidad $=180.000 .000$ euros

150.000 unidades $\times 600$ euros/unidad $=90.000 .000$ euros

225.000 unidades $\times 900$ euros/unidad $=202.500 .000$ euros

140.000 unidades $\times 900$ euros $/$ unidad $=126.000 .000$ euros

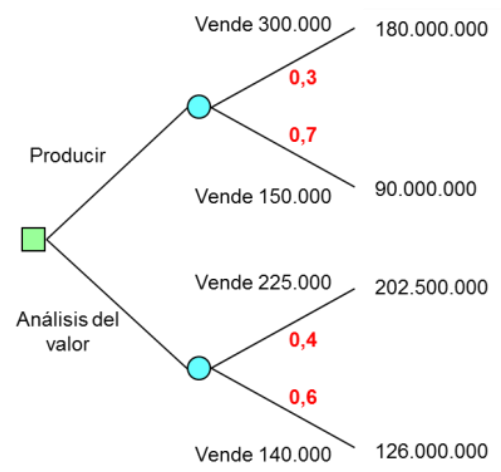


Paso 6 - Resuelva el árbol de decisión de derecha a izquierda. Dado que la etapa final es probabilista debe aplicar el criterio de la esperanza matemática con el objetivo de determinar el beneficio esperado.

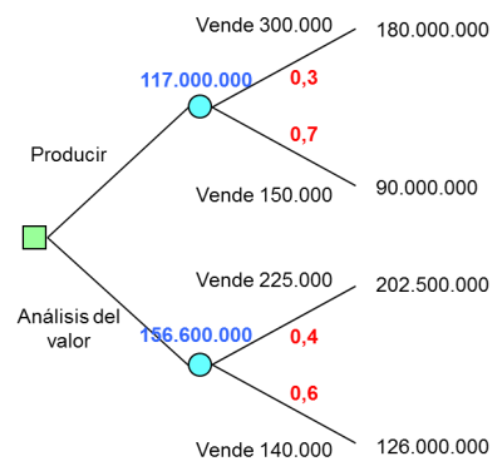

$$
\begin{aligned}
& (180.000 .000 \times 0,3)+(90.000 .000 \times 0,7)=117.000 .000 \text { euros } \\
& (202.500 .000 \times 0,4)+(126.000 .000 \times 0,6)=156.600 .000 \text { euros }
\end{aligned}
$$

Paso 7 - Resuelva la etapa anterior. Dado que esta primera etapa es determinista y que los valores que ha calculado son beneficios, debe elegir la alternativa cuyo beneficio sea mayor y colocar el resultado encima del nudo correspondiente.

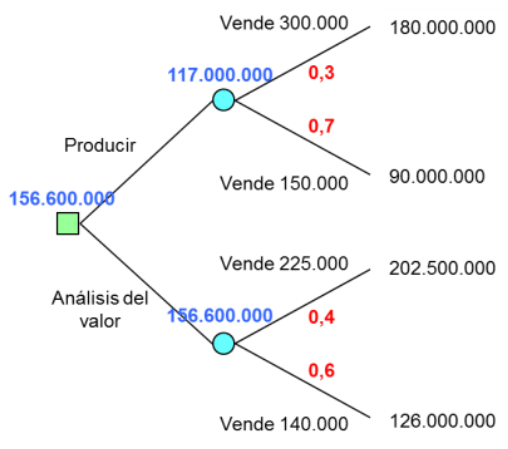

La decisión óptima que debe tomar la empresa es la de llevar a cabo el análisis del valor de la nueva línea de productos, esperando alcanzar unos beneficios de 156.600 .000 euros. 


\section{Ejercicio 23}

La dirección de una empresa dedicada a la fabricación y venta de cremosos helados, se está planteando la compra de una nueva máquina para la fabricación de su nuevo helado de chocolate con el perfil de uno de los participantes en un famoso concurso. Tres son los modelos de la máquina que hay en el mercado en función de la calidad (tipo 1, tipo 2 y tipo 3). Si dicho concursante gana el concurso los beneficios que presume la dirección de la empresa que se alcanzarán son de 70.000, 75.000 y 80.000 euros para cada modelo de máquina, si por el contrario el concursante resulta finalista, pero no ganador del concurso, los beneficios estimados son 65.000, 70.000 y 75.000 euros, pero si dicho concursante es expulsado antes de llegar a la final, los beneficios esperados son tan solo de 55.000, 60.000 y 65.000 euros, respectivamente. La dirección de la empresa, tras una ronda de consultas con familiares, amigos, clientes, etc., estima que la probabilidad de que dicho concursante acabe ganando el concurso es del 10\%, que llegue a finalista y no gane el concurso es también del 30\%, y que lo expulsen del concurso antes de llegar a la final del 60\%. Sugiera a la dirección de la empresa la máquina que debe adquirir.

\section{Solución:}

Paso 1 - Enumere las diferentes alternativas de decisión.

\section{Comprar máquina tipo 1.}

Comprar máquina tipo 2.

\section{Comprar máquina tipo 3.}

Paso 2 - Enumere para cada una de las alternativas de decisión, los estados de la naturaleza asociados a la misma.

\begin{tabular}{|c|c|}
\hline Alternativas & Estados de la naturaleza \\
\hline Tipo 1 & $\begin{array}{c}\text { Concursante ganador } \\
\text { Concursante finalista } \\
\text { Concursante expulsado }\end{array}$ \\
\hline Tipo 2 & $\begin{array}{c}\text { Concursante ganador } \\
\text { Concursante finalista } \\
\text { Concursante expulsado }\end{array}$ \\
\hline Tipo 3 & $\begin{array}{c}\text { Concursante ganador } \\
\text { Concursante finalista } \\
\text { Concursante expulsado }\end{array}$ \\
\hline
\end{tabular}


Paso 3 - Explicite el árbol de decisión.

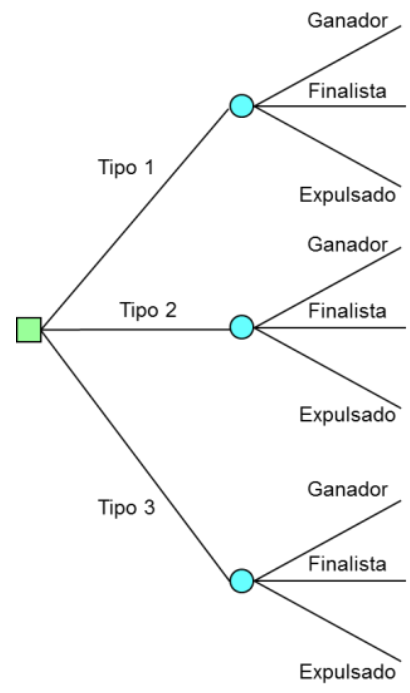

Paso 4 - Asigne las probabilidades a priori de cada uno de los estados de la naturaleza.

Las probabilidades a priori de cada estado de la naturaleza vienen dadas en el enunciado del ejercicio: probabilidad del $10 \%$ de que el concursante resulte ganador, probabilidad del $30 \%$ de que el concursante sea finalista, y probabilidad del $60 \%$ de que el concursante sea expulsado del concurso.

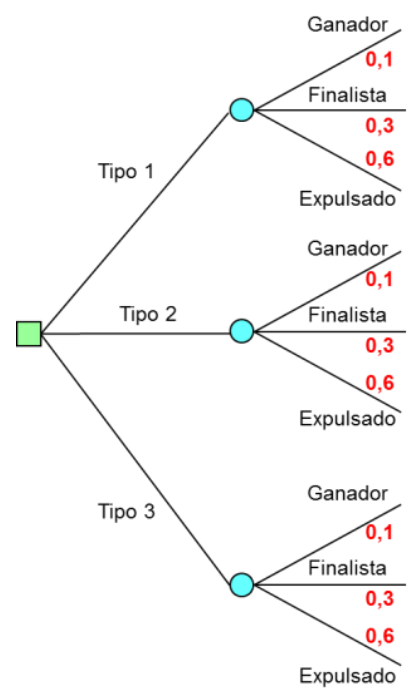


Paso 5 - Calcule el beneficio de cada una de las ramas del árbol.

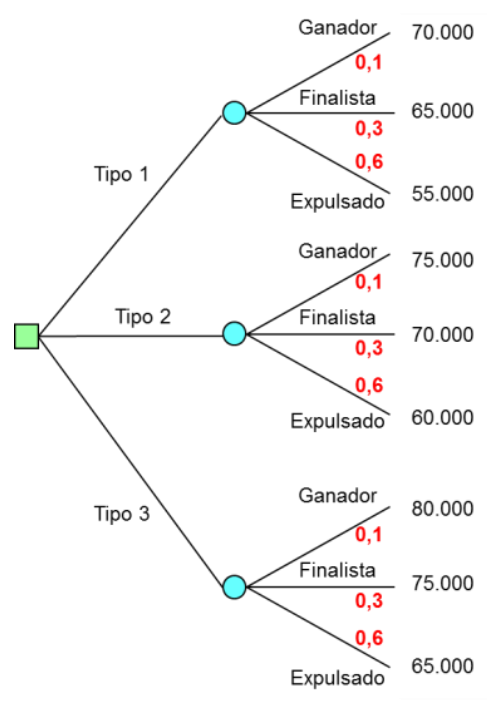

Paso 6 - Resuelva el árbol de decisión de derecha a izquierda. Dado que la etapa final es probabilista debe aplicar el criterio de la esperanza matemática con el objetivo de determinar el beneficio esperado.

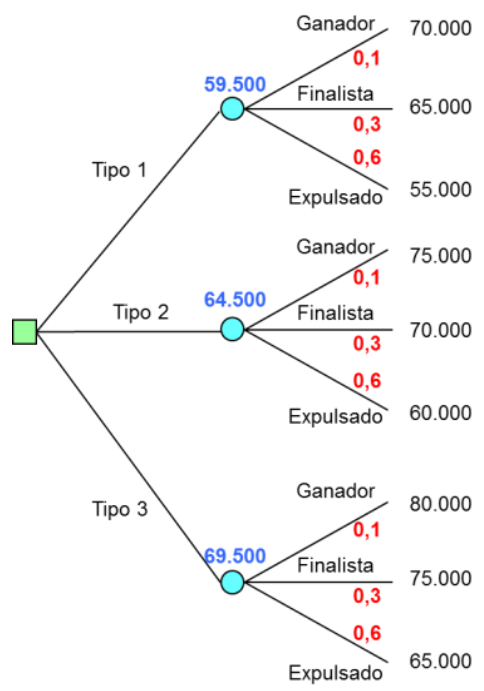

$$
\begin{aligned}
& (70.000 \times 0,1)+(65.000 \times 0,3)+(55.000 \times 0,6)=59.500 \text { euros } \\
& (75.000 \times 0,1)+(70.000 \times 0,3)+(60.000 \times 0,6)=64.500 \text { euros } \\
& (80.000 \times 0,1)+(75.000 \times 0,3)+(65.000 \times 0,6)=69.500 \text { euros }
\end{aligned}
$$


Paso 7 - Resuelva la etapa anterior. Dado que esta primera etapa es determinista y que los valores que ha calculado son beneficios, debe elegir la alternativa cuyo beneficio sea mayor y colocar el resultado encima del nudo correspondiente.

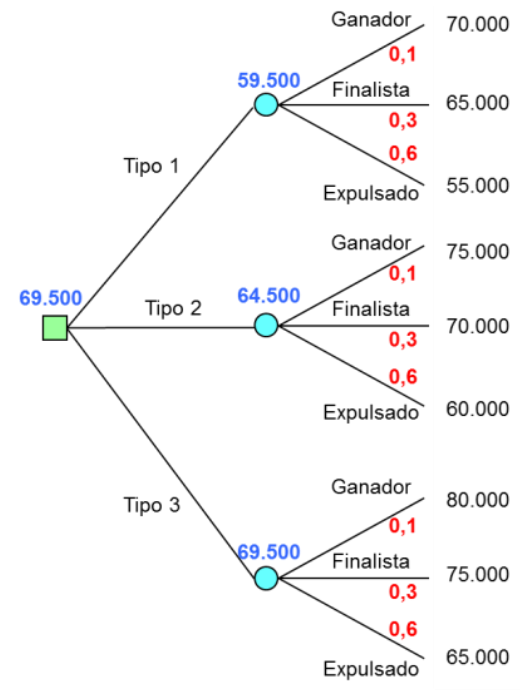

La decisión que debe tomar la empresa es la de comprar la máquina tipo 3, esperando alcanzar unos beneficios de 69.500 euros. 


\section{Ejercicio 24}

Una empresa está considerando cambiar uno de sus equipos tecnológicamente avanzados, para ello dispone de dos opciones, la primera es comprar dos nuevos equipos idénticos al actual a 200.000 euros cada uno, y la segunda consiste en comprar un nuevo sistema integrado por 800.000 euros. Las ventas estimadas por la empresa a lo largo de la vida útil de cualquiera de sus equipos son de 5.000 .000 de euros en el caso de que el mercado sea alcista, a lo que la empresa le asigna una probabilidad de que suceda del $30 \%$, en caso contrario, si el mercado es bajista las ventas esperadas son de 3.500 .000 euros. Indique al director de dicha empresa la opción que debe tomar.

\section{Solución:}

Paso 1 - Enumere las diferentes alternativas de decisión.

\section{Opción 1.}

\section{Opción 2.}

Paso 2 - Enumere para cada una de las alternativas de decisión, los estados de la naturaleza asociados a la misma.

\begin{tabular}{|c|c|}
\hline Alternativas & Estados de la naturaleza \\
\hline Opción 1 & $\begin{array}{l}\text { Mercado alcista } \\
\text { Mercado bajista }\end{array}$ \\
\hline Opción 2 & $\begin{array}{l}\text { Mercado alcista } \\
\text { Mercado bajista }\end{array}$ \\
\hline
\end{tabular}

Paso 3 - Explicite el árbol de decisión.

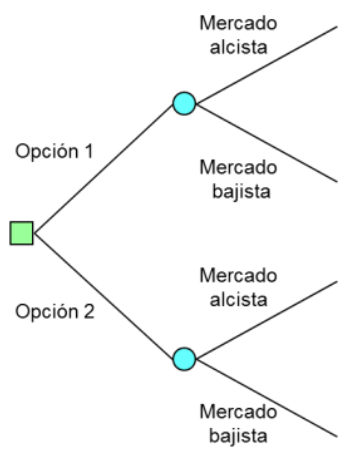


Paso 4 - Asigne las probabilidades a priori de cada uno de los estados de la naturaleza.

Las probabilidades a priori de cada estado de la naturaleza vienen dadas en el enunciado del ejercicio: probabilidad del $30 \%$ de que el mercado sea alcista, y por lo tanto, probabilidad del $70 \%$ de que el mercado sea bajista.

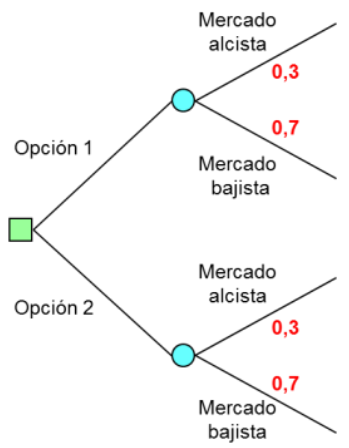

Paso 5 - Calcule el beneficio de cada una de las ramas del árbol.

Beneficio si elige la opción 1 y el mercado es alcista:

$$
5.000 .000-400.000=4.600 .000 \text { euros }
$$

Beneficio si elige la opción 1 y el mercado es bajista:

$$
3.500 .000-400.000=3.100 .000 \text { euros }
$$

Beneficio si elige la opción 2 y el mercado es alcista:

$$
5.000 .000-800.000=4.200 .000 \text { euros }
$$

Beneficio si elige la opción 2 y el mercado es bajista:

$$
3.500 .000-800.000=2.700 .000 \text { euros }
$$




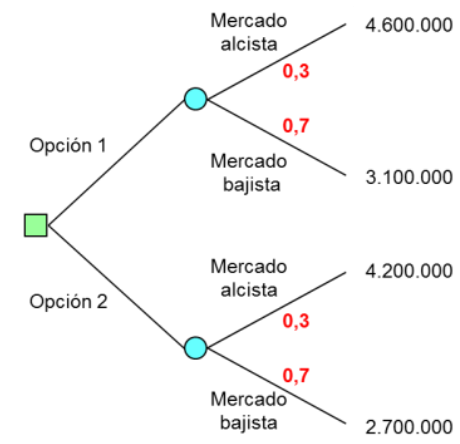

Paso 6 - Resuelva el árbol de decisión de derecha a izquierda. Dado que la etapa final es probabilista debe aplicar el criterio de la esperanza matemática con el objetivo de determinar el beneficio esperado.

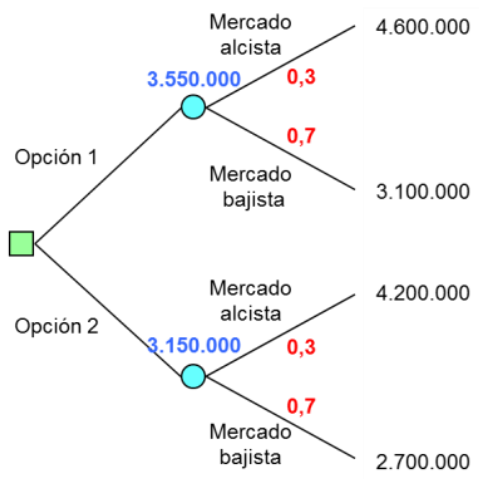

$$
\begin{aligned}
& (4.600 .000 \times 0,3)+(3.100 .000 \times 0,7)=3.550 .000 \text { euros } \\
& (4.200 .000 \times 0,3)+(2.700 .000 \times 0,7)=3.150 .000 \text { euros }
\end{aligned}
$$


Paso 7 - Resuelva la etapa anterior. Dado que esta primera etapa es determinista y que los valores que ha calculado son beneficios, debe elegir la alternativa cuyo beneficio sea mayor y colocar el resultado encima del nudo correspondiente.

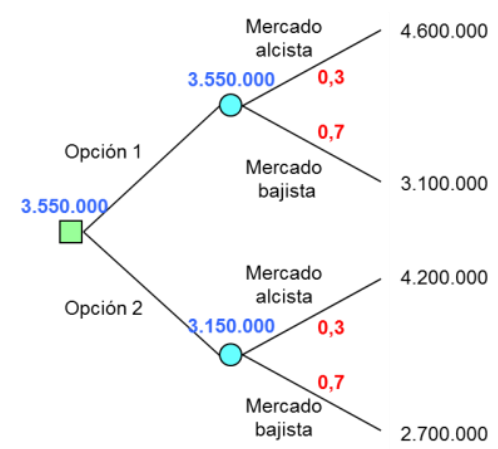

La opción por la que debe decantarse la empresa es la opción 1, consistente en comprar dos nuevos equipos idénticos al actual, con ello se espera alcanzar unos beneficios de 3.550 .000 euros. 


\section{Federico Garriga Garzón}

Federico Garriga Garzón es Doctor Ingeniero Industrial e Ingeniero Industrial especializado en Organización por la Universidad Politécnica de Cataluña (UPC). En la actualidad es profesor del Departamento de Organización de Empresas de la Escuela Técnica Superior de Ingenierías Industrial y Aeronáutica de Terrassa de la UPC. 